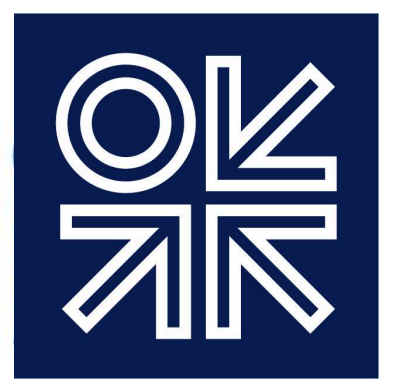

THE OXFORD

INSTITUTE

FOR ENERGY

STUDIES

\title{
Overcoming the Market Constraints to On-Grid Renewable Energy Investments in Nigeria
}

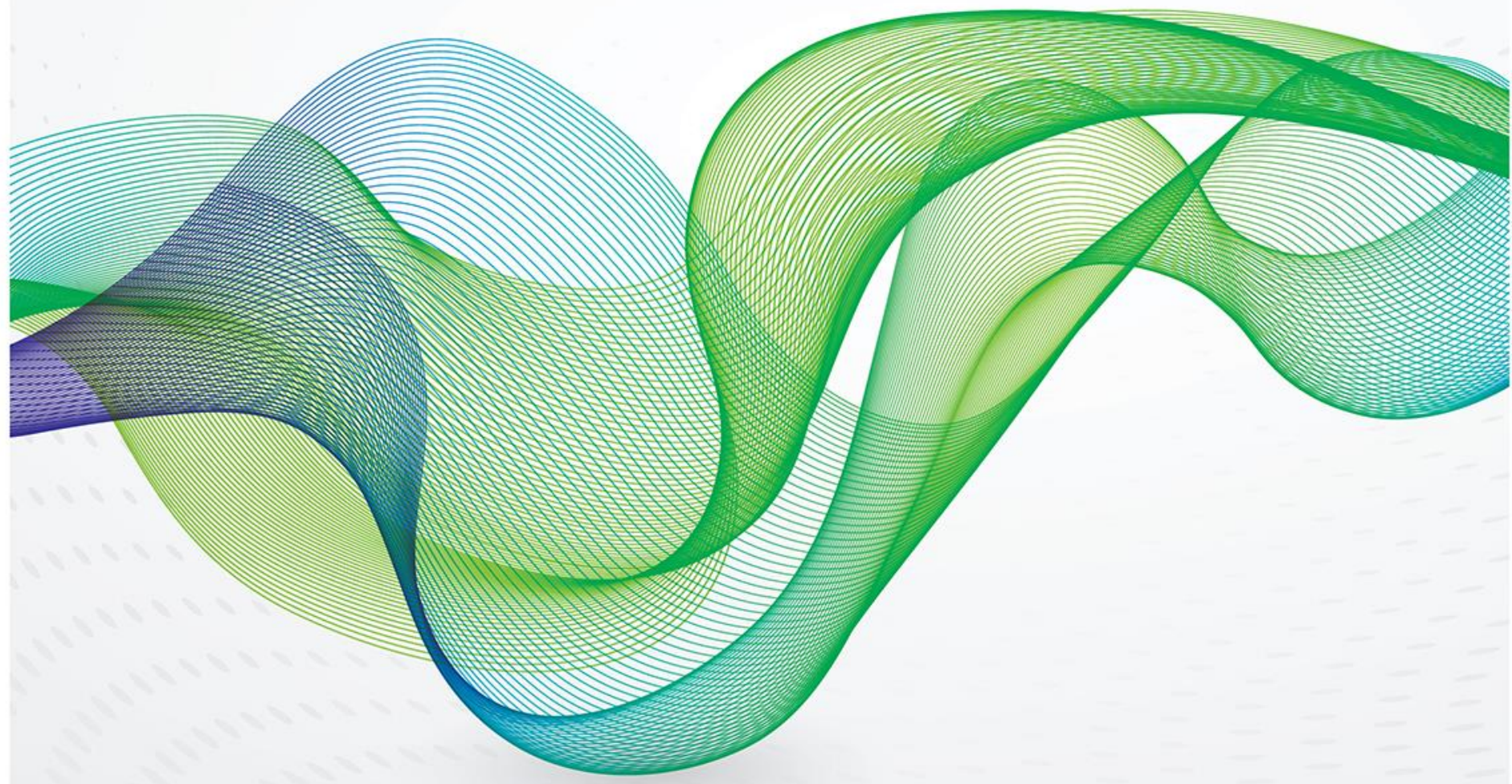



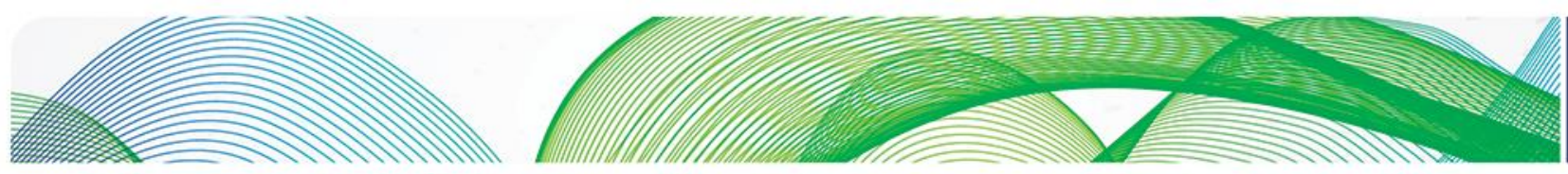

\section{이존}

The contents of this paper are the author's sole responsibility. They do not necessarily represent the views of the Oxford Institute for Energy Studies or any of its members.

Copyright $\odot 2019$

Oxford Institute for Energy Studies

(Registered Charity, No. 286084)

This publication may be reproduced in part for educational or non-profit purposes without special permission from the copyright holder, provided acknowledgment of the source is made. No use of this publication may be made for resale or for any other commercial purpose whatsoever without prior permission in writing from the Oxford Institute for Energy Studies.

ISBN 978-1-78467-149-5

DOI: https://doi.org/10.26889/9781784671495 

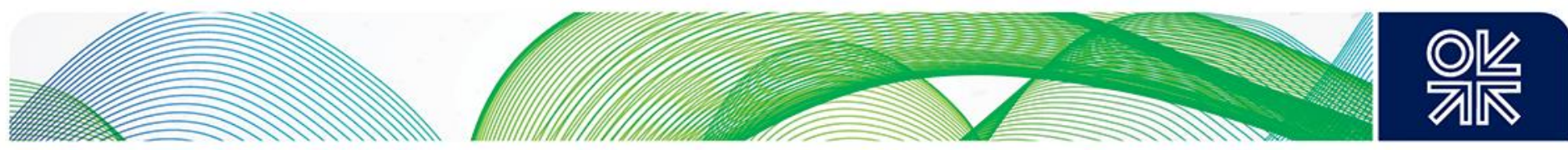

\begin{abstract}
This paper explains the constraints to on-grid renewable energy (RE) investments in Nigeria. It moves past the prevailing argument that establishes a dichotomy between an emerging RE niche and a dominant resistive hydrocarbon-intense regime. It argues that in Nigeria, there are wider industrial organizational issues that constrain on-grid RE investments in the Nigerian electricity supply industry (NESI). It analyses the NESI within the commercial and regulatory dimensions. The structure-conductperformance-regulation (SCPR) framework, which is based on the traditional structure-conductperformance (SCP) framework, was used in this paper to evaluate the NESl's structure, which constrains new investment. The SCPR framework adds the regulatory dimension of analysis to industries such as the NESI, where government intervention is significant and necessary. Data from 24 semi-structured interviews and various reports from NESI actors were analysed in preparing this paper. Findings show that the market structure of the NESI has created a liquidity crisis in the sector, and this liquidity crisis constrains on-grid RE investments in Nigeria. The liquidity crisis constrains not only ongrid RE investments, but also conventional on-grid generation investments in Nigeria.
\end{abstract}



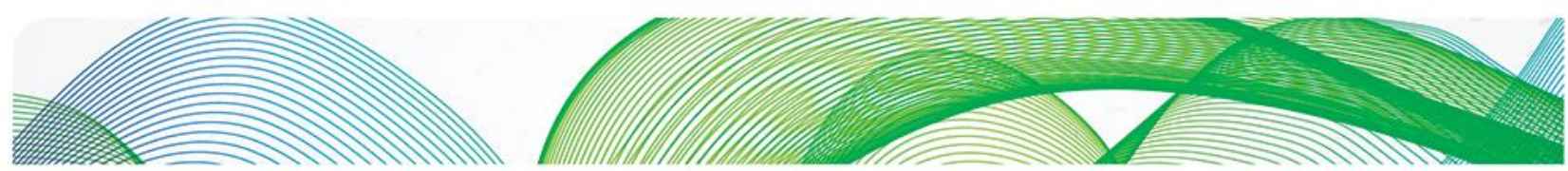
애잦

\section{Contents}

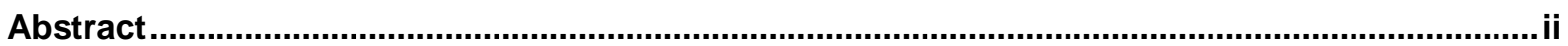

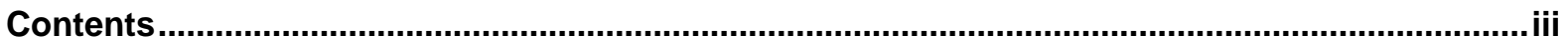

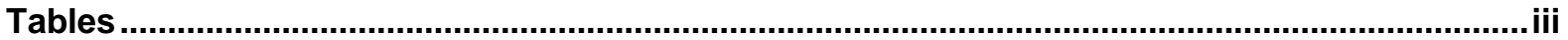

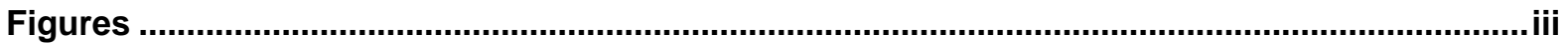

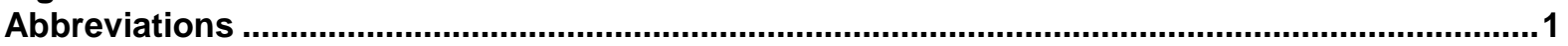

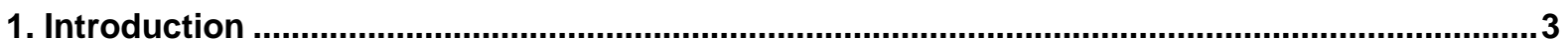

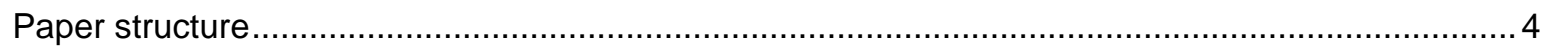

2. SCPR framework

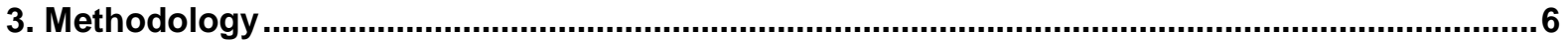

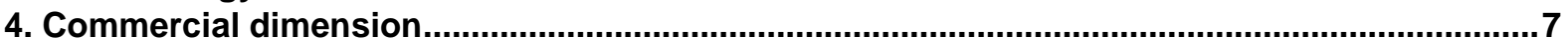

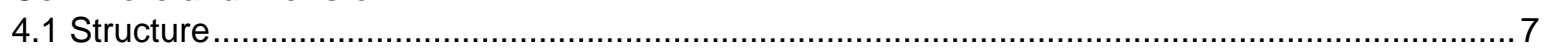

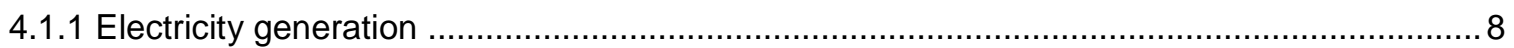

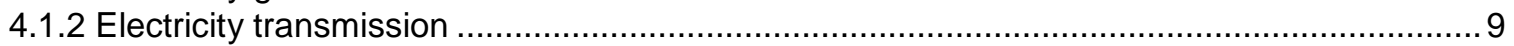

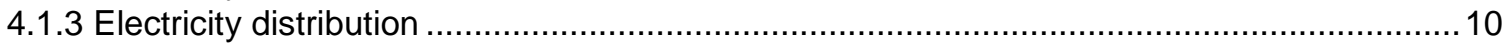

4.1.4 Nigerian Electricity Regulatory Commission (NERC) ….............................................. 11

4.1.5 Nigerian Bulk Electricity Trading Company (NBET) …................................................... 11

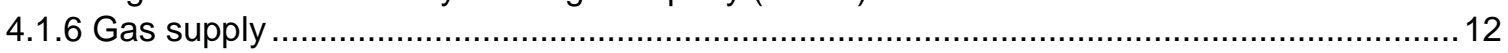

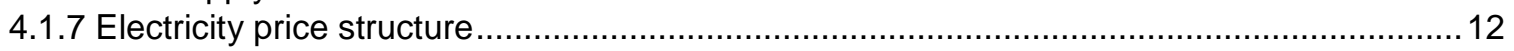

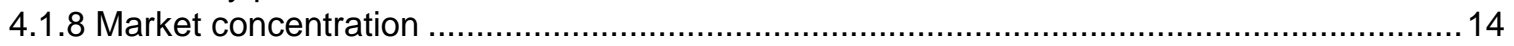

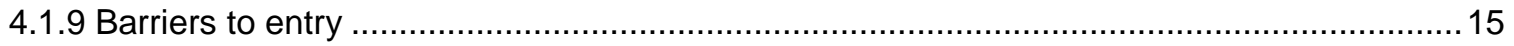

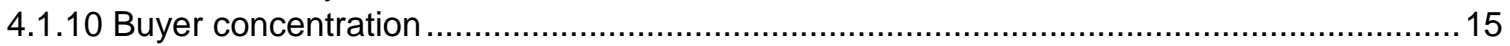

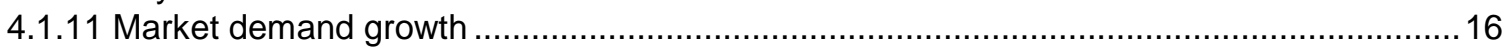

4.2 Conduct

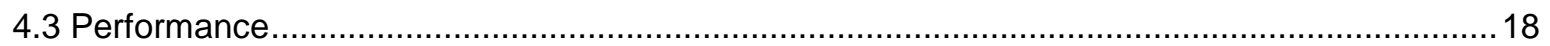

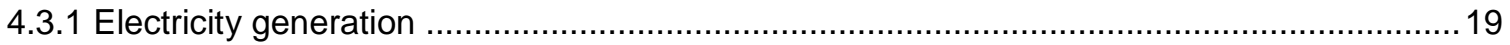

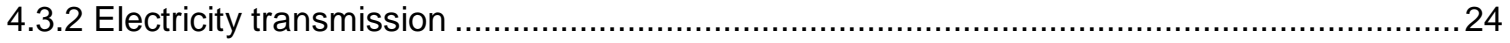

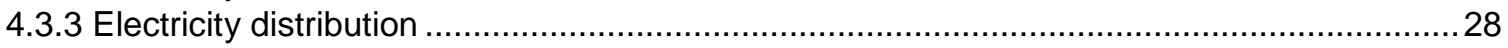

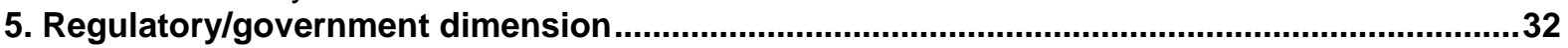

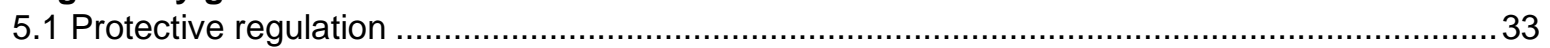

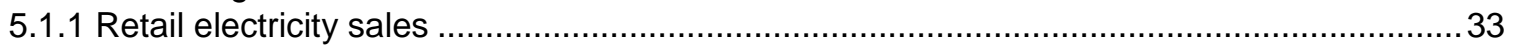

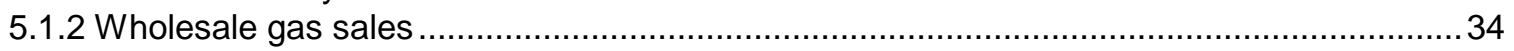

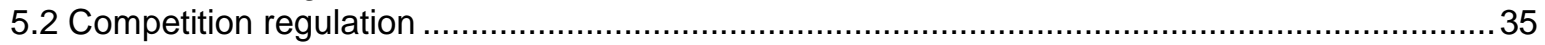

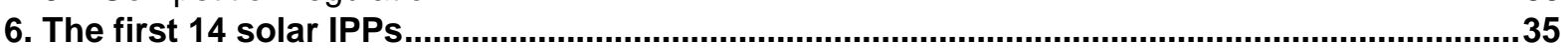

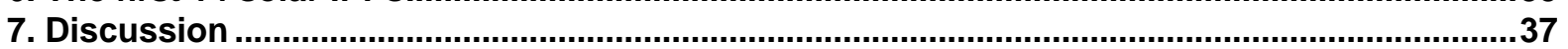

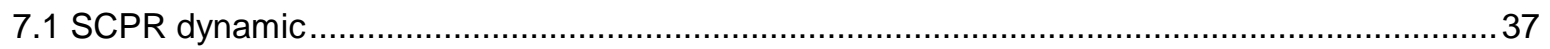

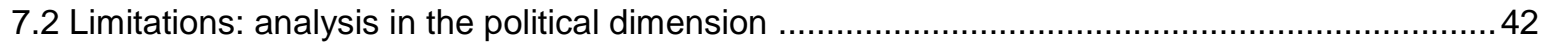

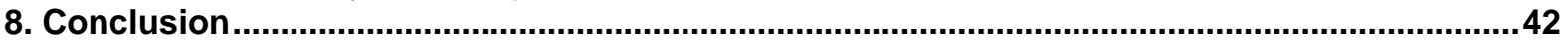

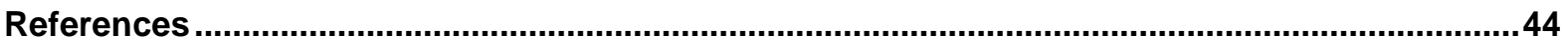

\section{Tables}

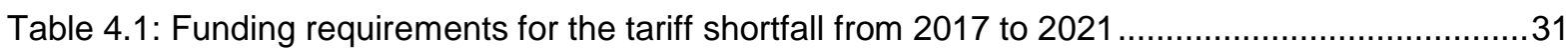

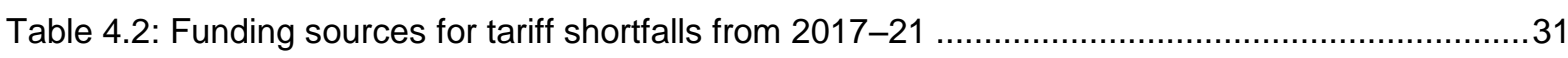

\section{Figures}

Figure 2.1: The Structure-Conduct-Performance-Regulation (SCPR) Paradigm...............................

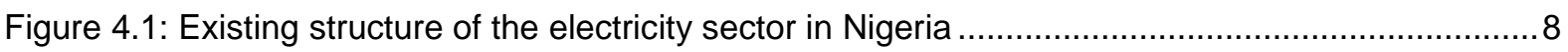

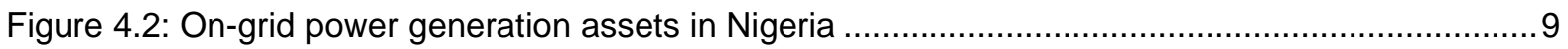



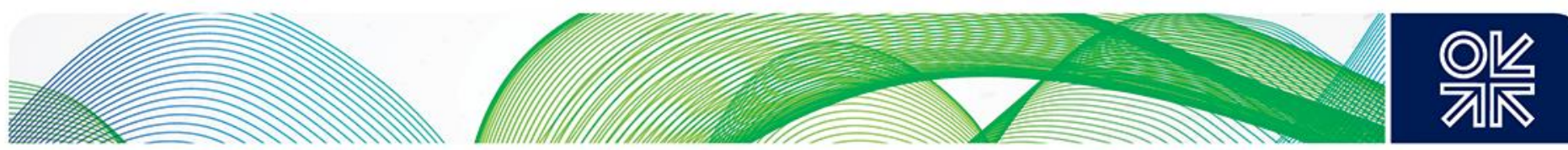

Figure 4.3: TCN's drawing of the electricity transmission network in Nigeria .10

Figure 4.4: The licensed coverage area of Nigeria's 11 electricity distribution companies (DisCos) ...11

Figure 4.5: Cost modules of the end-user or 'retail' electricity tariff................................................13

Figure 4.6: Energy billed to NBET (in Naira) by GenCos when a new gas IPP entered the market ....18

Figure 4.7: Operational capacity, average availability, and installed capacity from 2011 to $2016 \ldots \ldots .19$

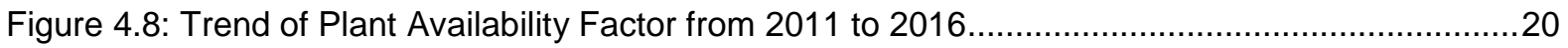

Figure 4.9: Trends of the average installed and available capacity factors on the grid in Nigeria from 2011 to 2016 .20

Figure 4.10: Annual energy sent out from hydro and gas power stations to the grid from 2011 to 2016 (GWh) 21

Figure 4.11: Average monthly energy production from hydropower stations and seasonal variation of

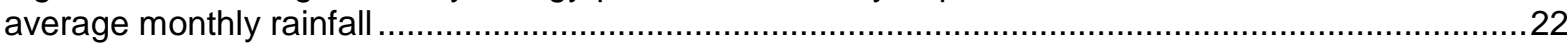

Figure 4.12: Average monthly thermal energy sent out (MWh) in 2015 and 2016 showing susceptibility to vandalism and industrial action .23

Figure 4.13: Trend of GenCos (in NGN billions) commercial performance for 14 months between August

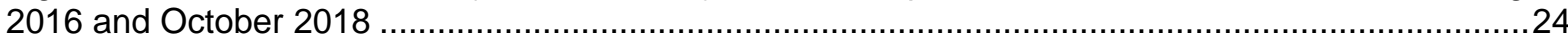

Figure 4.14: Trend of national simultaneous maximum demand from 2011 to 2017 .......................25

Figure 4.15: Total number of grid collapses in Nigeria from 1997 to 2016 sorted by cause ...............26

Figure 4.16: Trend of total and partial system losses on the grid in Nigeria .....................................27

Figure 4.17: Annual transmission losses on the grid in Nigeria from 2010 to 2016 ...........................27

Figure 4.18: Projected grid electricity demand in Nigeria including suppressed demand ...................28

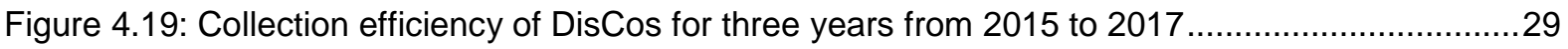

Figure 4.20: Trend of the ATC\&C losses on all 11 distribution networks in Nigeria for three years from

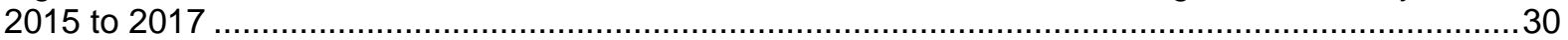

Figure 4.21: DisCo settlement of NBET invoices from August 2016 to October 2018 ........................30

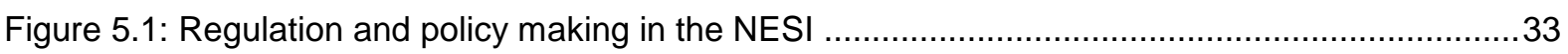

Figure 6.1: Feed-in-tariffs in South Africa and Nigeria between 2009 and 2012 in USD ....................36

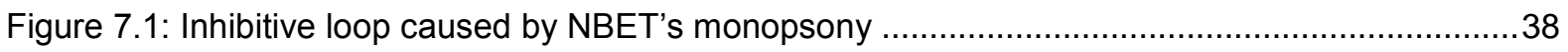

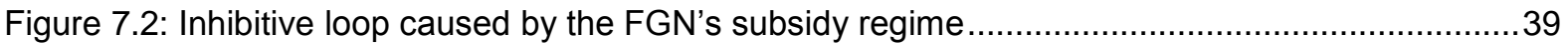

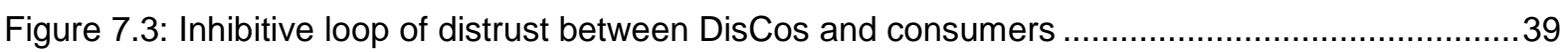

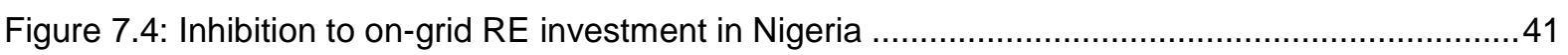



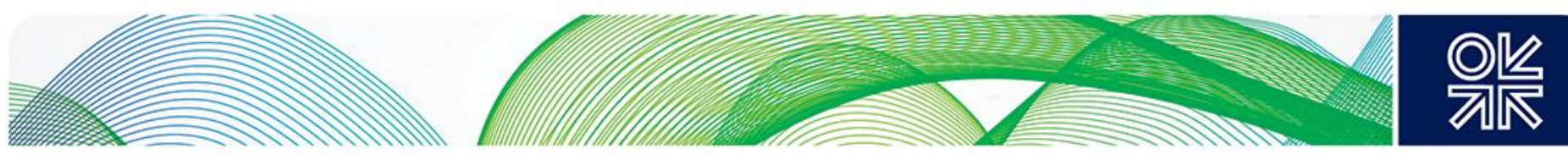

\begin{tabular}{ll} 
Abbreviations \\
AGC & Automatic Generation Control \\
AT\&C & Aggregated Transmission and Commercial Losses \\
ATC\&C & Aggregated Transmission Commercial and Collection Losses \\
CBN & Central Bank of Nigeria \\
DFI & Development Finance Institution \\
DGSO & Domestic Gas Supply Obligation \\
DisCo & Distribution Company \\
DPR & Department of Petroleum Resources \\
EPSR & Electric Power Sector Reform \\
FEC & Federal Executive Council \\
FGN & Federal Government of Nigeria \\
FIT & Feed-In Tariff \\
FMEnv & Federal Ministry of Environment \\
FMoF & Federal Ministry of Finance \\
FMPWH & Federal Ministry of Power, Works and Housing \\
GACN & Gas Aggregation Company of Nigeria \\
GasCo & Gas Company \\
GDP & Gross Domestic Product \\
GenCo & Generation Company \\
GHG & Greenhouse Gas \\
GSA & Gas Supply Agreement \\
GTA & Gas Transportation Agreement \\
GW & Gigawatt \\
GWh & Gigawatt-hour \\
HV & High Voltage \\
IOC & International Oil Company \\
IPP & Independent Power Producer \\
KPI & Key Performance Indicator \\
LCOE & Levelized Cost of Electricity \\
LNG & Liquefied Natural Gas \\
LRMC & Long-Run Marginal Cost \\
MAP & Meter Asset Provider \\
MDA & Ministry, Department and Agency \\
MLP & multi-level perspective \\
MO & Market Operator \\
MPR & Ministry of Petroleum Resources \\
MW & Megawatt \\
MWh & Megawatt-hour \\
& Multi-Year Tariff Order \\
\hline MYT &
\end{tabular}



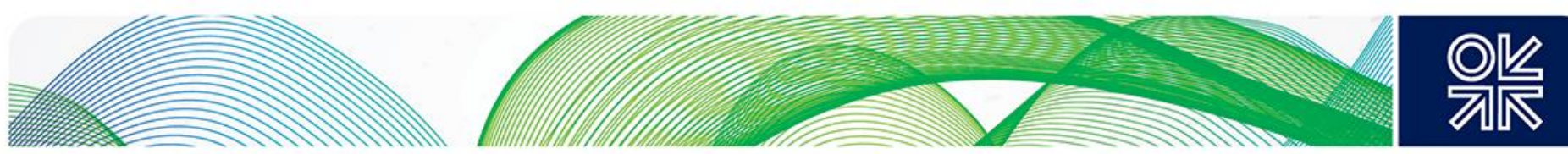

\begin{tabular}{ll} 
NACOP & National Council on Power \\
NBET & Nigerian Bulk Electricity Trading Company \\
NCC & National Control Centre \\
NCNC & National Council of Nigeria and Cameroon \\
NCP & National Council on Privatisation \\
NDC & Nationally Determined Contribution \\
NDPHC & Niger Delta Power Holding Company \\
NEEP & National Electric Power Policy \\
NEP & Nigerian Electrification Project \\
NEPA & National Electric Power Authority \\
NERC & Nigerian Electricity Regulatory Commission \\
NESI & Nigerian Electricity Supply Industry \\
NESO & Nigerian Electricity System Operator \\
NGC & Nigerian Gas Company \\
NGN & Nigerian Naira \\
NIPP & National Integrated Power Projects \\
NNPC & Nigerian National Petroleum Corporation \\
NREEEP & Nigerian Renewable Energy and Energy Policy \\
ONEM & Operator of the Nigerian Electricity Market \\
PCOA & Put-Call Option Agreement \\
PHCN & Power Holding Company of Nigeria \\
PPA & Power Purchase Agreement \\
PRG & Partial Risk Guarantee \\
PSRP & Power Sector Recovery Programme \\
PV & Photovoltaic \\
RE & Renewable Energy \\
REFIT & Renewable Energy Feed-In Tariff \\
REIPPP & Renewable Energy Independent Power Procurement Programme \\
SCADA & Supervisory Control and Data Acquisition \\
SCP & Structure-Conduct-Performance \\
SCPR & Structure-Conduct-Performance-Regulation \\
SO & System Operator \\
SSA & sub-Saharan Africa \\
TCN & Transmission Company of Nigeria \\
TEM & Transitional Electricity Market \\
TSP & Transmission System Planning \\
TUoS & Transmission Use of System \\
UNFCCC & United Nations Framework Convention on Climate Change \\
USD & United States Dollar \\
VAT & Value Added Tax \\
\hline &
\end{tabular}



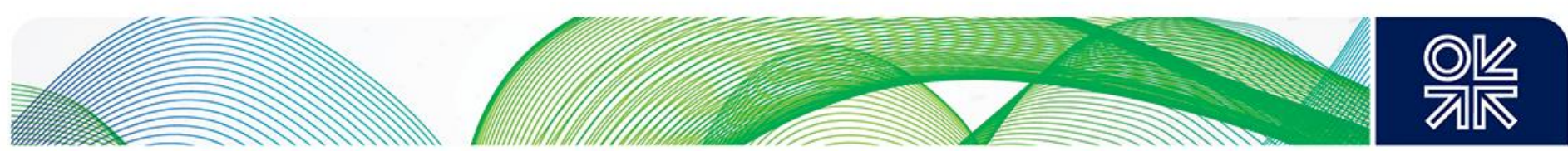

\section{Introduction}

Economic prosperity in low and middle-income nations, including those in sub-Saharan Africa (SSA), is dependent on productive energy consumption (Eggoh et al., 2011; Kahsai et al., 2012; Pablo-Romero and Sánchez-Braza, 2015). Of the world's 28 poorest countries, 27 are in Africa, and all 27 of these have poverty rates above 30 per cent (World Bank, 2019a). Only 42.7 per cent of the population in SSA has access to electricity (World Bank, 2019b). Nigeria, SSA's most populous country, has just 59 per cent electricity access for its 190 million people (World Bank, 2019c), and those with access do not receive adequate and reliable supply. The demand-supply gap in Nigeria's electricity sector has farreaching implications for the economic growth and social wellbeing of Nigerians. The country's electricity sector suffers from frequent outages - to the point that almost all industrial consumers and a significant number of residential and other non-residential consumers generate their own electricity, at enormous cost to themselves and the Nigerian economy. The Federal Government of Nigeria (FGN), in its efforts to develop a sustainable electricity industry, privatized the sector in 2013; however, performance is stagnant.

Nigeria's gas-dominated electricity sector has a liquidity crisis, and is susceptible to gas pipeline sabotage and global oil and gas market shocks. Its impact on the environment is also often detrimental, especially in the Niger Delta region of Nigeria where oil and gas firms mine the raw fuels. As Nigeria pushes its economic growth agenda, gas power generation on the grid, which currently accounts for 71 per cent of electricity supply, will increase over the next few decades causing a higher demand for fossil fuels. This may lead to further degradation of the environment, especially in the Niger Delta.

In addition to environmental degradation resulting from fuel mining, Nigeria also suffers the devastating effects of climate change, which is in part caused by global fossil-fuelled energy production. Africa, as a whole, is one of the continents which is most vulnerable to climate change, due to its low adaptation capacity. The devastating impacts of climate change in Nigeria, in particular, include the restriction of choice in crops produced in the country over the last four decades. The lifestyle and security of communities around Lake Chad in north-eastern Nigeria have also been drastically affected - by 2010 the lake had shrunk to 5.6 per cent of the size it had been in 1960 (Akpodiogaga-a and Odjugo, 2010). As a result of the impacts of climate change, Nigeria committed itself to the global effort to combat climate change when it signed the Paris Agreement in 2015 at the United Nations Framework Convention on Climate Change (UNFCCC) and subsequently developed its Nationally Determined Contribution (NDC), the country's strategy to combat climate change and its impacts.

In Nigeria's NDC, the country committed to deploying renewable energy (RE) technologies, among other strategies to mitigate climate change. However, Nigeria's NDC only considered the deployment of small-scale RE technologies, amounting to 13 Gigawatts (GW), even though deployment of large ongrid RE technologies has been considered for two decades in Nigeria. The deployment of on-grid RE technologies in Nigeria is a viable solution to such issues as the low security of gas supply, devastating climate change impacts, and the environmental concerns of oil and gas mining in the Niger Delta. Its attractiveness as a solution is further enhanced by the fact that the global costs of RE technologies such as solar photovoltaic (PV) technology have dropped drastically in the last decade and are close to grid parity. The Federal Government of Nigeria (FGN) has published and promoted several on-grid $\mathrm{RE}$ policies for nearly two decades, but there is still no RE plant on the national electricity grid. This paper explains how the structure of the NESI and the conduct of actors within it constrain on-grid RE investments.

The central argument in this paper is that the structure of the NESI and the conduct of the actors within it create constraints to all new on-grid investments, including on-grid RE investments.

This paper uses the structure-conduct-performance-regulation (SCPR) framework to explain how the structure of the NESI constrains on-grid RE investments. Peng and Poudineh (2016) developed the SCPR framework, which is based on the traditional Structure-Conduct-Performance (SCP) framework. The traditional SCP framework theorizes that the structure of a market determines the conduct of actors 

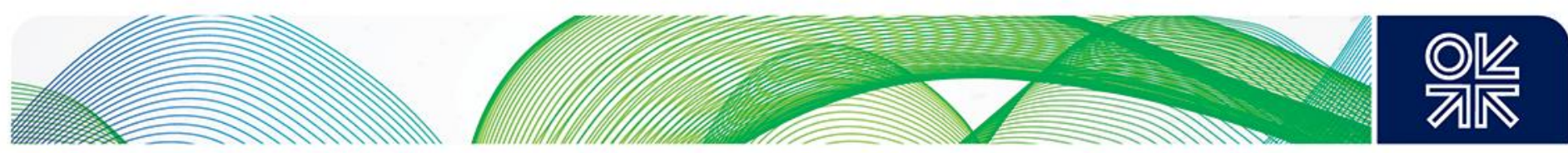

within it; the conduct of actors affects the performance of the market; and there are feedback loops that link performance, structure, and conduct. The SCPR framework provides an additional dimension of analysis to the traditional SCP framework by considering the role of government intervention (regulation) to protect consumers against the overbearing influence of powerful firms, and to reform imperfect markets. Underperformance within the NESI, and the subsequent intervention of the FGN, necessitates the use of the SCPR framework to capture the impacts of government regulation on the NESI.

This paper shows how the liquidity crisis in the NESI constrains on-grid RE investments in Nigeria. It also establishes the need for an analysis of the political dimension behind the crisis in the NESI using a political economic framework. The outcome of this paper is the development of a set of causal links that explain how the structure of NESI and the actions of its participants inhibit on-grid RE deployment. The paper also shows that the NESI would benefit from the introduction of competition in the wholesale electricity market that avoids the pitfalls of the NESI and at the same time, improves the liquidity of the NESI.

\section{Paper structure}

This paper is divided into eight sections. The first section is the introduction, which presents the paper overview and this outline of the paper's structure. Section 2 explains the SCPR framework used in this paper, while Section 3 describes the methodology. The findings are presented in three sections. An analysis of the commercial dimension, using the SCPR framework, is shown Section 4. The findings in Section 5 show the impact of government regulation on the NESI, and Section 6 shows the obstacles facing 14 licensed on-grid solar projects in the NESI. The findings are discussed in Section 7 and the conclusion of this paper is presented in Section 8.

\section{SCPR framework}

This paper is set within the wider energy transition literature relating to the conditions required for energy transition from hydrocarbon fuels to renewables. Several conceptual frameworks have been developed and proposed to understand energy transitions. Most of these conceptual frameworks start by identifying the constraints on, and the barriers to, energy transition before proposing the conditions required for successful energy transition. These conceptual frameworks include the hydrocarbon curse theory and the multi-level perspective (MLP) theory.

The carbon curse theory proposes that countries endowed with surplus hydrocarbon fuels are likely to have higher GHG emissions than countries that do not (Friedrichs and Inderwildi, 2013). Two of the four key arguments in the carbon curse theory suggest that the energy mix of a country is influenced by institutionalized hydrocarbon fuel subsidies and easy access to hydrocarbon fuels in fuel-rich countries. This suggests that the dominant hydrocarbon fuel industries and legacy hydrocarbon infrastructure in fuel-rich countries inhibit and, to an extent resist, energy transitions. The implication is the establishment of a dichotomy between emerging renewables and a resistive hydrocarbon regime.

The MLP theory infers the same dichotomy. The MLP theory emphasizes the social-cultural drivers in the literature on energy transitions, recognizing the interaction between people and technology in 'sociotechnical systems'. It also recognizes that most sustainable technological transitions struggle to compete with established technology regimes, especially when external costs of established technologies are not considered; and that the involvement of dominant incumbent firms in supporting new technologies is often required to accelerate the breakthrough of technological innovations (Geels, 2011). The MLP theory suggests that resistive technology regimes inhibit innovative technologies.

The prevailing theme across these conceptual frameworks is the existence of a dichotomy between an emerging $R E$ niche and a resistive hydrocarbon-intense regime. This paper moves past the dominant argument that establishes this dichotomy. While the dichotomy may eventually exist in countries like 

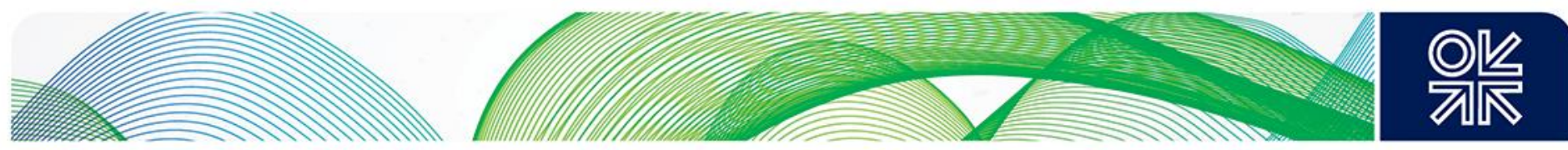

Nigeria, this paper argues that there is currently a wider industrial-organizational issue that constrains RE investments on the grid in Nigeria.

To explore the wider industrial organizational issues in the NESI, this paper uses the SCPR framework. The SCPR framework shown in Figure 2.1 was developed by Peng and Poudineh (2016) to understand the causal links and interdependencies that exist within the electricity and gas sectors, in order to explain the performance of both sectors in the UK. The SCPR framework argues that the regulatory aspect is a critical dimension of analysis because government regulation, which governments usually introduce to protect consumers and correct imperfect markets, can alter the SCP dynamic and the performance in the market. Generally, the government's intention is usually to alter the SCP dynamic to improve performance in regulated markets.

This paper shows how the SCPR paradigm can be used to explain the current underperformance in the NESI. It also shows how the underperformance of the NESI constrains on-grid RE investments.

The structure $(S)$ of a market is a group of interconnected characteristics of that market such as: the number and relative power of buyers and sellers; degree of product differentiation; and ease of entry and exit from the market. These characteristics determine how competitive a market is, because unbalanced organizational powers in the market give the buyers or sellers undue control over prices. The SCPR framework argues that the ownership structure in a market, such as the NESI, influences the conduct $(C)$ of industry actors and vice versa. It also proposes that the conduct of industry actors can be grouped into two types: long-term conduct $(C 1)$ that changes the capacity of infrastructure, and short-term conduct $(C 2)$ that influences the way the infrastructure is used. Long-term conduct involves the increase in the capacity of infrastructure through new investments, or the decrease in capacity of infrastructure through the retirement of assets. In the NESI, conduct (Cl) means either new investments in any part of the electricity grid infrastructure, or the retirement of any asset in any part of the electricity grid infrastructure. New investments to deploy on-grid RE in the NESI falls under $C 1$. So this paper explains the causal links that constrain $C l$ - the conduct to increase RE investment on the grid in the $\mathrm{NESI}$. Conduct (C2), within the context of the NESI, refers to the way NESI operators use the electricity grid infrastructure. Long-term conduct $(C 1)$ affects short-term conduct $(C 2)$ because the way NESI operators use the grid is constrained by the capacity of the grid. For example, the electricity output of NESI operators is, on occasion, constrained by the capacity of the grid infrastructure. Conduct (C2) also affects conduct (C1), because the operation of the infrastructure determines the NESI's performance, which determines whether more long-term investments are made. As shown in Figure 2.1, the SCPR framework argues that the performance $(P)$ of a market is dependent on the conduct $(C 2)$ of industry actors. The performance of a market is dependent on the way in which the infrastructure in that market is used by industry actors. In the NESI, the performance of the market is dependent on the way NESI operators use the assets under their control. 

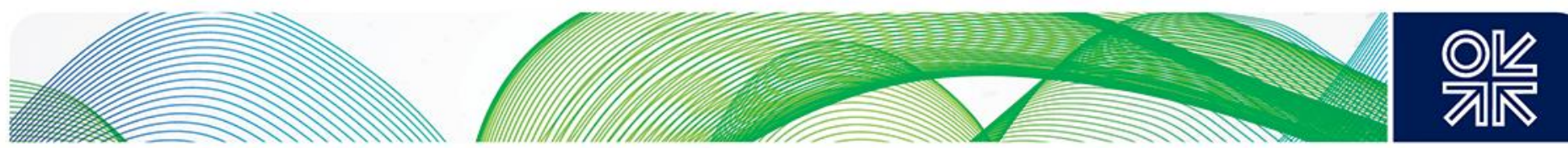

Figure 2.1: The Structure-Conduct-Performance-Regulation (SCPR) Paradigm

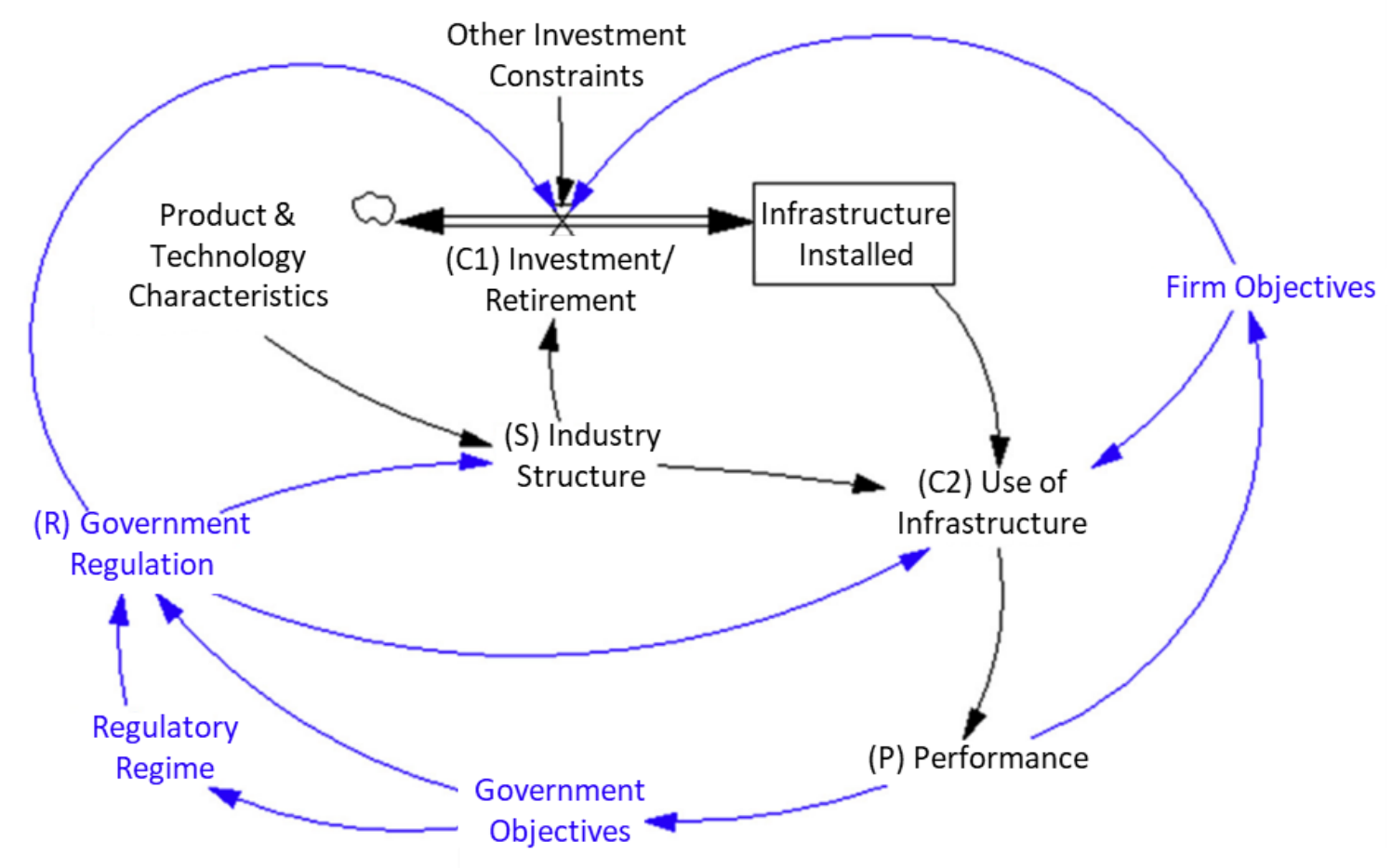

Source: (Peng and Poudineh, 2016).

Finally, the main addition of the SCPR to the traditional SCP framework is the inclusion of a regulatory dimension. The SCPR framework argues that government intervention is necessary in imperfect and dysfunctional markets. Government interacts with the market through policies and regulations $(R)$, based on its evaluation of industry performance. When government intervenes, it does so through industry regulations, which has up to three implications in a market.

First, it can cause an increase or reduction in the capacity of infrastructure (C1). In the NESI, this is equivalent to the FGN constraining or encouraging additional investments on the grid. At the end of this paper, it can be seen that government policy increases the constraints on additional investments, including on-grid RE investments. Second, government regulation can influence the way infrastructure is used $(C 2)$ by industry operators. In the NESI, the government's grid codes - a guideline for NESI operators - determine the way NESI operators use the grid infrastructure. The government's pricing regulation also constrains the pricing of services within the NESI. Third, government's regulation affects the structure $(S)$ of the market. Governments often introduce competition regulations to prevent unbalanced powers and underperformance in the market.

In this paper, the SCPR framework was used to show how on-grid RE investments $(C 1)$ are constrained by: government regulation $(R)$, the relative market power of NESI actors $(S)$, the way NESI actors use the infrastructure $(C 2)$, and the resulting poor performance $(P)$ of the NESI.

\section{Methodology}

The findings in this paper were arrived at using a mix of approaches and methods. This paper uses quantitative data to present a clear picture of the performance and structure of the Nigerian electricity market, and it uses qualitative data to explain how the structure (S), conduct (C2) of NESI actors, and performance $(P)$ in the NESI act to constrain new investments $(C l)$ in the market. This paper explains 

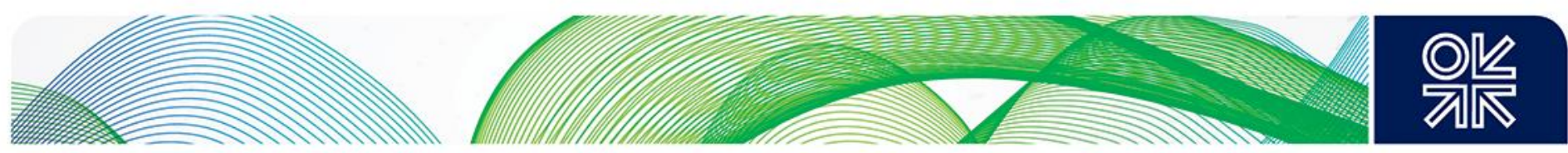

the market constraints to on-grid RE investments by using data collected from stakeholders within the energy industry to develop causal links between the market structure, stakeholders' conduct, and industry performance using the SCPR framework. A checklist developed by Jamasb et al. (2006) was used as a data collection template for industry-wide performance in the NESI. The datasets used in this paper were collected through questionnaires, industry reports, policy and regulation documents, and one-to-one semi-structured interviews with 24 industry stakeholders. All the relevant data collected were analysed using theory-driven thematic analysis based on the SCPR framework.

\section{Commercial dimension}

An analysis, made using the SCPR framework, of the commercial performance of the NESI is presented in this section. The commercial dimension is the first dimension of analysis because it sheds light on the engineering and commercial bottlenecks in the NESI. It also exposes the market inefficiencies that inhibit investments in the NESI. The analyses in this section show how the structure of the NESI affects the conduct and performance of firms within it. This section also shows how the conduct and performance of firms also depend on the conduct and performance of other actors within the NESI.

\subsection{Structure}

To analyse the market structure of the NESI, it is first important to describe it. This subsection describes the commercial operation of the sector; it describes the role and function of each commercial actor within the sector; and finally, it analyses four market structure characteristics of the NESI: market concentration, barriers to entry, buyer concentration, and market demand growth.

The Nigerian on-grid electricity sector has a partially liberalized market with a single-buyer model, where the government-owned buyer is the sole buyer of electricity from public and private generation companies (GenCos) and the sole seller of electricity to all distribution companies (DisCos), which are privatized. There is also a government-owned and government-run nationwide transmission network. The current market structure, shown in Figure 4.1, came into effect in 2013 when some governmentowned GenCos and all the DisCos were privatized, with a total transaction cost of \$3 billion (KPMG, 2016). The process for privatization of the sector was initiated in 2001.

In 2001, during the first administration of Nigeria's fourth republic, the FGN developed the National Electric Power Policy (NEEP), which established the need for the unbundling of the former vertically integrated state-owned utility known as the National Electric Power Authority (NEPA). This policy led to the proposed Electric Power Sector Reform (EPSR) bill, which was developed to encourage private sector participation in a sector that was riddled with inefficiency, corruption, and infrastructural decay. However, due to labour union opposition, and several other factors, efforts to enact the proposed EPSR bill were frustrated (Joseph, 2014).

To improve the NESI infrastructure before the passage and implementation of the EPSR bill, the FGN developed the National Integrated Power Project (NIPP) bill, which became an Act in 2004. The bill allowed the national legislature to appropriate funds for turnkey transmission projects, distribution projects, and gas-fuelled power generation projects. The power generation projects under the NIPP were to be privatized once completed. The NIPP generation projects are a group of distribution, transmission, and 10 gas-powered projects owned by the Niger Delta Power Holding Company (NDPHC) in the natural gas-rich southern region of Nigeria. The NDPHC is a special purpose vehicle jointly owned by the three tiers of government: federal, state, and local governments. It is the implementation arm for NIPP projects (KPMG, 2016).

One year after the NIPP (2004) Act, the previously resisted EPSR bill was signed into law. The EPSR (2005) Act established the Power Holding Company of Nigeria (PHCN), which took over the assets and liabilities of the former vertically integrated utility, NEPA. The PHCN was made up of six generation companies (GenCos), eleven distribution companies (DisCos), and one transmission company, the Transmission Company of Nigeria (TCN). However, sluggishness in moves towards privatization in the 

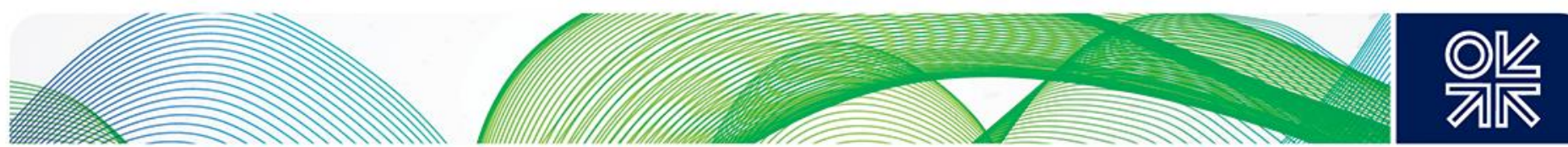

sector persisted after the EPSR Act was established. Eventually, the Roadmap for Power Sector Reform (2010), developed by a new government, laid out the framework to: remove obstacles to privatization, clarify government's strategy on divesture, and reform the fuel-to-power market. Some PHCN assets were eventually sold in 2013, while others were handed over to concessionaires.

Figure 4.1: Existing structure of the electricity sector in Nigeria

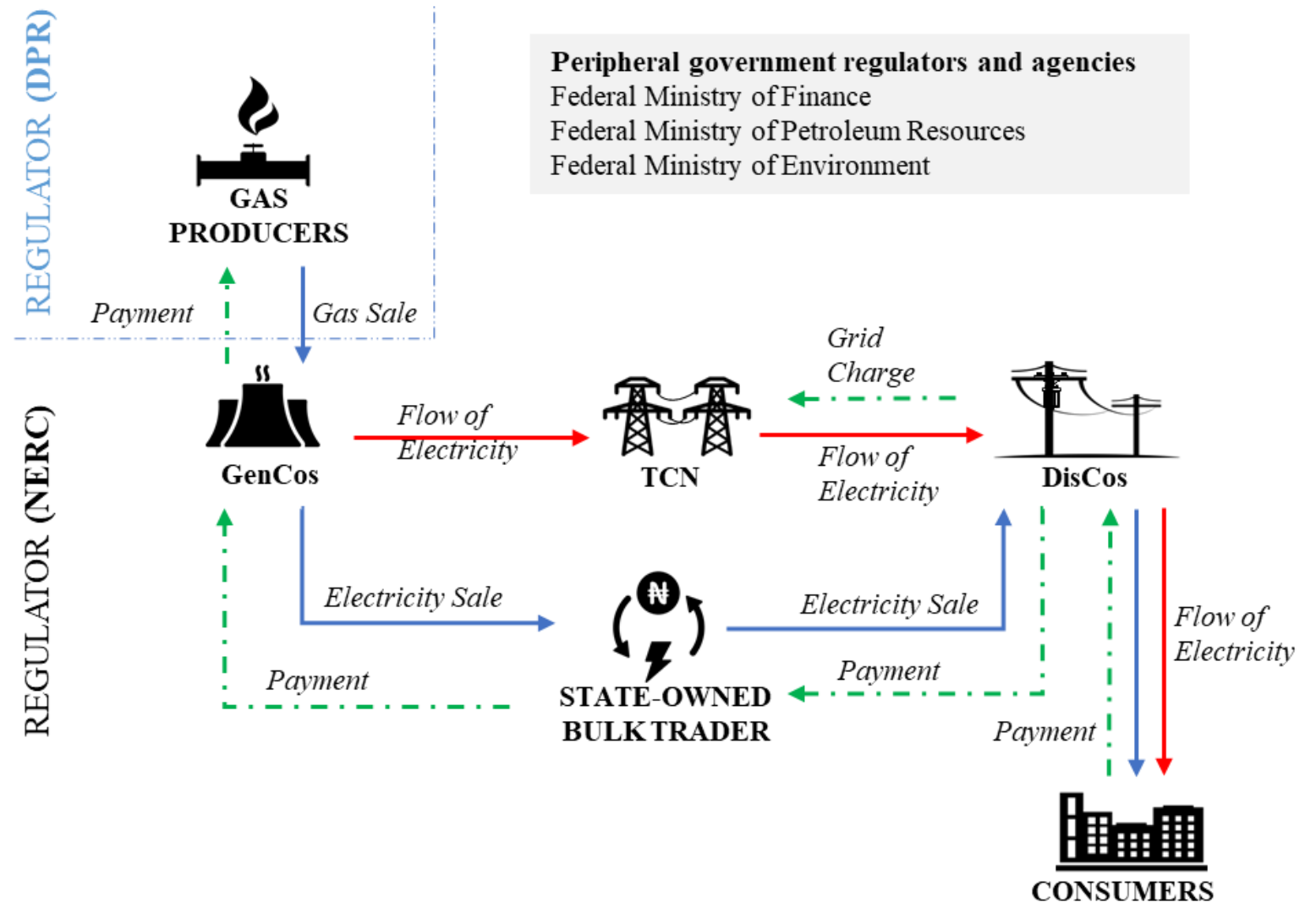

Source: Author.

\subsubsection{Electricity generation}

The electricity market in Nigeria has four groups of GenCos:

- $\quad$ the concessionaires of the privatized 'legacy assets';

- $\quad$ the NDPHC subsidiaries which operate the NIPP gas power plants;

- $\quad$ Independent Power Producers (IPPs) that existed before privatization;

- $\quad$ one post-privatization IPP.

There are 28 grid-connected power plants in Nigeria with a total installed capacity of 12,310 MW and total operational capacity of 7,788 MW. On average, just 3,000-4,500 MW are available annually, due to unavailability of gas, breakdowns, water shortage, and commercial and grid constraints. The gasfired electricity generation plants produce 71 per cent of daily electricity, whilst large hydroelectric power stations make up the rest. These GenCos sell electricity to the state-owned bulk trader, which in turn sells to the financially non-credible DisCos at a loss. This arrangement will stay in place until the DisCos reach a sufficient level of creditworthiness to purchase power directly from the GenCos. This current arrangement is called the Transitional Electricity Market (TEM). The TEM was put in place to increase 

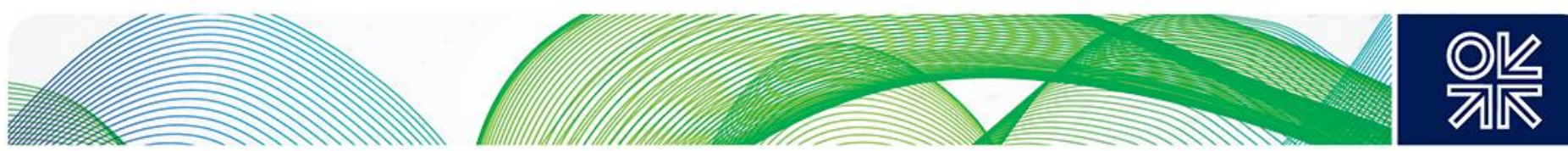

the confidence of GenCo investors in the NESI. Figure 4.2 shows the location of all 28 grid connected power stations on a map of Nigeria. The gas power plants are located in the gas-rich southern region of the country while the hydropower plants are in the country's middle belt.

Figure 4.2: On-grid power generation assets in Nigeria

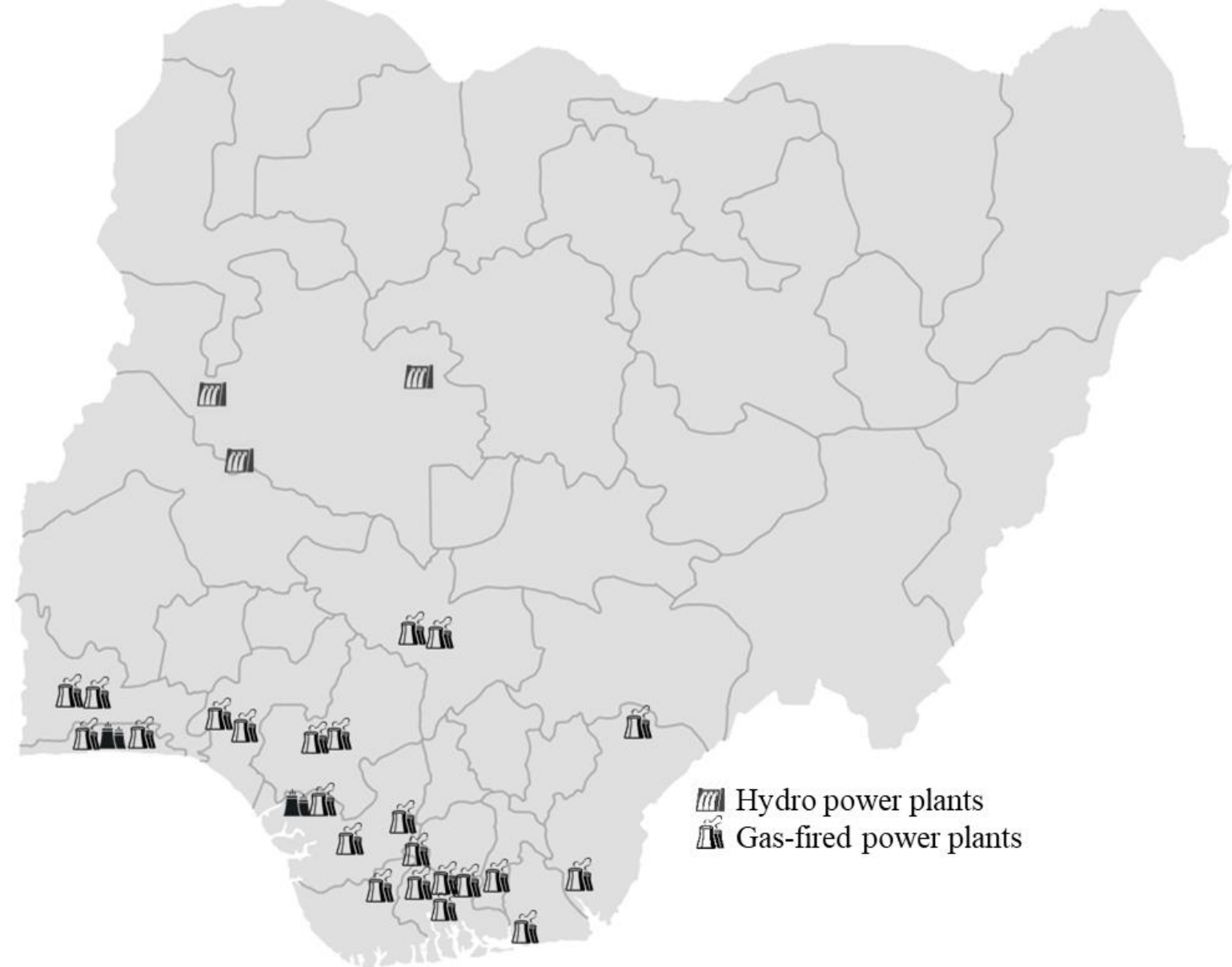

Source: Author.

\subsubsection{Electricity transmission}

The transmission company of Nigeria (TCN) has a monopoly in the transmission spectrum of the market. It claims to have a transmission capacity of 7,500 MW and over 20,000 km of transmission lines. The highest amount of power ever transmitted on the transmission network is 5,222 MW. The TCN has three major functions and it executes these functions with three semi-autonomous units:

- $\quad$ Transmission System Planning (TSP), which owns and manages the assets;

- Nigerian Electricity System Operator (NESO), which operates the transmission infrastructure;

- Operator of the Nigerian Electricity Market (ONEM), which balances the market transactions between GenCos, NBET, and DisCos. 

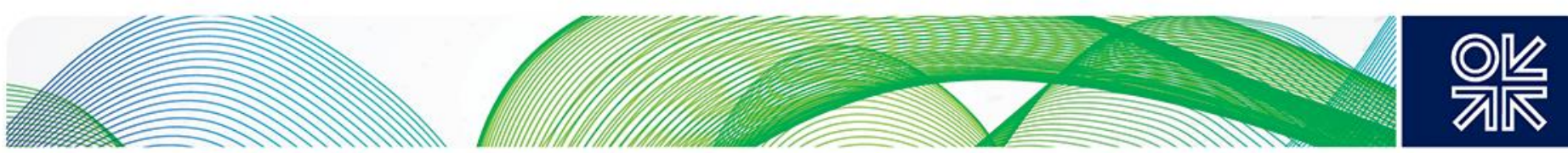

In line with the EPSR (2005) Act, TCN was managed by a private contractor from privatization in 2013 for three years. In 2016, the agreement was not renewed. The existing transmission network can be seen in Figure 4.3.

Figure 4.3: TCN's drawing of the electricity transmission network in Nigeria

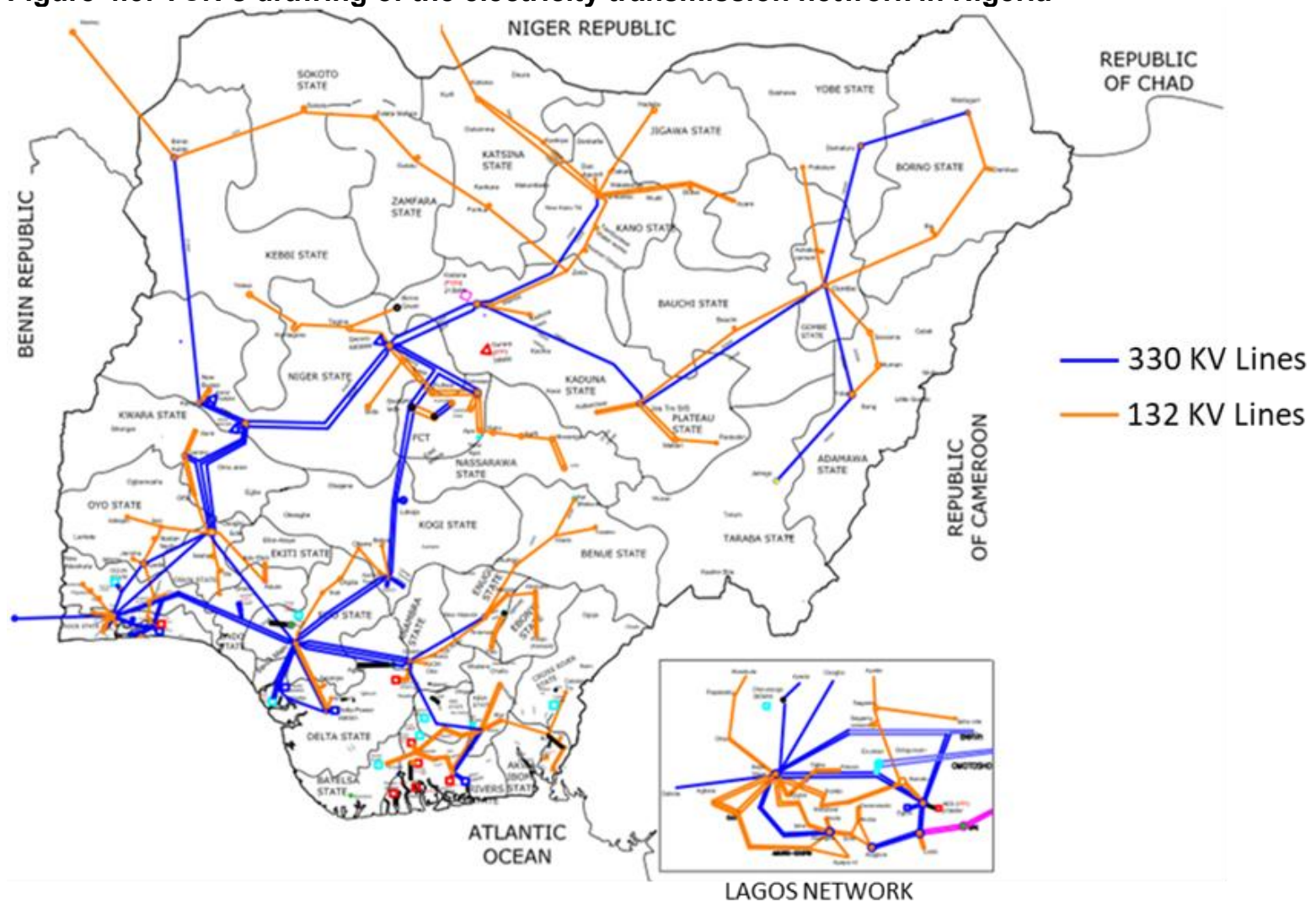

Source: (TCN, 2015)

\subsubsection{Electricity distribution}

There are 11 distribution companies in the NESI. Their coverage area is shown in Figure 4.4. The DisCos buy electricity from NBET and sell directly to consumers, with huge collection losses which are detailed in Section 4.3.3. The distribution companies were sold by the FGN to the current private sector owners; however, the FGN kept a 40 per cent stake in all the distribution companies. Although the DisCos have a joint distribution capacity of $24,457 \mathrm{MW}$, they only have an injection capacity of 13,571 MW. The distribution capacity is constrained by the injection capacity, just as the injection capacity is constrained by the transmission capacity. However, as this paper reveals, none of these upper limits are ever reached, because there is a more pressing commercial constraint. 

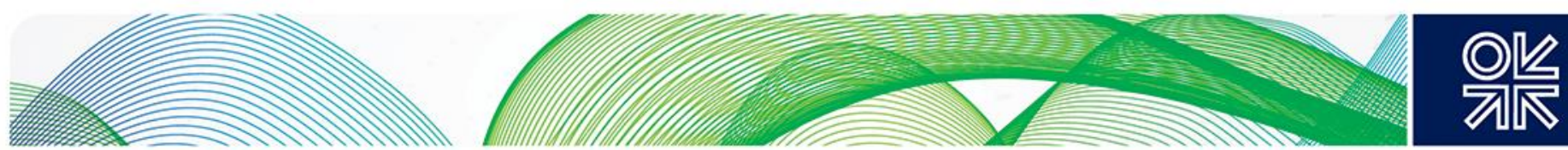

Figure 4.4: The licensed coverage area of Nigeria's 11 electricity distribution companies (DisCos)

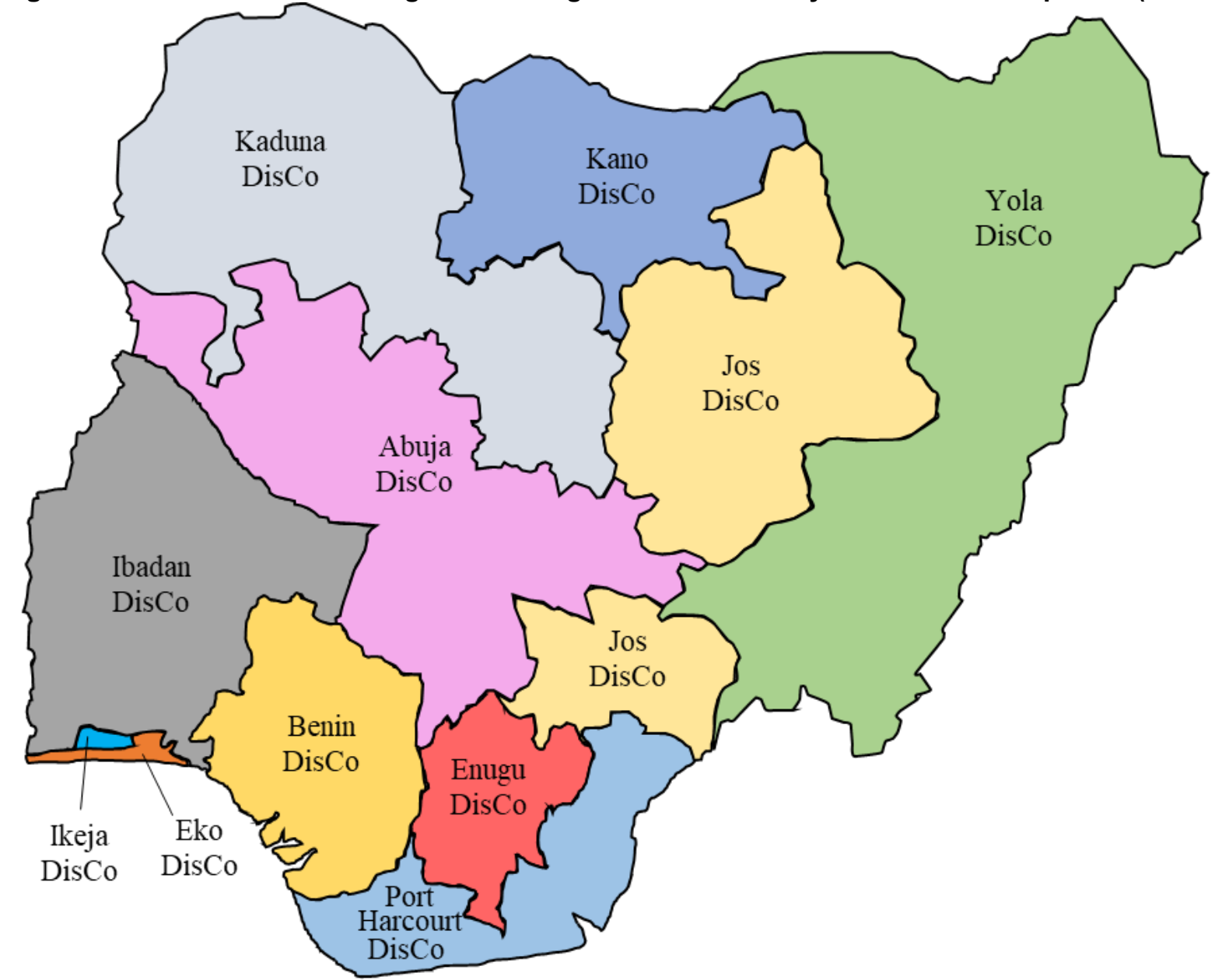

Source: Author.

\subsubsection{Nigerian Electricity Regulatory Commission (NERC)}

NERC is the independent regulator in the NESI. It was established in 2005 by the EPSR (2005) Act. It undertakes engineering regulations in the sector through the grid codes, which determine the confines within which NESI operators can function. It also undertakes commercial regulation through its tariff order, which determines how much each NESI operator is able to charge for its services. NERC also issues licences to operate within the sector.

\subsubsection{Nigerian Bulk Electricity Trading Company (NBET)}

The NBET is the only bulk trader of electricity. It is owned and run by the FGN through two FGN agencies:

- the Bureau of Public Enterprise - a government agency that serves as the secretariat for the National Council on Privatisation (NCP), and which implements the government's privatization policies;

- $\quad$ the Federal Ministry of Finance (FMoF).

NBET purchases bulk electricity from the generation companies through power purchase agreements (PPAs) and sells electricity to the DisCos through vesting contracts. The FGN created NBET to give generation-side investors the confidence and guarantee that the power they generate will be bought 

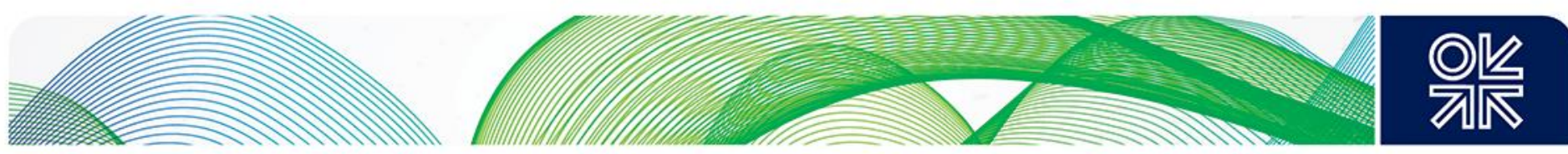

from them at a price agreed upon in the PPA. The investors need this guarantee because the DisCos, to whom they would otherwise sell electricity, are not creditworthy. NBET is the only firm that offers a bankable PPA because it is owned by the FGN and is backed by sovereign guarantees.

\subsubsection{Gas supply}

There are 10 gas supply companies (GasCos) that supply gas-fired power stations within the NESI. These companies include international oil companies (IOCs), the Nigerian National Petroleum Corporation (NNPC), ${ }^{1}$ and other private sector firms. The gas suppliers sell gas to the GenCos through the Gas Aggregation Company of Nigeria (GACN). GACN is a government institution which serves as a middle man and a market operator. Only three ${ }^{2}$ groups of consumers are allowed to purchase gas through the GACN, including GenCos. These three groups of gas consumers each have an FGNdetermined fixed price for gas. GACN aggregates gas supply and administers the pricing mechanism, which determines the price of domestic gas based on the quantity of gas purchased by each consumer group at its FGN-determined price.

\subsubsection{Electricity price structure}

The Multi-Year Tariff Order (MYTO) lays out the methodology used to set the price of electricity on the grid in Nigeria. The EPSR (2005) Act, which established the current liberalized electricity sector in Nigeria, empowers NERC through Section 32(d) to ensure fair prices for consumers and a fair return on investment for investors. The EPSR (2005) Act also empowers NERC through Section 76 to create a methodology to determine the price of electricity on the grid. The MYTO allows electricity sellers to sell electricity at cost-reflective tariffs, and it brings certainty to the pricing structure and allocates risks to industry stakeholders efficiently. Efficient risk allocation is achieved by ensuring that parties who are responsible for certain performance levels bear the risk of non-performance. It defines wholesale and retail tariff structures, including transmission charges. The MYTO is also an incentive-based tariff model which rewards utilities' performance on loss reduction and improved standards. The methodology provides an allowance for minor reviews twice a year and major reviews every five years; this allows the tariff to be updated to account for new macroeconomic and sector-specific realities such as inflation, the US dollar (USD) to Naira (NGN) exchange rate, and generation capacity on the grid.

The retail price of electricity to consumers has four constituent modules (see Figure 4.5) which are

- generation cost or 'wholesale' tariff;

- $\quad$ transmission cost;

- distribution cost;

- $\quad$ other sector services and tax.

The distribution tariff is not be mistaken for the end-user tariff, which is a summation of all the four aforementioned modules across the value chain. Each of the four modules is developed around three building blocks: allowed return on capital; allowed return of capital; ${ }^{3}$ and efficient operating costs and overheads.

The generation cost module, which accounts for 36.36 per cent of the retail tariff, is the base cost of the electricity tariff in Nigeria. It is also referred to as the wholesale price of electricity because it is the price at which the bulk buyer, NBET, buys electricity from the generation companies before selling to the DisCos. The generation cost module allows GenCos to retrieve their return on capital; return of capital; and efficient operating costs and overheads. Each one of the 28 GenCos agrees to its own wholesale price of electricity with NBET through a PPA that is subject to the approval of the regulator, NERC. The

\footnotetext{
${ }^{1}$ The national oil company.

${ }^{2}$ These three groups are: GenCos who solely supply electricity to the national grid; companies that require gas as an input for their end products; and local gas distribution companies that sell gas to other commercial and industrial companies in the domestic market.

${ }^{3}$ Capital allowance.
} 

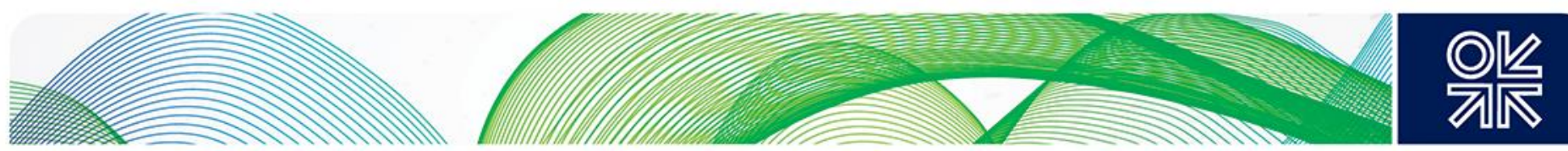

exceptions are the NIPP GenCos; their PPAs are referred to as 'energy-only' PPAs because the NIPP PPAs do not allow the NIPP GenCos to retrieve their capital or return on capital. NIPP GenCos are only paid for their operating costs and not for the capital investment in their eight gas power plants. The generation cost module is crucial for private sector investment in the expansion of generation capacity, because it determines the level of attractiveness to investors. It is also important to the FGN because it is, in principle, one of the few levers for establishing competition in the electricity market, which has several natural monopolies. The wholesale tariff is, in principle, to be reviewed as changes occur in inflation, the USD to NGN exchange rate, and the price of gas.

Figure 4.5: Cost modules of the end-user or 'retail' electricity tariff

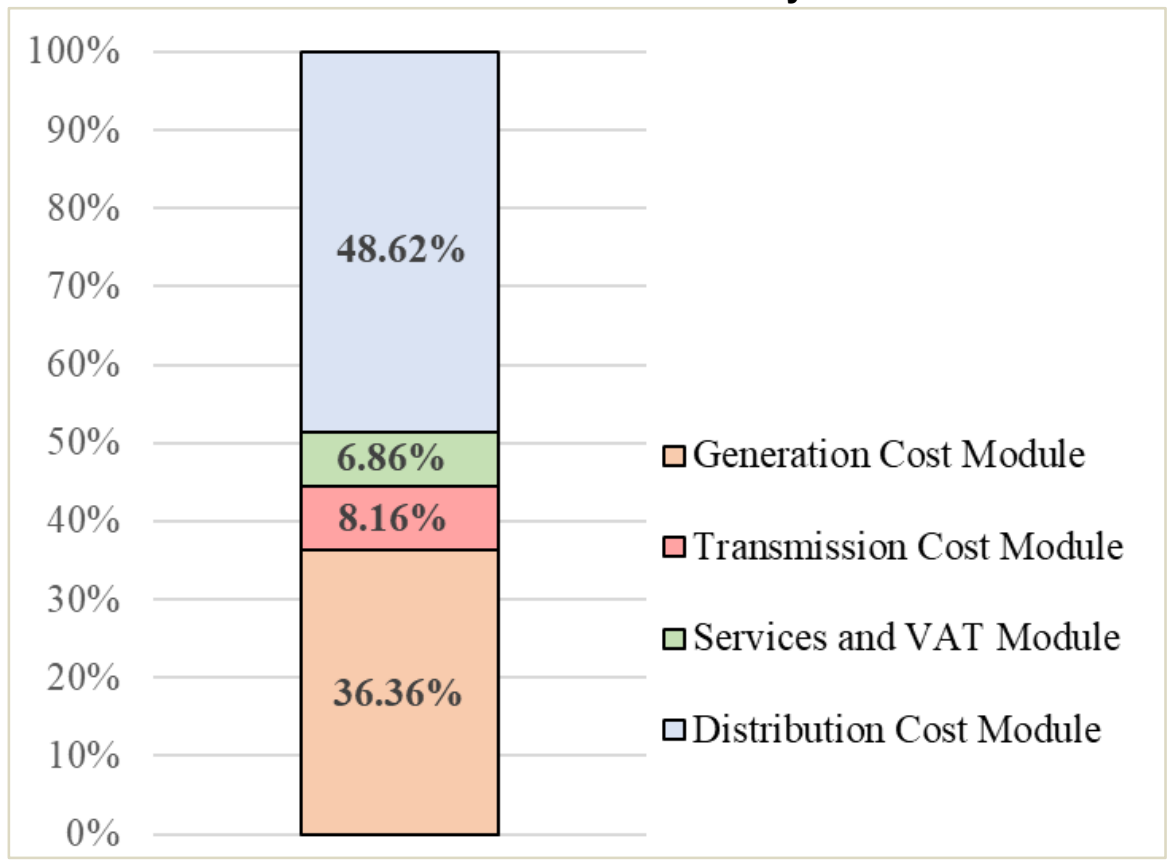

Source: Author.

The transmission cost module, which accounts for 8.16 per cent of the retail tariff, is the second layer of the electricity tariff in Nigeria. It is called the Transmission Use of System (TUoS) Charge or 'grid charge'. The TUoS charge is paid to TCN by the DisCos. The payment is made to TCN for transmitting electricity from the GenCos through the TCN-owned transmission network to the DisCo-owned substations for onward distribution to consumers. The TUoS charge allows TCN to retrieve existing and forecast capital costs, efficient operating costs, and allowances for return on capital and depreciation. This TUoS charge is uniform across Nigeria. The TUoS is regulated by NERC because TCN is the only transmission services provider in Nigeria, and almost all electricity on the Nigerian grid flows through its network. The TUoS is also, in principle, indexed to inflation and the exchange rate with the USD.

The services and tax module, which accounts for 6.86 per cent, is the third and smallest layer of the electricity tariff. This module contains the cost of running institutions, including NERC and NBET, which operate and facilitate the NESI. Other institutions include System Operator (SO) and Market Operator (MO).

The distribution cost module is the final and largest layer (48.62 per cent) of the electricity price in Nigeria. It is called the distribution charge, and it covers the cost of electricity distribution by the DisCos. This charge varies across the 11 distribution networks according to the density of customers on the distribution network and the terrain in which the network is located. Consequently, in less densely populated areas, the distribution charge and end-user tariffs are higher than in more dense areas. 

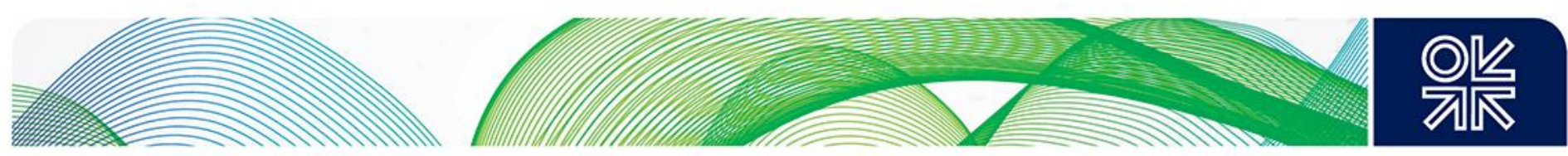

There is also a cross-subsidy regime in operation at the retail end of the electricity price. There are five classifications of consumers in the Nigerian electricity market. These are:

- residential consumers,

- commercial consumers,

- industrial consumers,

- $\quad$ street lighting,

- $\quad$ special consumers, which include schools, churches, mosques, military barracks, and agroprocessing plants.

These consumer classes have several sub-classes, which all have different retail tariffs. Special consumers and consumers, who consume low quantities of electricity pay lower electricity tariffs and are subsidized by the larger consumers.

\subsubsection{Market concentration}

An on-grid electricity market typically requires some natural ${ }^{4}$ monopolies in parts of its value chain. The high capital costs in the transmission and distribution parts of the value chain make it uneconomic for new entrants to compete against existing transmission companies and DisCos. The NESI is similar. It has monopolies in both parts of the value chain.

All 11 DisCos have monopolies in their respective licence coverage areas, while TCN has a national monopoly on transmission. The level of market concentration at the distribution and transmission ends of the NESI necessitates price regulation. Price regulation allows regulators to set prices at a level which induces productive efficiency (Depoorter, 1999). Prior to regulatory intervention, DisCos, which have a monopoly in their coverage area, charged consumers for collection losses, a risk that should have been borne by DisCos, who are responsible for collecting revenues from billed customers. NERC, the regulator, stopped this practice, forcing the DisCos to put more effort into the efficiency of their bill collection operation. The structure of the DisCo market caused the regulator's conduct to change the regulatory regime.

Monopoly status in the NESI is not just enjoyed by DisCos and TCN. The NBET is the only firm that offers bulk trading services in Nigeria, and while it is not a natural monopoly, the liquidity crisis in the sector prevents any new competitor from entering the market. The FGN-owned bulk trader has lost money steadily since the TEM was declared. Any new bulk trader would have to deal with the losses without government liquidity support. This gives NBET huge market power, as it ultimately decides which new GenCos can come into the market and at what price. If NBET does not accept a prospective GenCo's wholesale tariff, there is no chance of it entering the market. This has been one of the causes of the slow adoption of RE on the grid. It took six years from the time they started for some of the earliest on-grid RE project developers to be able to sign PPAs with NBET. No new entrant could finance their on-grid projects without a PPA from NBET.

While NBET, TCN, and the DisCos are monopolies, the GenCos and GasCos are not. However, they are effectively oligopolies, with a few dominant firms. The price of domestically consumed gas is regulated to protect consumers from the high export gas price, which is based on external global supply and demand forces. GasCos are not regulated just because of their selling power, but also because of the NESI's unattractiveness in comparison to the gas export market. The gas sector regulators assign each GasCo a pre-determined quantity of gas to be supplied to the domestic market annually. Theses supply obligations are unattractive to GasCos because of the inability of GenCos to pay their bills and the low government-regulated price compared to the export market.

\footnotetext{
${ }^{4}$ Natural monopolies occur where a single firm can produce output such as to supply the market at a lower per unit cost than can two or more firms. Natural monopolies also experience high fixed costs and average costs that decline as output increases.
} 

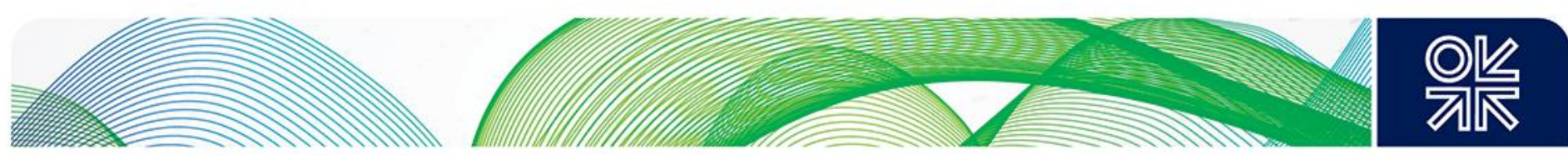

\subsubsection{Barriers to entry}

The typically high capital cost of assets in the NESI discourages new entrants from entering into the generation and gas sectors of the NESI. Prospective GenCos also have to deal with inadequate regulatory synergy within the regulatory dimension (discussed in Section 5).

In the distribution end of the electricity network, DisCos are natural monopolies. However, although DisCos are monopolies, the FGN offers other competitors the chance to manage the DisCo assets even if they may not own them. If DisCos do not meet their operational obligations the FGN, during its fiveyear performance review, may remove the DisCos as operators of their own assets, forcing the DisCos to hire external operators. However, it's not that straightforward, because the DisCos can argue, as they already do, that they are unable to meet some of their obligations because the FGN itself has not met some of its own obligations. This stalemate has caused a legal and political deadlock, which is expanded upon in Section 4.3.3.

The operation of the national electricity grid also typically requires one $\mathrm{SO}$ to operate the entire transmission infrastructure as a monopoly. A monopoly in the transmission end of the NESI allows the SO to maintain a uniform frequency, which requires a single coordinator of supply and demand. Whilst the FGN policy is to maintain ownership and hire a management contractor to manage the transmission assets, this has not happened. In 2013 , the FGN hired a management company which managed the TCN throughout its four-year mandate; however, the FGN did not subsequently start another competitive process to hire another management company, or renew the contract of the first management company. There is no indication that the current decision to halt another competitive hiring process is a result of the performance of the first company. There is also currently little market-based incentive for the TCN bureaucrat-led management to operate as efficiently as possible.

In the electricity wholesale trading business in the NESI, the liquidity crisis prevents NBET from having any competition. Any other trader who enters the market with the current performance may suffer huge losses without government support. The liquidity crisis in the NESI also causes barriers to entry in the domestic natural gas supply market. However, domestic gas supply is an obligation imposed by the FGN. GasCos are typically willing to oblige the FGN, especially because of the returns they gain from their gas export trade.

\subsubsection{Buyer concentration}

In the wholesale electricity market, NBET has an effective monopsony. It has strong buyer power because it is currently the only bankable off-taker for GenCos. This, however, has little effect on the existing wholesale market price because of the negotiated contracts, PPAs, which the GenCos have with NBET. As Inderst and Mazzarotto (2008) argue, in intermediate markets with negotiated contracts, a greater concentration of purchases in the hands of a few buyers does not always lead to a decrease in profits for suppliers. They argue that there is not an automatic mirroring of seller concentration in buyer concentration, especially where there are fixed negotiated contracts. This is because the contacts are negotiated individually, and a lowering of price for one contract does not necessarily lead to a lowering in price for the contracts of other firms. This can be observed in the NESI; when the FITs for new solar IPPs were negotiated and then subsequently reduced, there was no effect on existing NESI GenCos. The cost-of-service approach, which is used to negotiate wholesale tariffs for GenCos, is not dependent on the cost of service of other GenCos. As mentioned earlier, the high buyer power of NBET is a barrier to entry for prospective GenCos (including solar IPPs), but it does not have the buyer power to alter wholesale electricity prices in existing contracts.

The retail market in the NESI is far less concentrated than the wholesale market. NESI has over 6.5 million consumers nationwide. These consumers are categorized into five groups:

- residential consumers,

- commercial consumers,

- industrial consumers, 

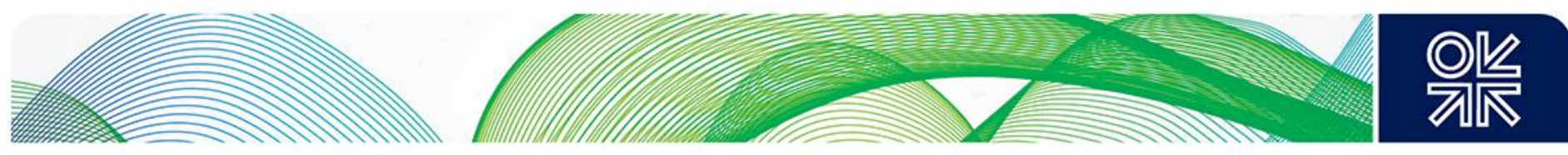

- $\quad$ street lighting,

- $\quad$ special consumers. ${ }^{5}$

Whilst there is low buyer concentration, the DisCos sometimes have to contend with the buying power of industrial and commercial consumers; although these consumers only account for 30 per cent $^{6}$ of the DisCos' market, they account for a disproportionately higher percentage of the DisCos' revenue. Industrial customers have proven to be more bankable consumers than residential consumers, who account for about 60 per cent of the DisCos' market. This, however, does not give enough buying power to the bankable customers to influence the retail electricity price, which is fixed by regulation.

In the wholesale electricity market, the 11 DisCos have a fairly even spread of consumption. There is low buyer concentration among the DisCos because their consumption is constrained by fixed contracted quotas and TCN's system balancing operations. TCN transmits electricity to DisCos vis-àvis contracted quotas; however, it sometimes prioritizes system stability when deciding how much power each DisCo gets. Notwithstanding, DisCos are monopolies in their respective coverage areas, effectively making them the only buyer in the wholesale market. They may not be able to use their market power to control price, but they have enormous powers to control quantity of supply from GenCos. The implications of the DisCos' ability to control the quantity of electricity they receive despite contracted quotas is discussed in Section 4.3.3.

While there are 25 GenCos that buy gas from GasCos, creating low buyer concentration, the GasCos still have to deal with very large buyer power, because they are compelled by regulation to supply a pre-determined amount of gas to the domestic market. Two-thirds of domestic gas supply obligations go to on-grid electricity production by regulation. Moreover, GasCos are required to sell at a fixed price, below the export market price. This makes the GasCos continue to sell to GenCos despite the accruing debt and low buyer power of GenCos.

\subsubsection{Market demand growth}

TCN estimates that Nigeria's demand for electricity will continue to grow at about 6 per cent annually to 2035 . This demand will, however, continue to be supressed by both inadequate electricity supply infrastructure and markets, stemming from the high debt and liquidity crisis in the NESI. That said, the Power Sector Recovery Programme (PSRP) - the FGN's response to the crisis in the NESI - states that more supply on the grid will lead to a larger sector deficit. As more electricity sales are recorded and fewer bills are paid, the debt in the sector widens, which in turn slows down market growth in the sector. The FGN's off-grid priority with its Nigerian Electrification Project (NEP) also contributes to the reduction in on-grid market growth rate in the sector, as FGN efforts and resources are diverted to offgrid electrification to avoid the issues of a central gird.

In the gas-to-power market, growth is supported by government regulation, which forces GasCos to sell to GenCos. However, recent events have shown that as a new gas GenCo comes on stream, gas supply to the new GenCo, which has FGN guarantees against insolvency, only replaces the gas demand of existing gas GenCos without such guarantees. There is little room for the gas-to-power market to grow with the existing liquidity crises in the sector. Intermediate and retail market growth is also limited by DisCos, which reject electricity supply in order to control their debt. Market demand will continue to grow in Nigeria; however, supply will continue to be restricted by the liquidity crisis in the retail market.

\footnotetext{
${ }^{5}$ Special consumers, according to NERC, include agriculture and agro-allied industries, water boards, religious institutions, government and teaching hospitals, government research institutes, and educational establishments.

${ }^{6}$ NERC Data.
} 

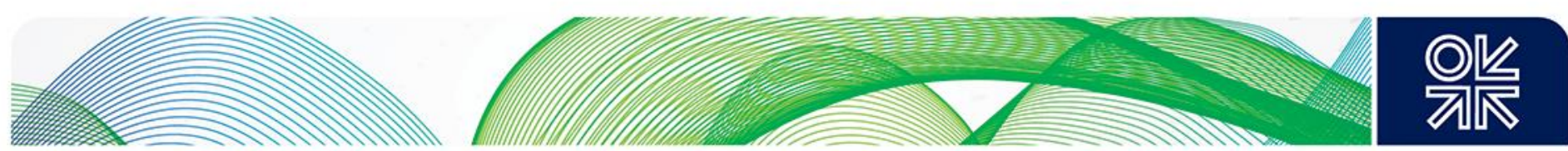

\subsection{Conduct}

In the NESI, commercial actors are unable to compete by price setting because all contracts in the NESI have fixed regulated prices and tariffs. The only opportunity for price competition is represented by new entrants, who compete by offering lower costs to NBET before entering the market. That said, some of the operational conduct of certain actors in the sector affects the electricity price in the NESI.

The major form of competitive conduct in the NESI is output adjustment. In the wholesale end of the sector, GenCos have a fixed regulated price for electricity, so the only way to maximize profit is to minimize down time and efficiently send out as much electricity to grid as possible. There is a general trust in the NESI that despite the liquidity crisis, the government will eventually step in to provide support where there are risks beyond commercial actors' control.

The capacity of a GenCo to maintain high output and thus high revenue is, however, constrained by the conduct of other actors in the NESI. Although the grid codes compel TCN to dispatch generators in economic merit order, TCN, in its role as the SO, also has an obligation to maintain system stability, which often requires less than optimal economic despatch of generators. In the merit order, hydroelectric generation units are the cheapest in the mix and as such should be fully deployed before gas-fuelled generation units. This is not always the case, as GenCos periodically complain about nontransparency in the despatch of GenCos. TCN's transmission line constraints also sometimes force it to restrict supply to some areas where the DisCos have bankable consumers.

Further down the value chain, DisCos artificially restrict demand, making it difficult for GenCos to reach their desired output and revenue levels. As Peng and Poudineh (2017) argue, the conduct and performance of firms within a market affects the performance and conduct of other firms within the same market. The DisCos' demand restriction also makes it difficult for the TCN to reach its own revenue targets (the TCN charges a tariff on all electricity that flows through its transmission lines from the GenCos to the DisCos). However, this 'load rejection' conduct of DisCos in restricting demand helps the DisCos to control their debt, thereby preventing worsening performance. The DisCos reject load in certain areas, knowing that those areas are only able to pay for a low quantity of electricity and are unable to pay a high enough fraction of their bill. In addition, the DisCos sometimes restrict the supply to areas where the price of electricity is insufficient to cover the cost of recovering payments from nonpaying customers.

Load rejection by DisCos and the resulting low revenue for GenCos and TCN leads to contestation between the groups of operators. This creates distrust in the sector and makes it difficult for operators to agree on the way forward, thereby stalling solutions to the crisis in the sector.

In addition to this, eight government-owned gas GenCos have suffered a worse fate. In 2017, the first privately ${ }^{7}$ financed IPP was commissioned. It is supported by several government guarantees protecting it from the liquidity crisis in the NESI. This new IPP also has a 'take or pay'8 PPA. Due to grid constraints and the liquidity crises, the FGN-owned GenCo, NDPHC, which does not have active PPAs for any of its eight power plants, has had to drop its output so that the FGN-owned NBET can accommodate the energy produced and sold by the new IPP. NBET must prioritize purchase from the new IPP at the expense of NDPHC, to avoid exacerbating FGN liabilities and decreasing confidence in the sector. As shown in Figure 4.6, when the new IPP began ramping up its electricity sale volumes between March and May 2018, there was a simultaneous winding down of electricity sale volumes by the state-owned NDPHC. Within two months, the new IPP's electricity sales increased by NGN5.2 billion (USD14.3 million) and NDPHC's electricity sales reduced by NGN5.5 billion (USD15.3 million). Meanwhile, sales from other GenCos have remained within recent boundaries - between NGN35 billion and NGN45 billion. It is evident that the NBET is incapable of supporting any further new generation

\footnotetext{
7 First non-IOC private IPP.

${ }^{8}$ A 'take or pay' PPA places the off-taker under an obligation to pay for electricity that the GENCO is able to generate regardless of whether the GENCO produces the power or not.
} 

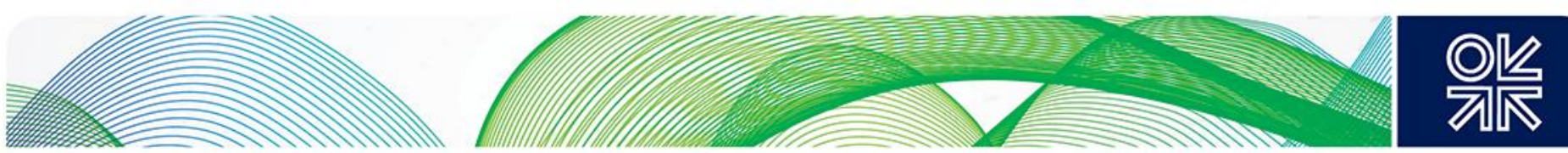

investments on the grid, as the government has evidently reduced the productivity of its own power plants to accommodate the new IPP, which is protected by several sovereign guarantees.

Figure 4.6: Energy billed to NBET (in Naira) by GenCos when a new gas IPP entered the market

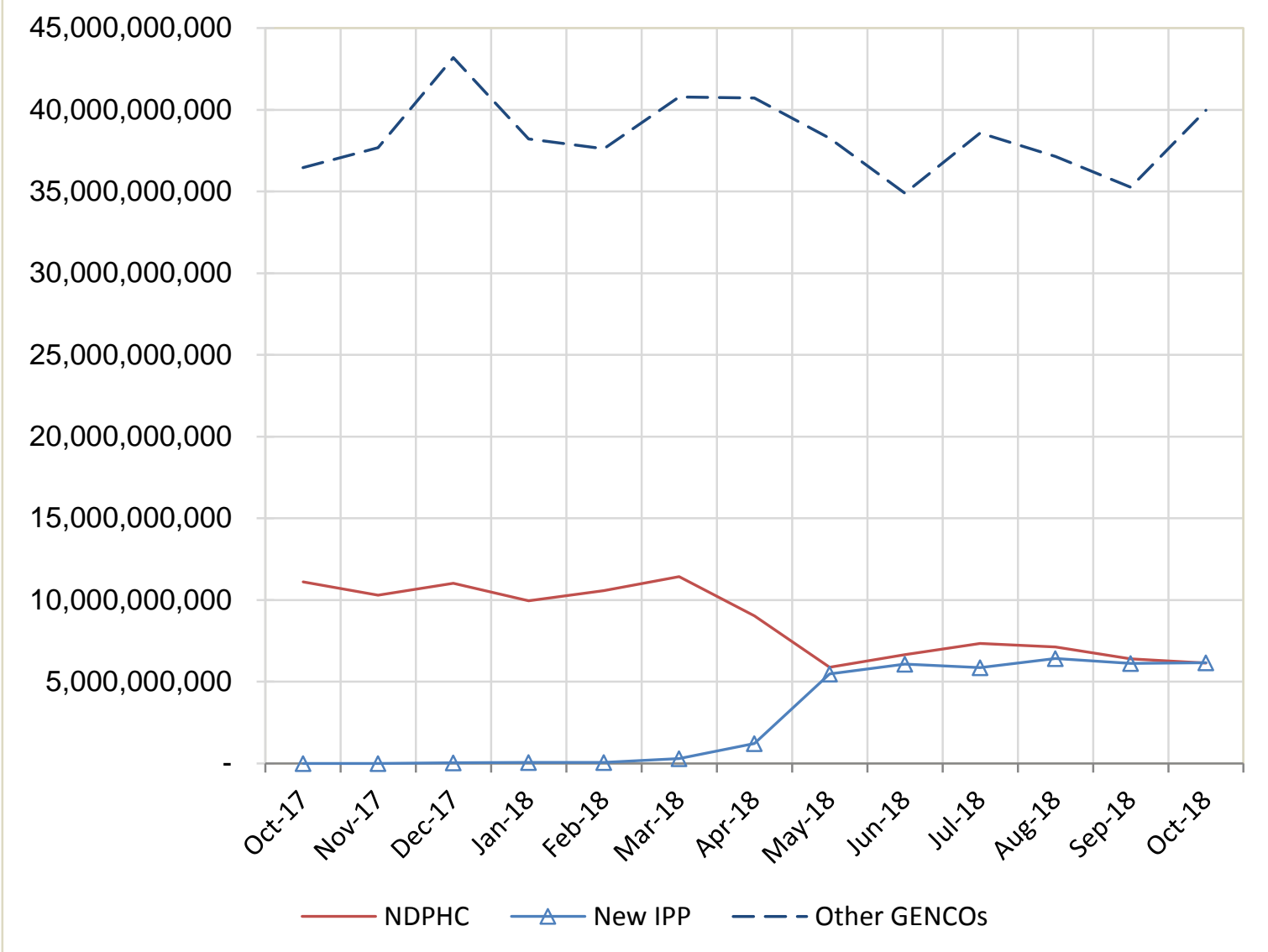

Source: Author.

Amongst the commercial operators in the NESI, there is little evidence of self-regulation. The commercial actors in the NESI have no direct control over price. However, self-regulation of the TCN within the current regulatory regime inadvertently affects the price of electricity within the sector.

TCN is obligated to employ the economic merit order to despatch generation units, but it frequently operates outside the economic despatch regime in order to meet its other obligation - to maintain system stability. The GenCos are also obligated to obey the SO's instructions according to the grid codes published by the regulator. However, this has an inadvertent effect on the wholesale price of electricity because the more expensive generation units sometimes come on before cheaper generating units, thereby altering the wholesale price of electricity.

\subsection{Performance}

The NESI is made up of three parts: generation, transmission, and distribution. This section presents the performance in all three parts and explains how the conduct of actors within the sector impacts performance. 

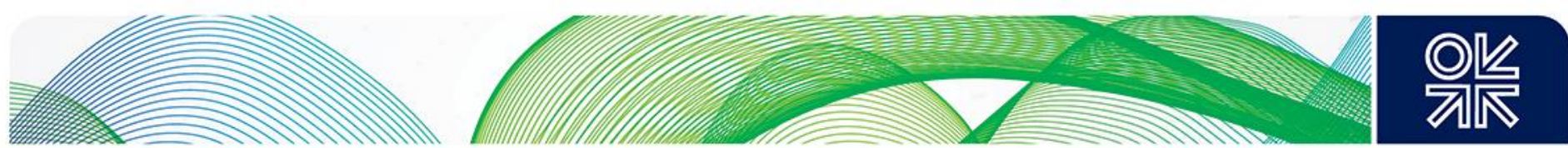

\subsubsection{Electricity generation}

The generation part of the NESI value chain had a total installed capacity of $12,310 \mathrm{MW}^{9}$ as of 2016 . Only $7,788 \mathrm{MW}$ of this was available on the grid in that year, due to extensive damage in a significant number of power stations, which required extensive overhaul and refurbishment. A few of the power stations are approaching the end of their expected lifespan, with no signs that the management of the plants is looking to decommission them. About 20 per cent of installed generation capacity is based on plants which are 25 years old, or older. ${ }^{10}$ Figure 4.7 shows that only 64 per cent of installed capacity was operational in 2016 due to plants awaiting refurbishment and repair to some of their generating units.

Figure 4.7: Operational capacity, average availability, and installed capacity from 2011 to 2016

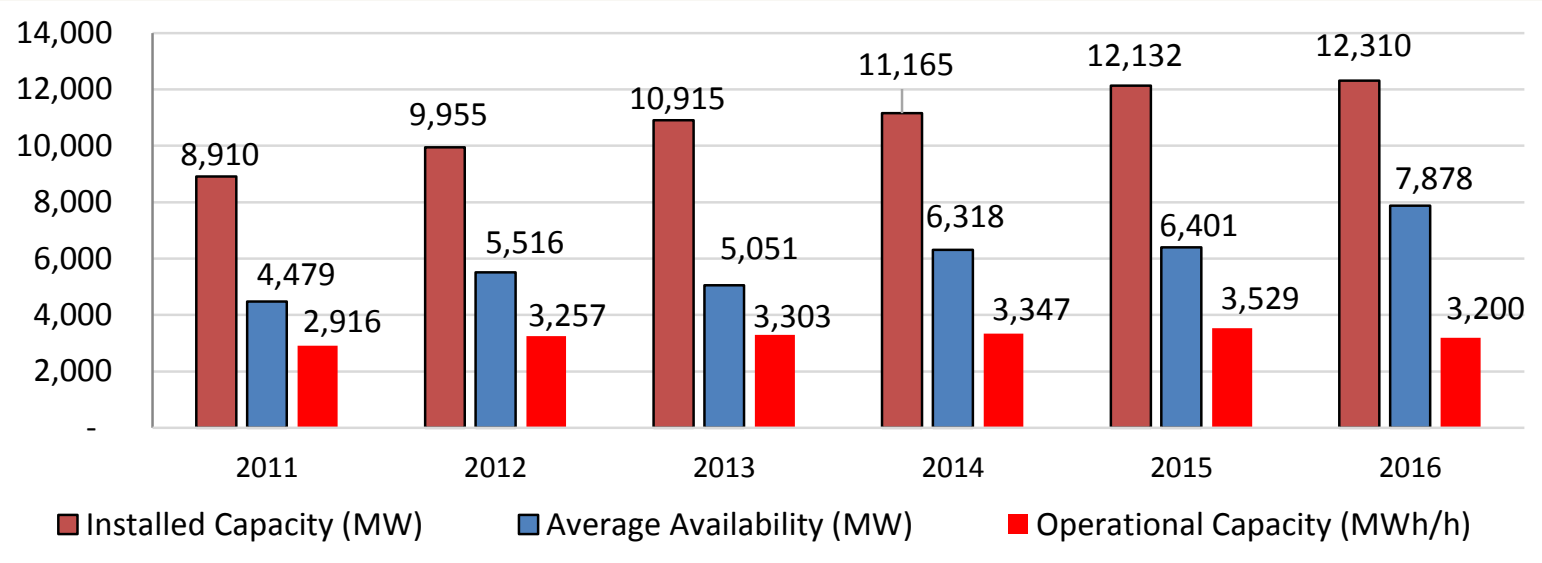

Source: Author.

The availability factor, which was 64 per cent in 2016, has seen an improvement from 2015 when the sector performed at a lower availability factor of 53 per cent. Although the figure for 2015 was worse than that for 2014, Figure 4.8 shows a modest but noticeable trend in improvement of performance since privatization in 2013. In 2016, average plant availability had risen to 64 per cent from 50 per cent in 2011. This is a result, on one hand, of private investment in the sector and on the other, the deployment of new power stations with relatively high availability factors.

While plant availability seems to be improving, the total capacity factor of the generation assets is on a steady decline. The capacity factor is the ratio of actual output over time to the maximum possible output over the same period. In Figure 4.9, two sets of capacity factors are presented. The higher range of capacity factors shows the capacity factor trend that assumes that the maximum possible output is constrained by plant availability, while the lower range assumes that the maximum possible output is constrained by installed capacity. Both show a steady decline in the productivity of the assets. This chart shows that as generation stations increase their generating capacity, their operational capacity declines.

\footnotetext{
${ }^{9}$ As of 2016, according to the National Control Centre (NCC) in Oshogbo.

${ }^{10}$ Transmission Expansion Plan 2017.
} 


\section{Figure 4.8: Trend of Plant Availability Factor from 2011 to 2016}

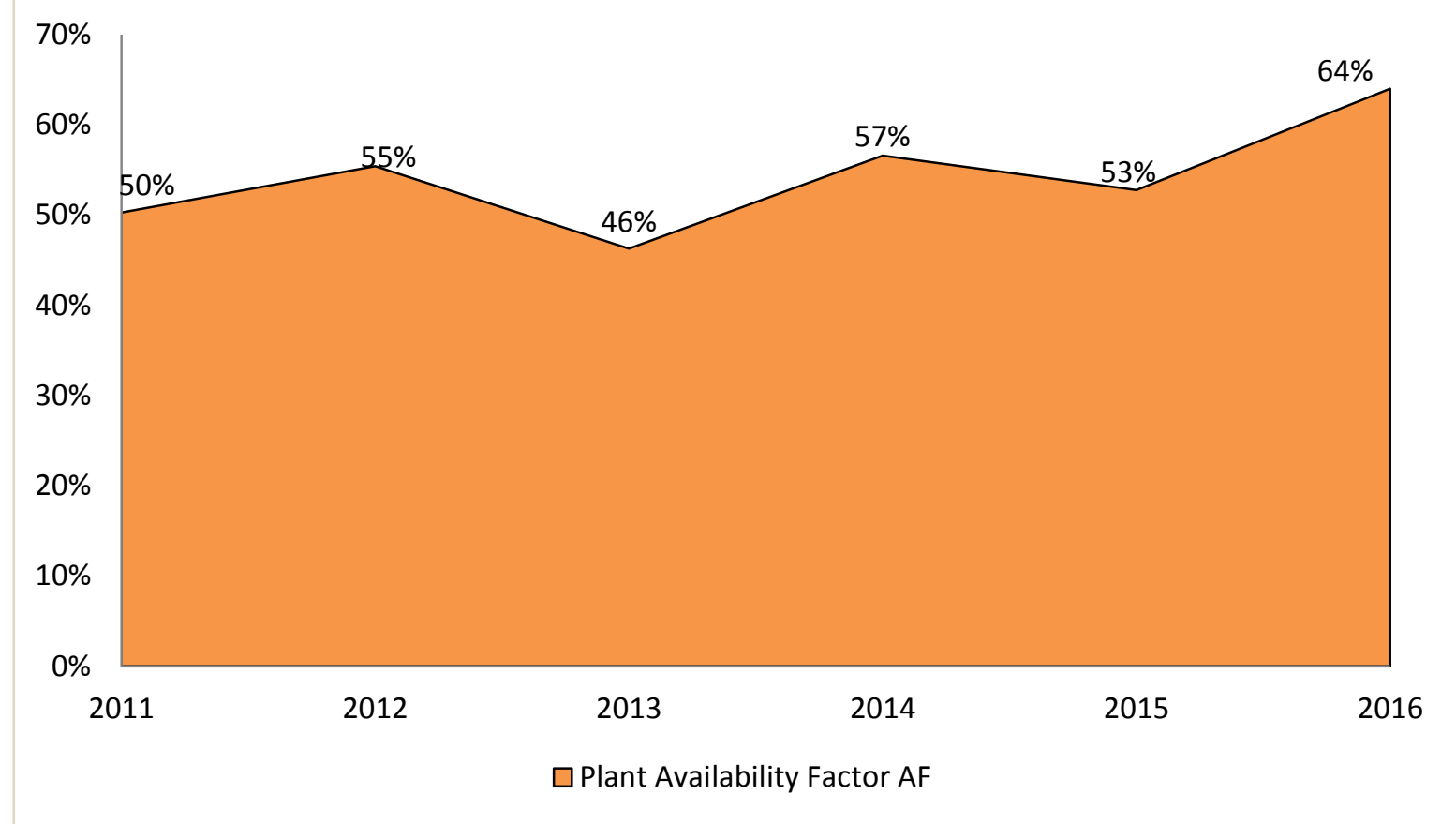

Source: Author.

The capacity factor of the generation assets is declining due to the effects of seasonal levels of rainfall on hydropower generation, gas supply constraints, transmission constraints, and the rejection of electricity by the DisCos.

Figure 4.9: Trends of the average installed and available capacity factors on the grid in Nigeria from 2011 to 2016

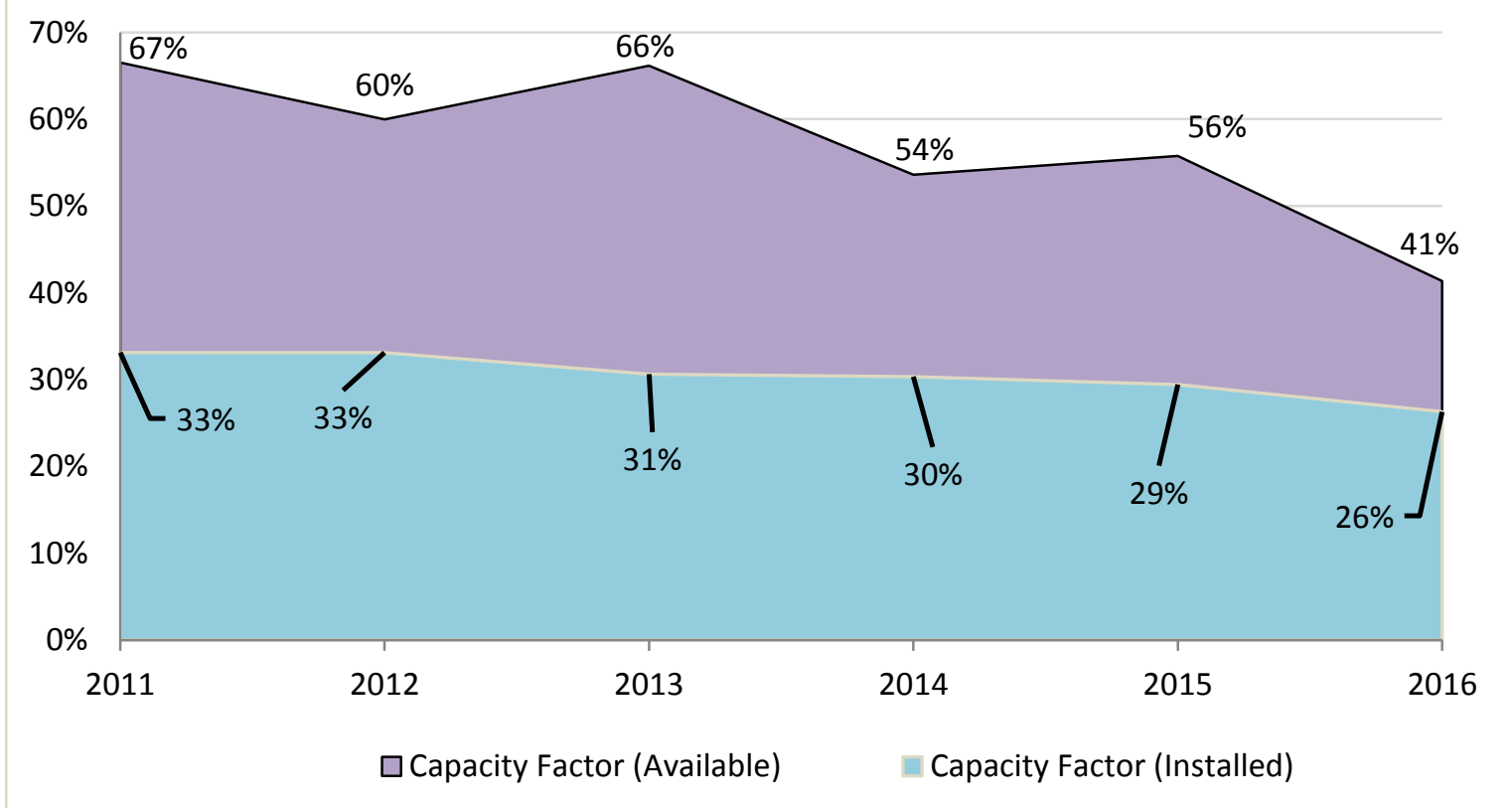

Source: Author. 

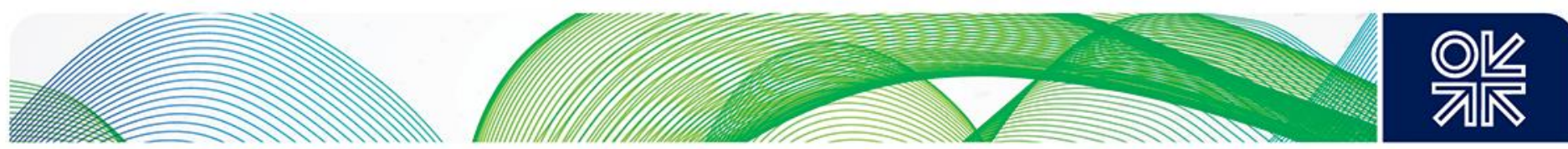

The NESI generates power from only two types of fuel: gas and hydro potential. The susceptibility of these technologies to the realities in Nigeria is high. From 2011 to 2016, about 71 per cent of the country's on-grid electricity came from gas power stations and 20 per cent came from hydropower stations (See Figure 4.10).

Figure 4.10: Annual energy sent out from hydro and gas power stations to the grid from 2011 to 2016 (GWh)

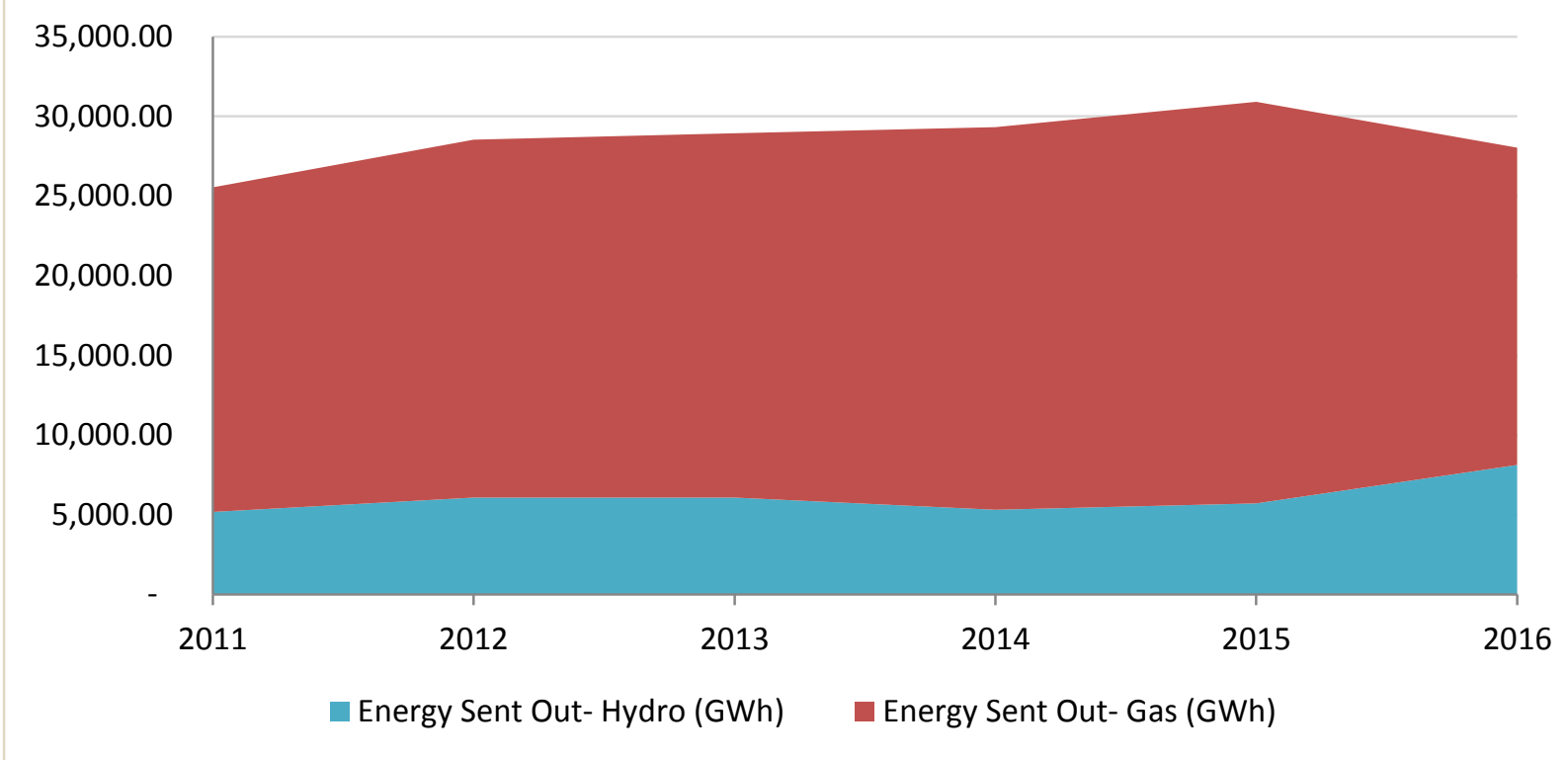

Source: Author.

The susceptibility of the electricity supply to the seasonal variation of the level of rainfall is one of the main constraints on electricity generation performance. Figure 4.11 shows the average electricity production levels of all three hydropower stations in Nigeria for six years from 2011 to 2016 plotted next to the average monthly rainfall in the same period. There are only two major seasons in Nigeria: rainy and dry. By mid-April, the end of the dry season, there is a 48 per cent reduction in monthly electricity generation levels compared to mid-October, the end of the wet season. The effect of the seasonal variability of rainfall is an 11 per cent monthly decline of hydropower generation on the grid during the dry season. This is significant because hydropower accounts for 20 per cent of all electricity sent out to the grid. 

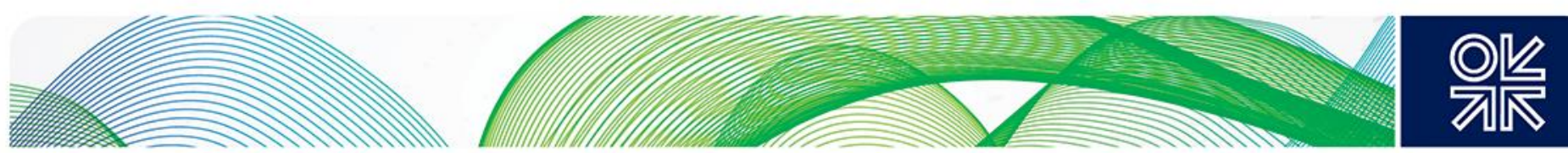

Figure 4.11: Average monthly energy production from hydropower stations and seasonal variation of average monthly rainfall

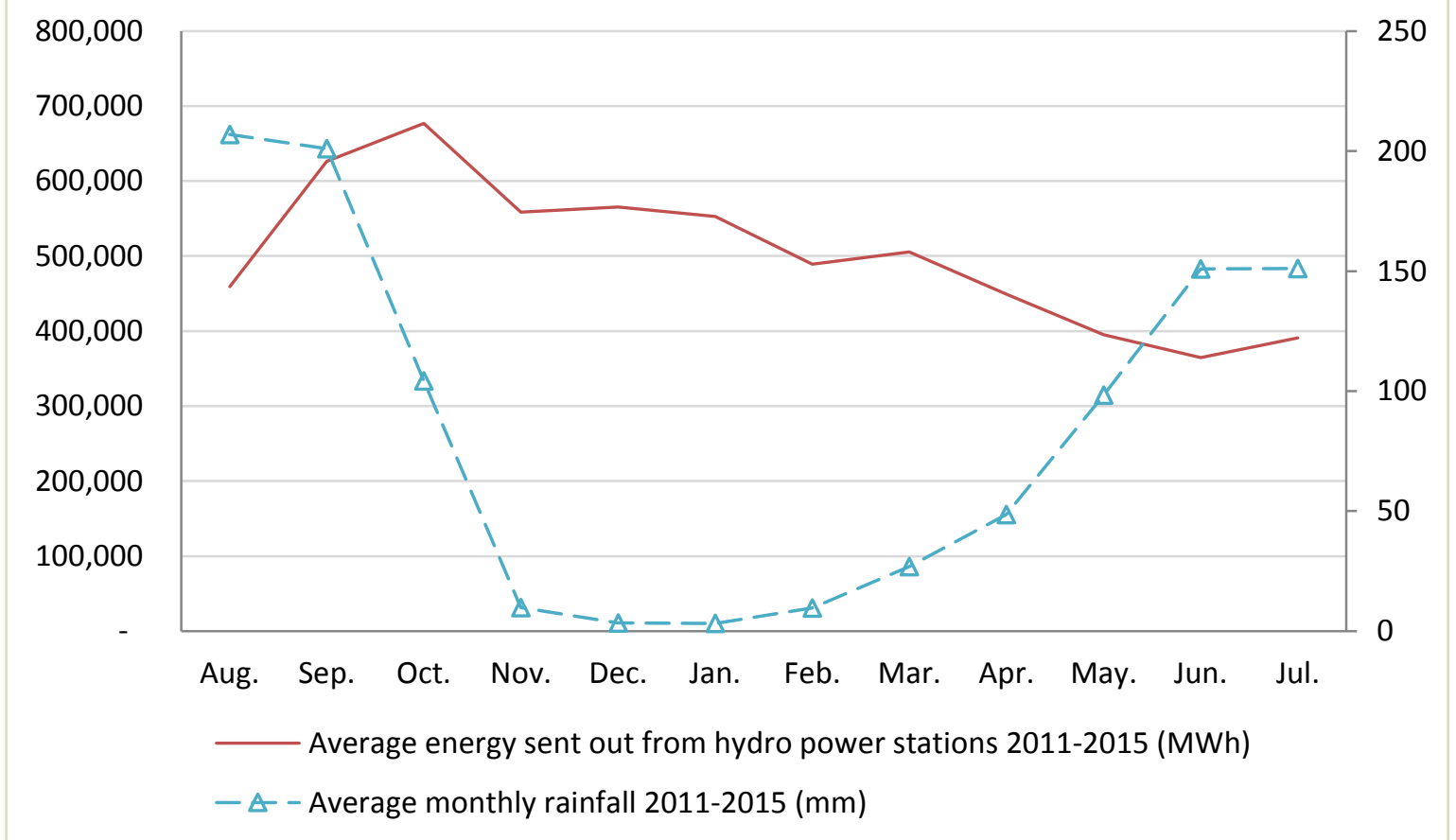

Source: Author.

Unreliable supply of gas is also an incessant constraint to performance in the NESI. Interruption of gas supply to the gas power stations, which account for 71 per cent of all electricity sent out to the grid, reduces the operational capacity of the gas generation assets. The interruption to gas supply is caused by gas transmission constraints, GenCo debts, and sabotage of gas transmission pipelines.

The enormous deficit in the gas supply infrastructure in Nigeria renders it incapable of meeting the gas demand of gas power stations. The state-owned gas transportation company, Nigeria Gas Company (NGC) - a subsidiary of the national oil company, Nigerian National Petroleum Corporation (NNPC) runs a monopoly and has been unable to invest enough capital into the infrastructure to keep up with the demand for gas transportation. In addition to this, the debts owed to gas producers by GenCos adds to the constraint on gas supply. GenCos that own gas power stations buy gas from gas suppliers through a gas supply agreement (GSA), and the gas is delivered by NGC through NGC's pipelines under a gas transportation agreement (GTA). The GenCos' debts resulting from their inability to meet their GSA obligations routinely result in gas being withheld by gas suppliers. GenCos are usually not able to pay the full bill for gas supplied to them. The total gas supply indebtedness of power plants from January 2015 to December 2016 is NGN155 billion (USD507 million). ${ }^{11}$ As Peng and Poudineh (2017) argue:

'the degree to which politicization or state intervention is active in a sector is dependent upon the degree to which its perceived/expected performance deviates from social/interest group expectations and government objectives.'

The enormous sector deficit necessitates government intervention, which makes additional analysis in the regulatory and political dimensions crucial.

\footnotetext{
${ }^{11}$ Data retrieved from Power Sector Recovery Programme (PSRP) January 2018.
} 

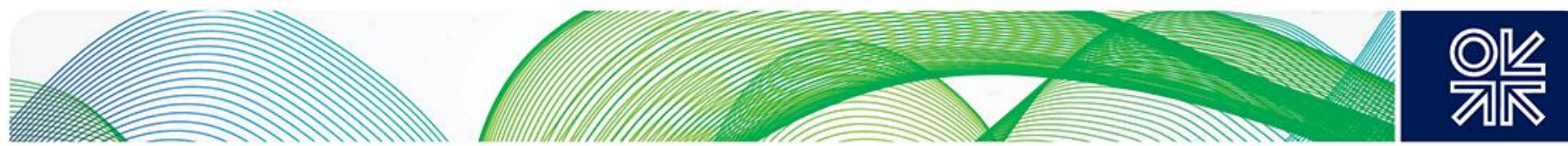

Gas supply is also interrupted sporadically by gas infrastructure vandalism, which reduces gas production and transportation. The effect of this was seen to be particularly severe for a significant period in 2016 (see Figure 4.12), resulting in the loss of 2,900 MW ${ }^{12}$ of operational electricity generation capacity.

The commercial performance of the GenCos is low. This performance is, however, a result of the conduct of other actors within the NESI. GenCos sell power to NBET through a PPA, which places an obligation on NBET to pay 100 per cent of its invoice for power sold to it. However, NBET has never been able to meet more than 50 per cent of its PPA obligations on its own. For 14 months between August 2016 and October 2018, NBET was only able to meet 26 per cent of its PPA obligations to GenCos (see Figure 4.13). This affects the capacity of GenCos to pay off their loans, pay gas supply bills, and carry out their infrastructure investment obligations. The FGN has been able to supplement NBET's payment through a loan to NBET to meet up to 80 per cent of its obligations to GenCos.

Figure 4.12: Average monthly thermal energy sent out (MWh) in 2015 and 2016 showing susceptibility to vandalism and industrial action

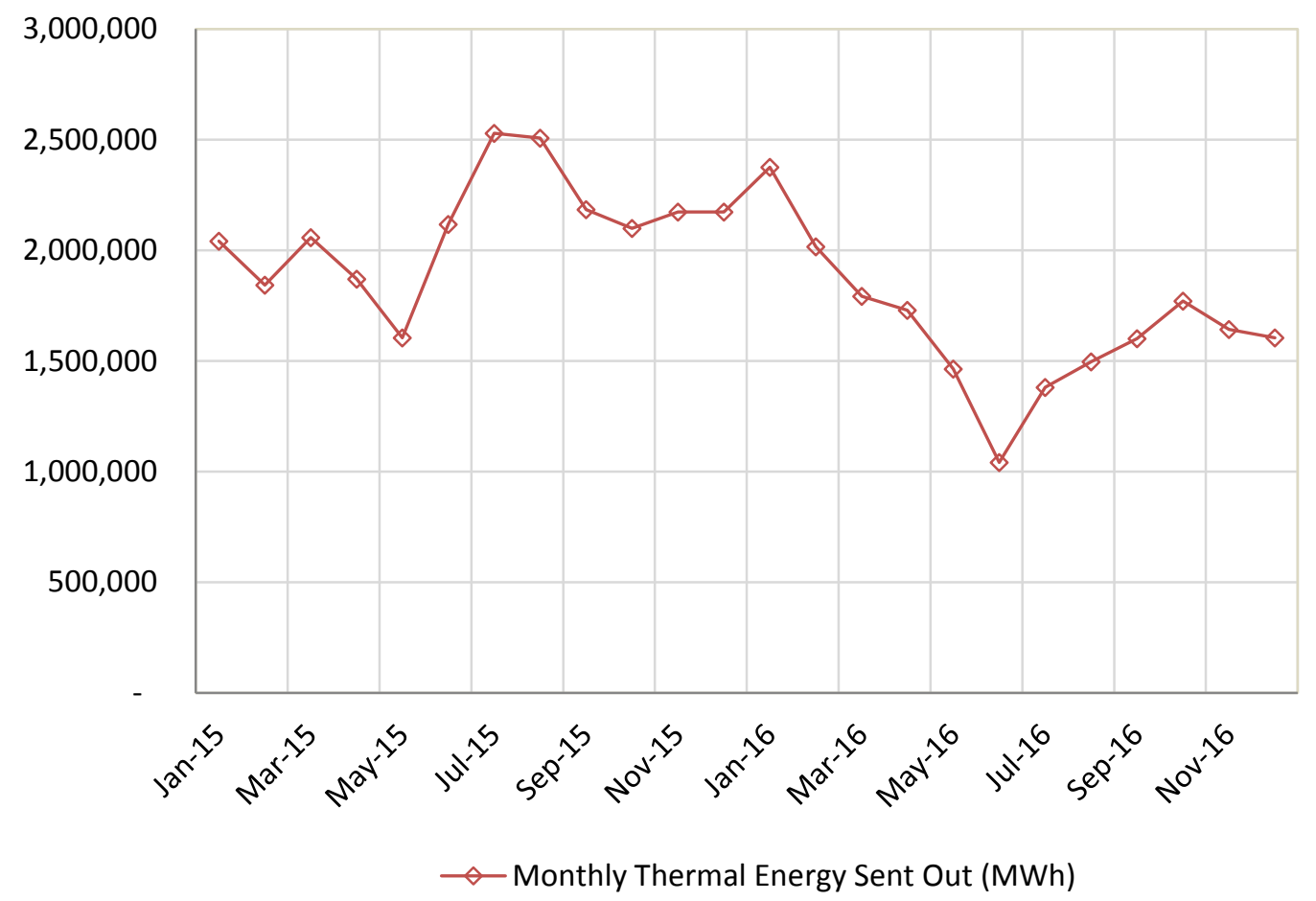

Source: Author. 

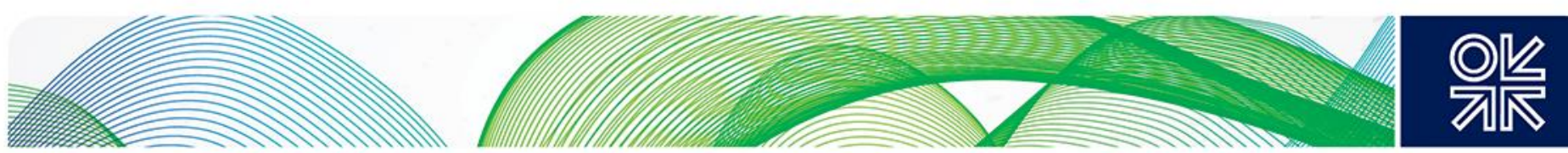

Figure 4.13: Trend of GenCos (in NGN billions) commercial performance for 14 months between August 2016 and October 2018

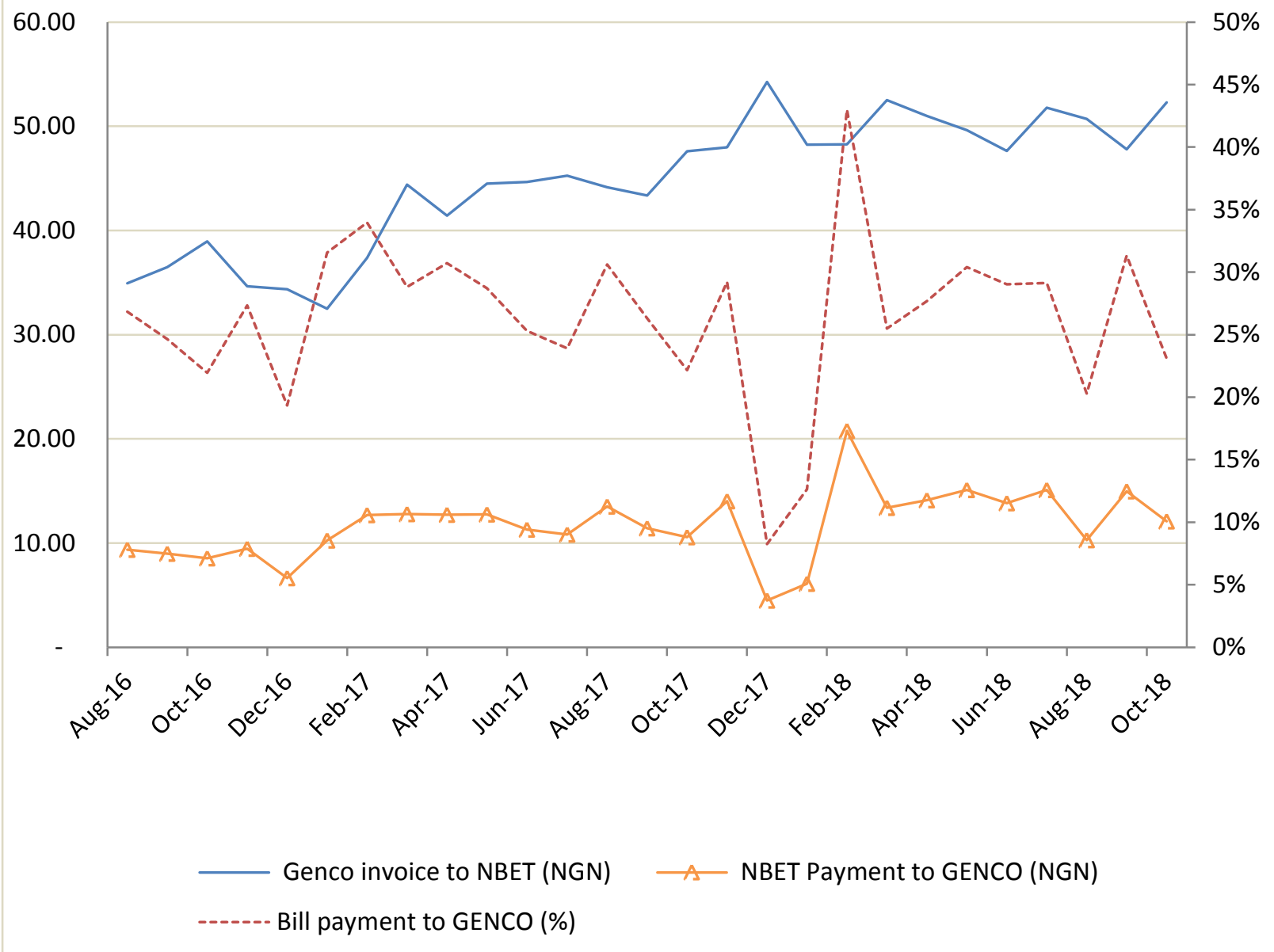

Source: Author.

\subsubsection{Electricity transmission}

The highest amount of electricity ever sent out through the transmission network is $5,222 \mathrm{MW}$. This occurred in December 2017. However, the SO claimed that the transmission network has the capacity to wheel 7,000 MW as of December 2018. In verifiable terms, there has been a steady increase in the total amount of electricity that the transmission network has transmitted at a single time (see Figure 4.14) from 3,804 MW in 2011 to 5,222 in 2017. 

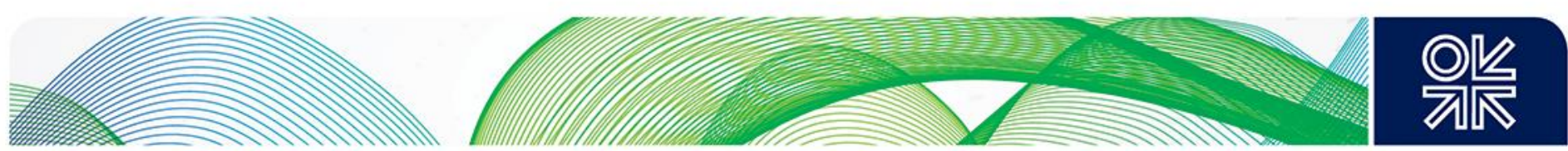

Figure 4.14: Trend of national simultaneous maximum demand from 2011 to 2017

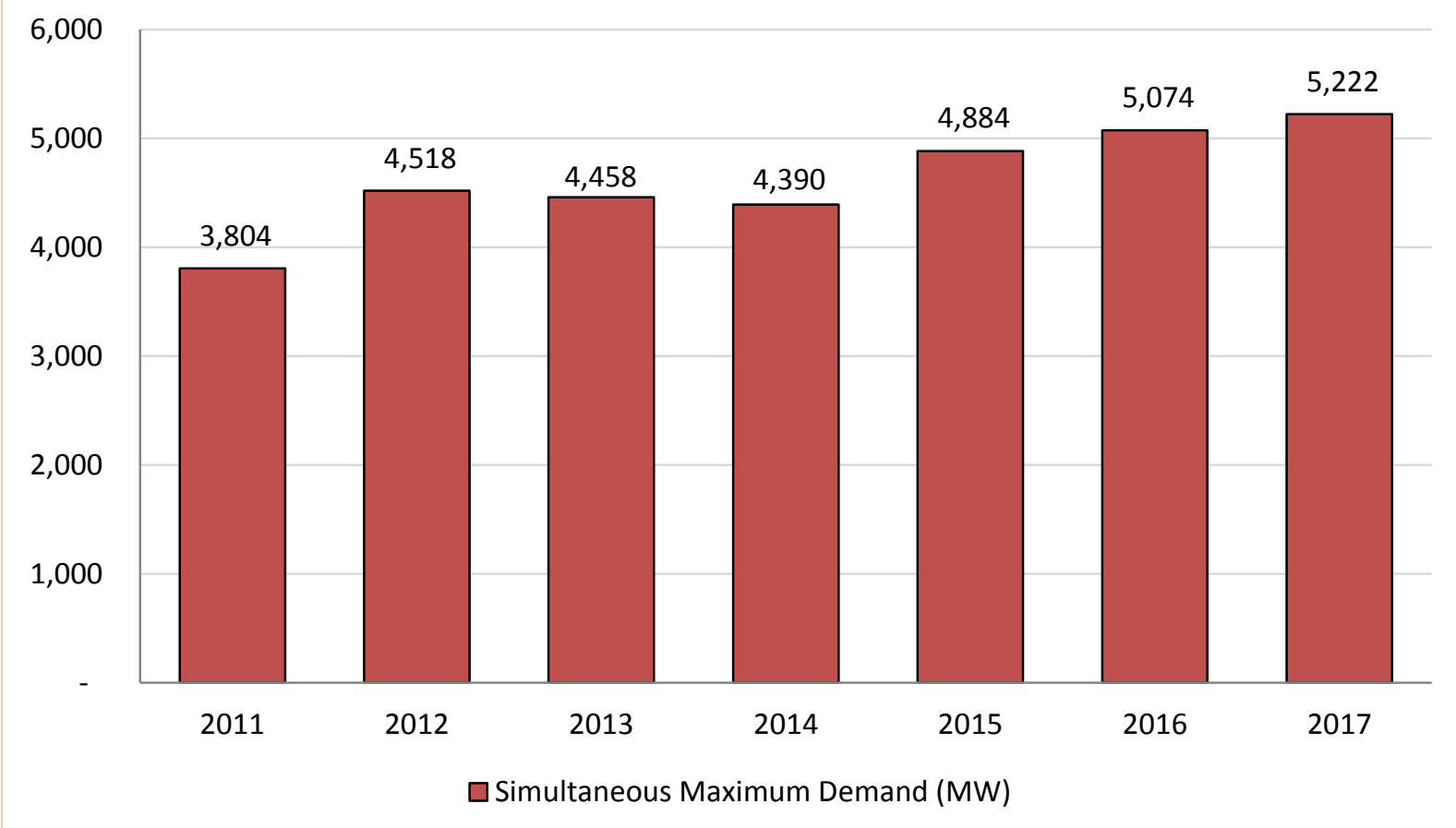

Source: Author.

Grid reliability has also shown some sign of improvement. From 2011 to 2016 , the grid recorded decreasing numbers of system collapses. Grid collapses decreased from an annual average of 35 between 2000 and 2009 to an average of 23 between 2010 and 2016 (see Figure 4.15), although, they spiked again in 2016 with 27 recorded incidences. Transmission faults were responsible for 19 of these system collapses. These transmission faults were a result of insufficient maintenance of the areas surrounding transmission line routes causing over growth of bush and consequently leading to ensnaring of transmission lines; and the use of unreliable and aging line protection equipment. There is also a lack of a comprehensive and modern Supervisory Control and Data Acquisition (SCADA). ${ }^{13}$

${ }^{13}$ Power Sector Recovery Programme (PSRP) January 2018. 

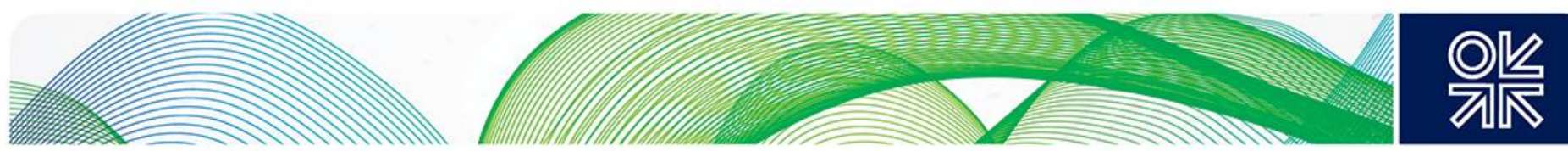

Figure 4.15: Total number of grid collapses in Nigeria from 1997 to 2016 sorted by cause

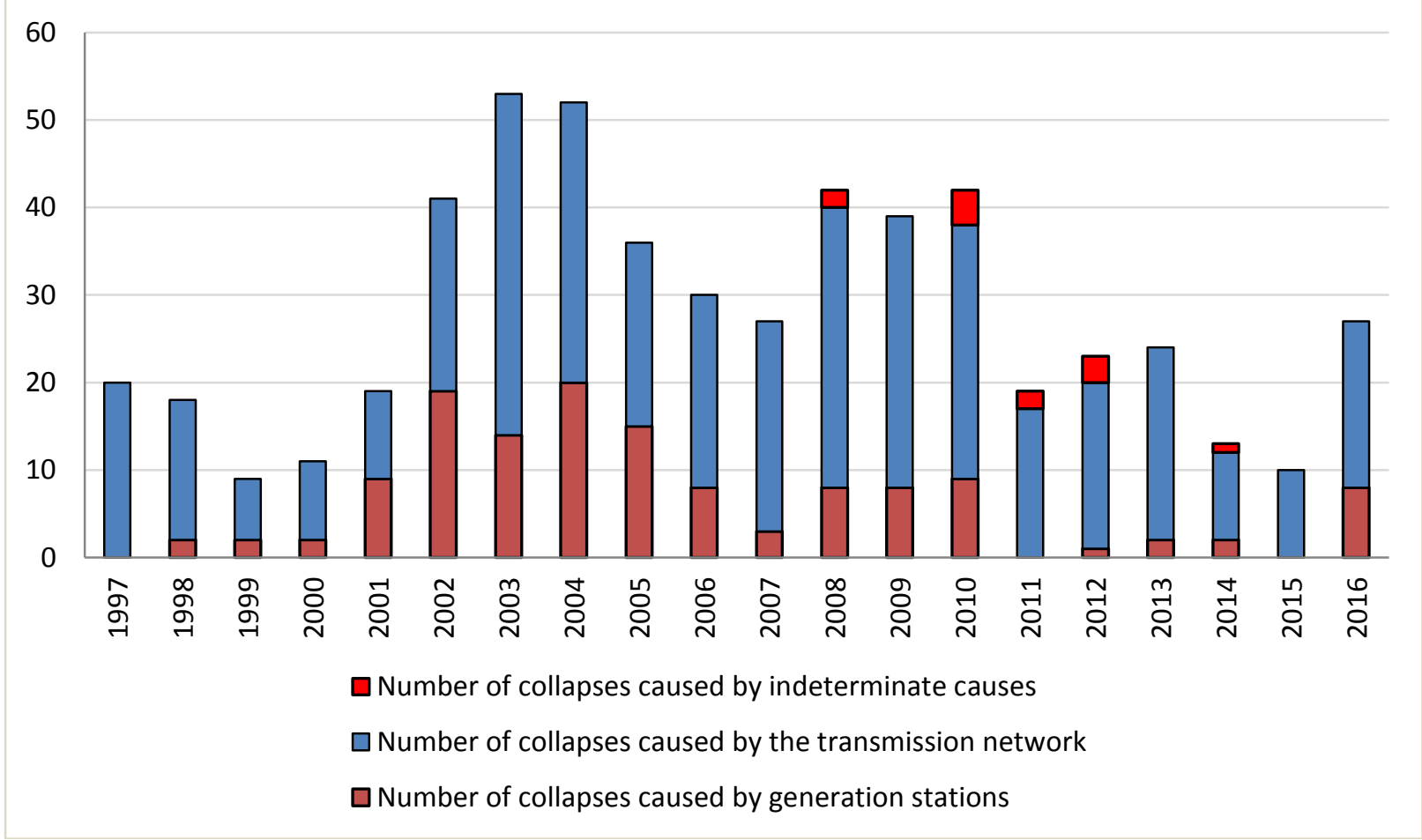

Source: Author.

Generation faults accounted for eight of the grid collapses in 2016. The generation faults were caused by the tripping of generation station units. When a significantly large generation unit drops from the grid, the frequency on the grid drops. This forces other generation units on the grid to increase output to pick up the frequency. However, this usually causes other generating units, which cannot handle the frequency change, to trip off the grid, resulting in a cascaded loss of most generating units until sufficient load has been shed, causing partial or total blackout. Abrupt generation reduction on the grid causes the system to collapse because not all generation station units use Automatic Generation Control (AGC), which would allow generation units to respond speedily to a drop in frequency on the grid.

Most of the grid collapses are total grid collapses (see Figure 4.16), which result in total black out. This suggests that the current manual systems that govern control in several power stations are not able to respond quickly enough to meet the challenge of falling grid frequency. There is also a need for spinning generation reserve. 

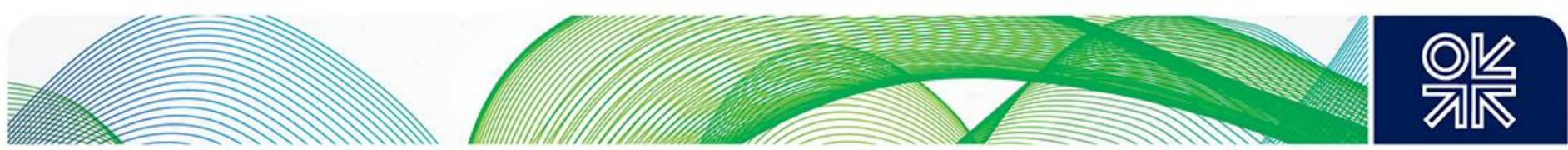

Figure 4.16: Trend of total and partial system losses on the grid in Nigeria

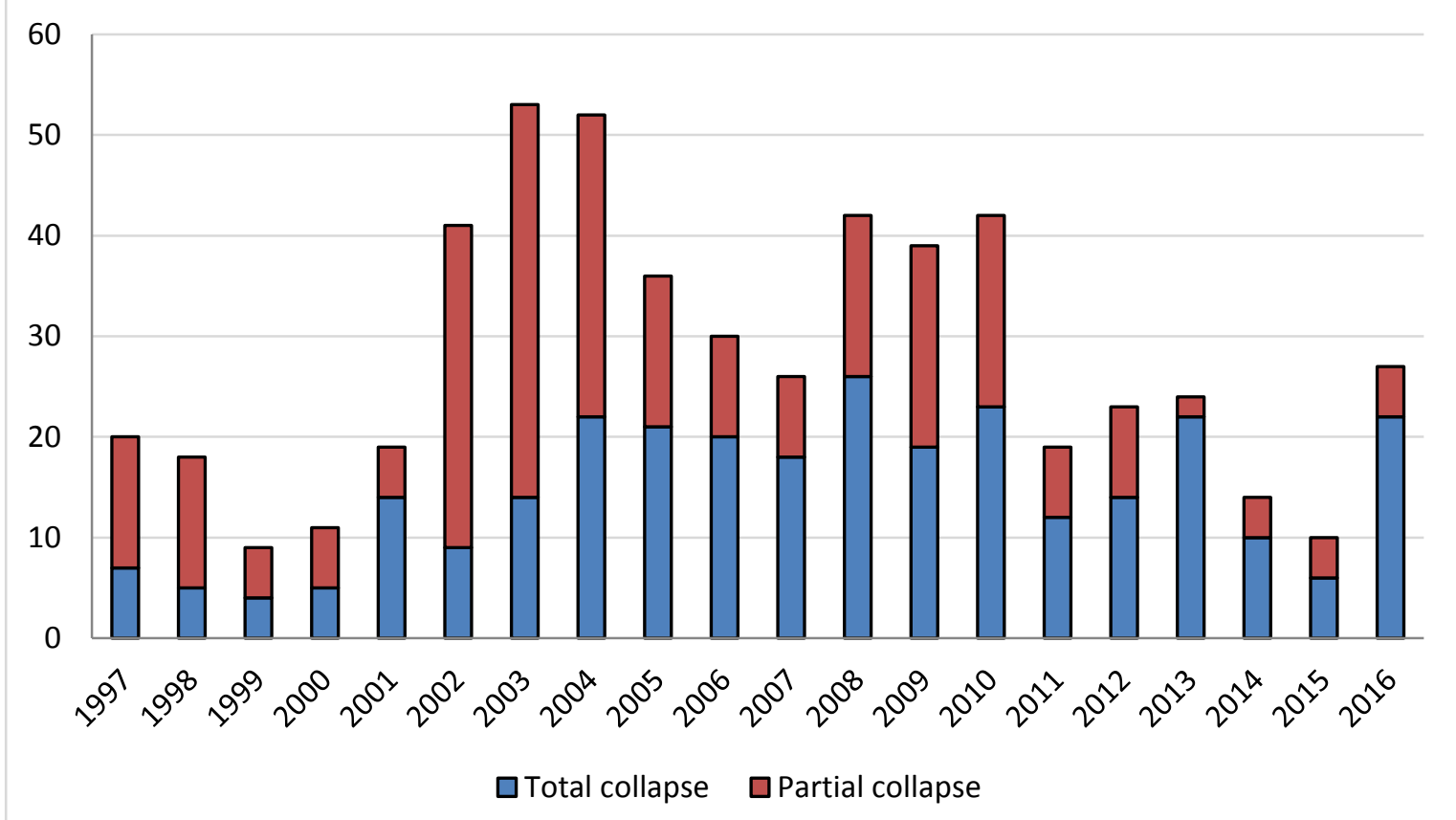

Source: Author.

The TCN has reduced transmission network losses between 2011 and 2016, but they have still hovered between 10 per cent and 12 per cent in recent years (see Figure 4.17). In comparison, the |Ghanaian transmission network losses are under 5 per cent and South African transmission losses are under 4 per cent.

Figure 4.17: Annual transmission losses on the grid in Nigeria from 2010 to 2016

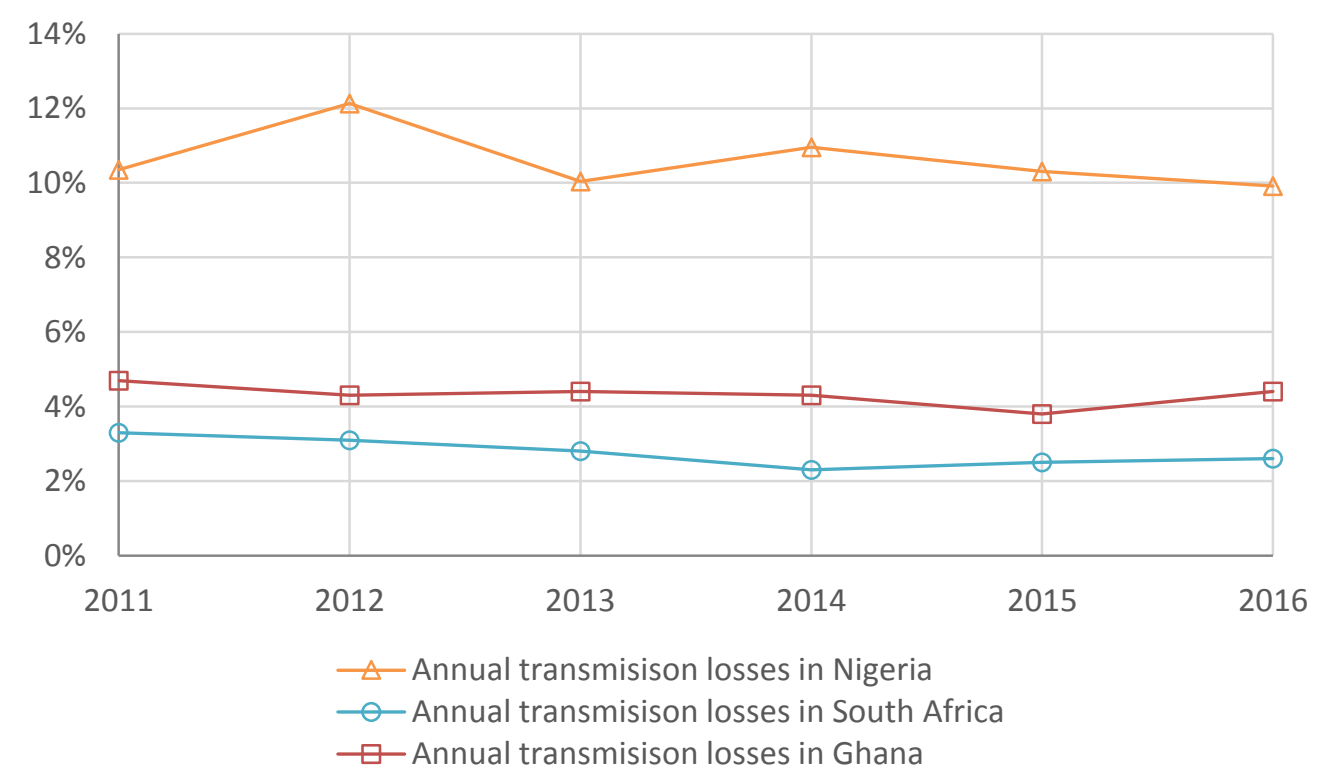

Source: Author. 

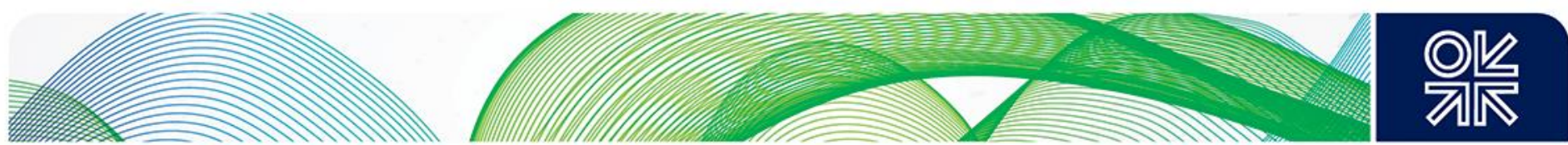

\subsubsection{Electricity distribution}

The FGN estimates the simultaneous peak electricity demand in Nigeria in 2016 - including supressed demand - at 15,271 MW (see Figure 4.18). This is almost three times higher than the highest recorded peak production on the grid in Nigeria. ${ }^{14}$ The DisCos are unable to meet the demand of consumers due to generation and transmission constraints. The DisCos also have their own technical and commercial constraints, which make them unable to deliver enough power to consumers.

Figure 4.18: Projected grid electricity demand in Nigeria including suppressed demand

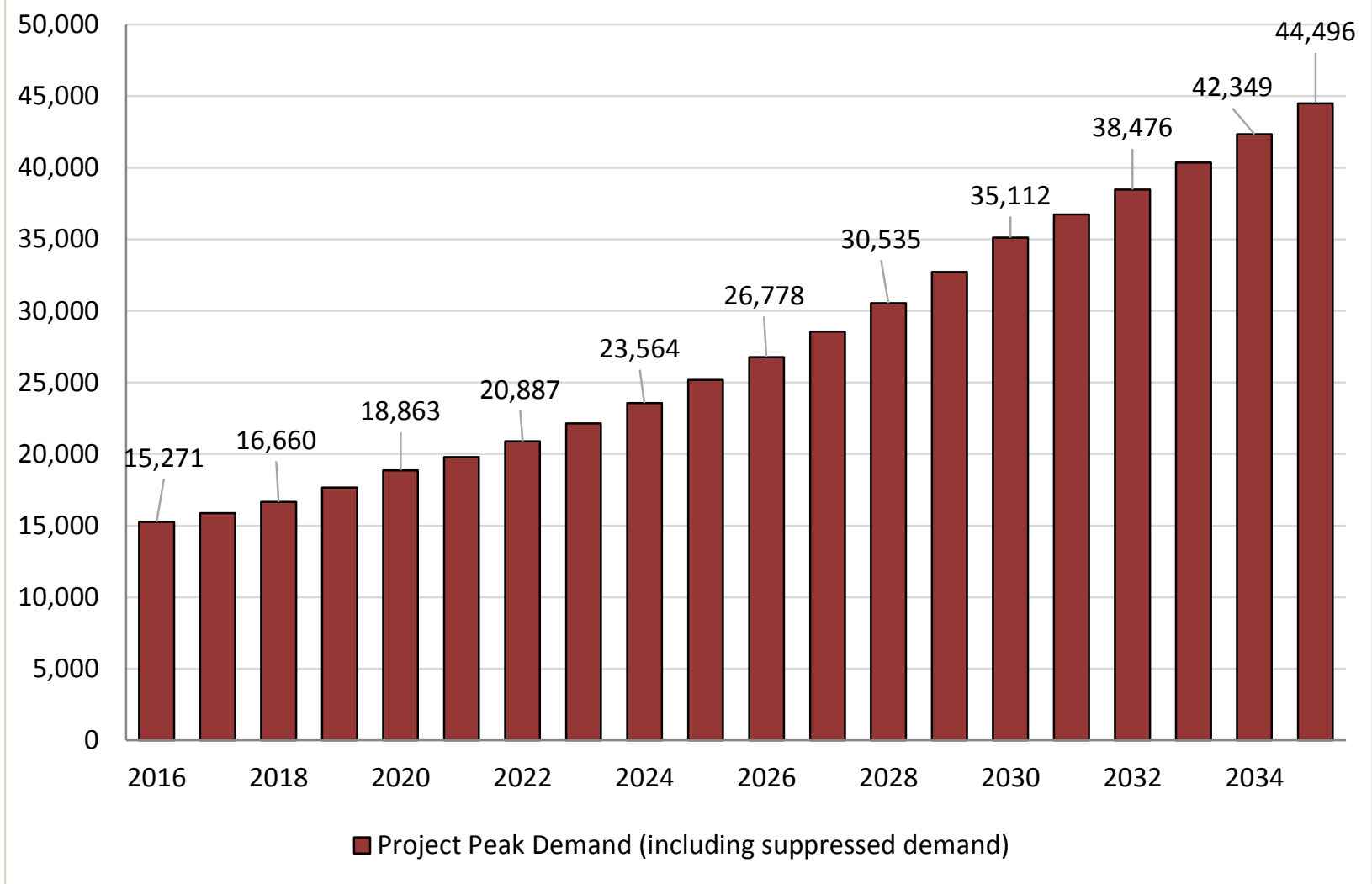

Source: Author.

The performance of the DisCos is crucial to the performance of the entire sector, because their financial viability determines the state of liquidity in the rest of the sector. DisCos' performance can be analysed by examining their Aggregated Transmission, Commercial, and Collection (ATC\&C) losses. The ATC\&C losses are the total amount of energy sent into the distribution network that is not paid for by consumers. It has three components: technical loss, commercial loss, and collection loss. The technical loss is the intrinsic loss that arises from the normal operation of any electrical system. This loss arises when electricity passes through resistive loads such as cables and transformers. These losses are unavoidable, but can be minimized with effective network maintenance.

Commercial losses, sometimes referred to as 'billing losses' are non-technical losses. They arise when the DisCos are unable to assign electricity consumption to any known consumer. This usually occurs when there is electricity theft by some consumers or when the DisCo is not aware of some of its consumers. This usually causes a revenue shortfall. When the DisCo assets were privatized, the government recognized this type of loss and agreed to have it built in as a component of the end-user

\footnotetext{
${ }^{14}$ Highest peak production on the grid in Nigeria is 5,222 MW.
} 

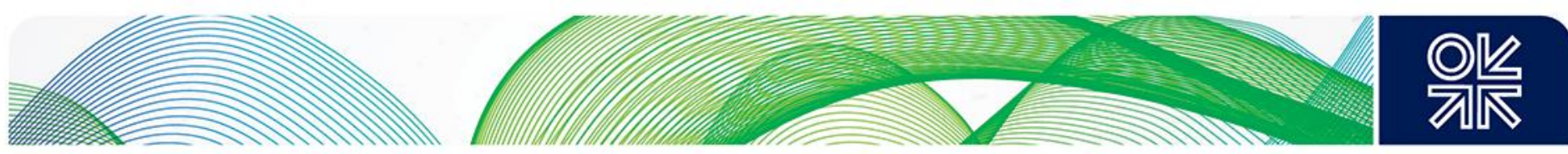

electricity tariff. This would mean that the DisCo investor would be able to recover commercial losses by making consumers pay for them through their energy bills. In practice, however, this has not happened due to two factors. First, the regulator has refused to build an accurate 'commercial loss' component into the end-user tariff. This means that DisCos have a revenue shortfall. Second, the consumers who are billed - and who are expected to pay their bills, including the commercial loss component - do not always pay 100 per cent of their bill. DisCos observe that, regardless of the amount of supply available, consumers usually have a fixed budget for electricity. This causes a larger revenue shortfall for DisCos. This second factor is referred to as collection loss.

The collection loss is the difference between the amount of energy billed to consumers and the amount of energy paid for by consumers. The collection loss is an important measure of performance, because the DisCos collect revenue for the rest of the sector. The amount they collect and remit to the rest of the sector determines the viability of the rest of the value chain. In 2016, DisCos collected only 57 per cent of the value of the bills they had sent to their customers, and only settled 29 per cent of their bills to NBET, which has to settle the bills from the GenCos. This was worse than their performance in 2015 when they had a 61 per cent collection rate and a 53 per cent invoice settlement rate. ${ }^{15}$ Figure 4.19 shows the collection efficiency of the DisCos over three years between 2015 and 2017. The collection efficiency of individual DisCos hovered between 35 per cent and 90 per cent between 2015 and 2017. The level of commercial and collection losses has created a liquidity crisis in the sector. The collection loss is in part due to the past dynamic between consumers and the former state-owned utility, which treated electricity like a social service. The low collection efficiency of the DisCos is also, in part, due to their limited capacity to collect bills across the entire span of their service area. Some DisCos cover densely populated areas, where it is easier and cheaper for them to collect higher revenues than it is for other DisCos which cover more sparsely populated areas.

\section{Figure 4.19: Collection efficiency of DisCos for three years from 2015 to 2017}

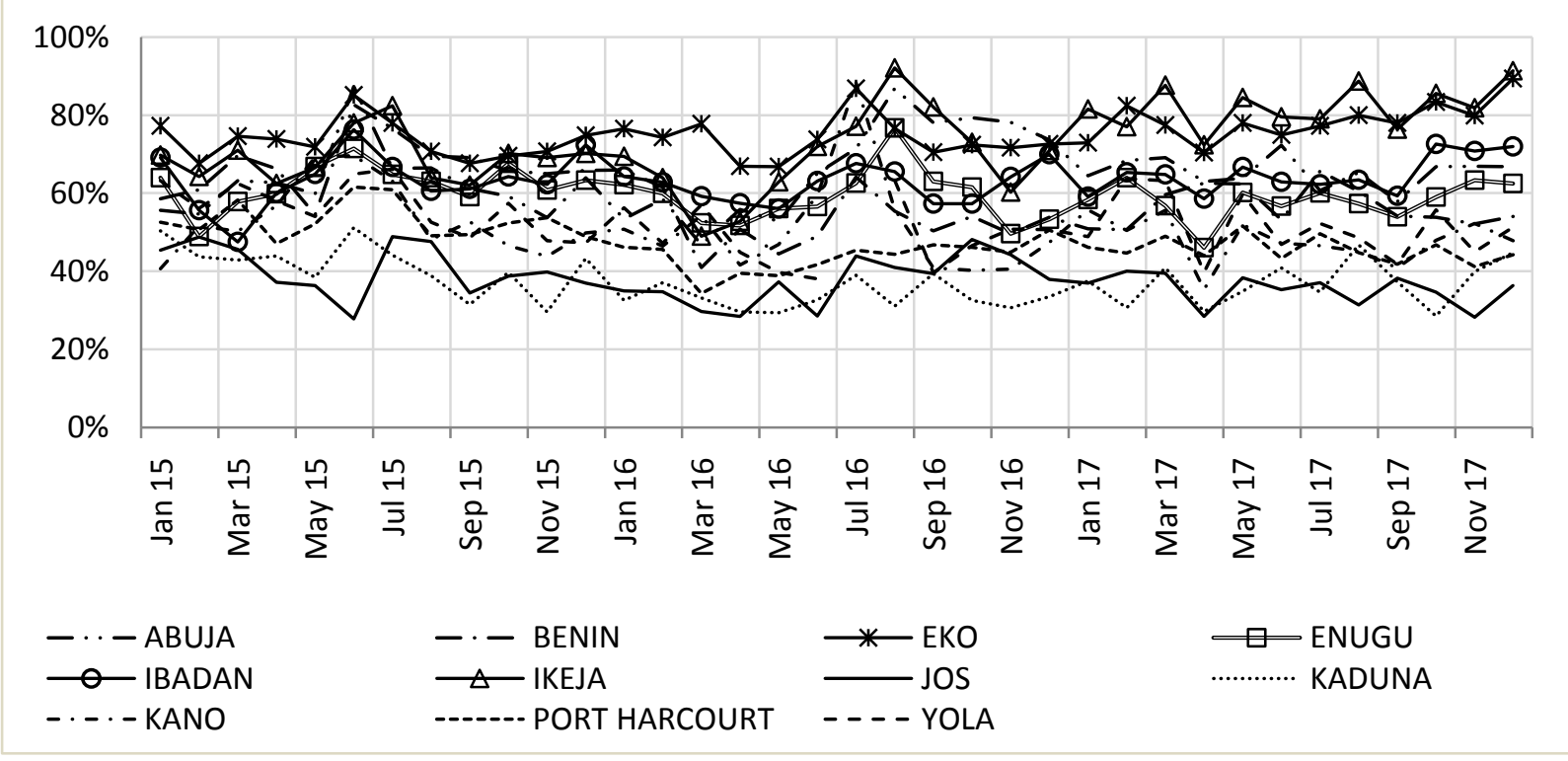

Source: Author.

The ATC\&C losses are costs to the DisCos, so it was agreed by the regulator that the ATC\&C losses were a necessary cost that should be recovered by the DisCos through the tariff. After privatization and further consultations, the collection losses were taken out of the tariff model. The regulator argued that it wasn't a cost component that consumers should pay for. They argued that it was the DisCos'

${ }^{15}$ Power Sector Recovery Programme January 2018. 

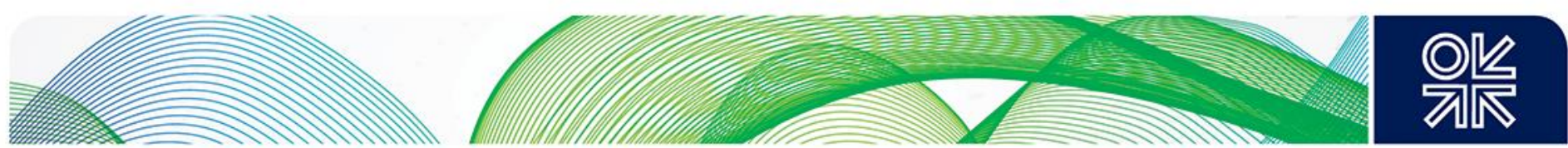

responsibility to collect their revenues. The ATC\&C (see Figure 4.20) losses were temporarily replaced with the Aggregated Transmission and Commercial (AT\&C) losses as cost components in the end-user tariff model. The DisCos agreed with this, but argued that the AT\&C components in the MYTO tariff model did not reflect the true nature of the losses on the system. This resulted in larger losses and caused DisCos to pay only fractions of NBET's invoices (see Figure 4.21). As of January 2018, even the FGN's Ministries, Departments, and Agencies (MDAs) had verified unpaid debts of NGN26 billion (USD84 million) owed to the DisCos. The collection loss component was later reinstated.

Figure 4.20: Trend of the ATC\&C losses on all 11 distribution networks in Nigeria for three years from 2015 to 2017

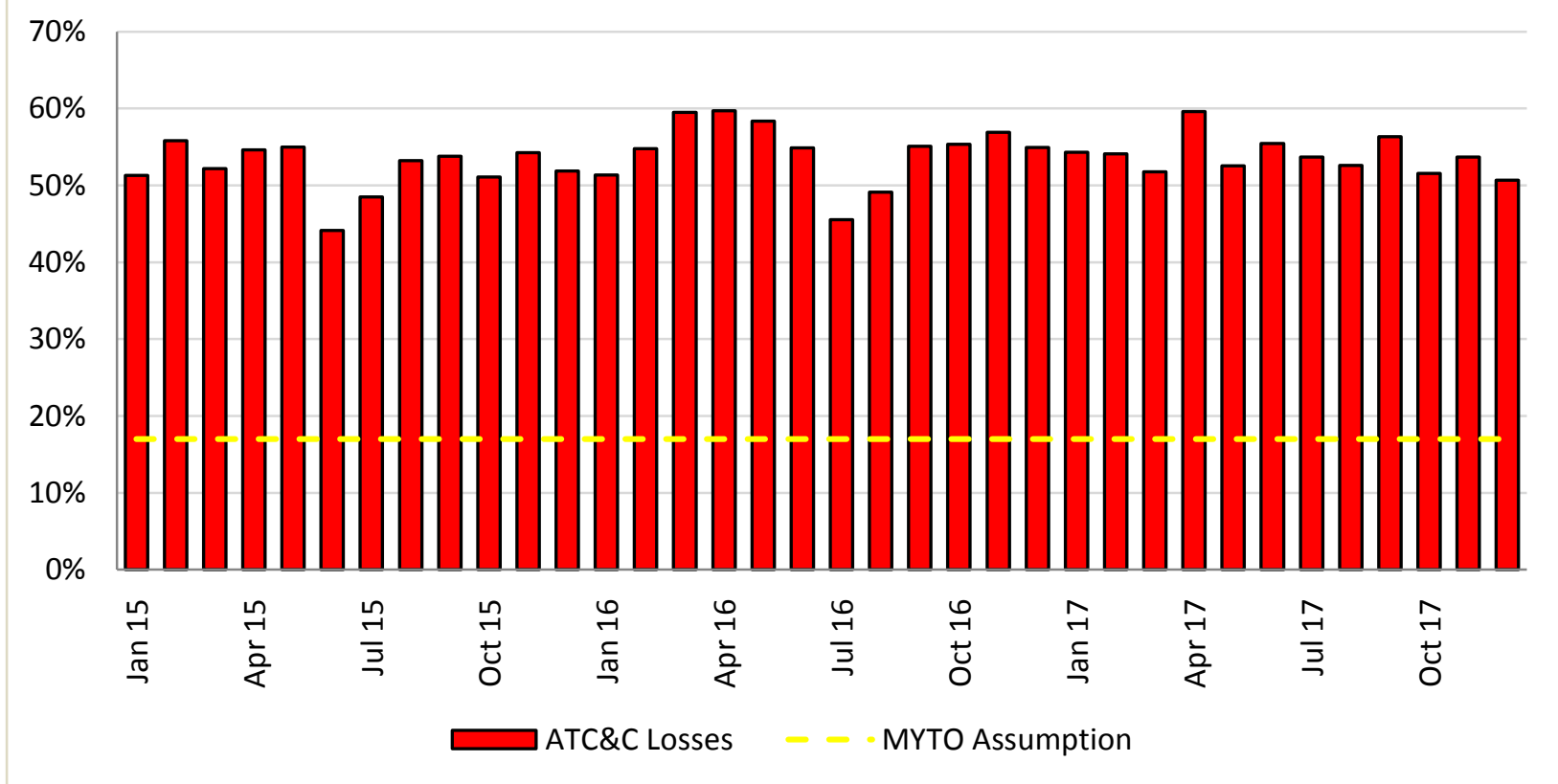

Source: Author.

Figure 4.21: DisCo settlement of NBET invoices from August 2016 to October 2018

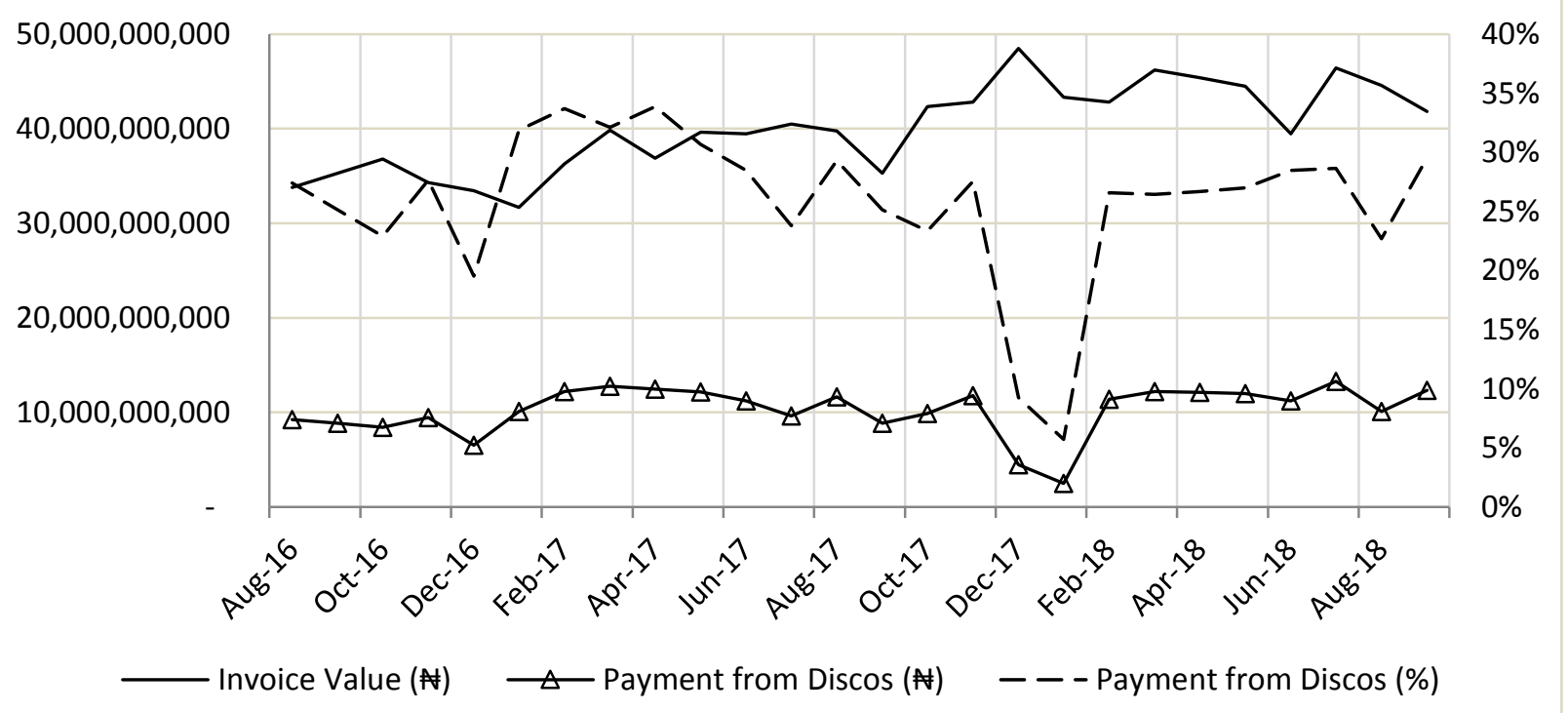

Source: Author. 

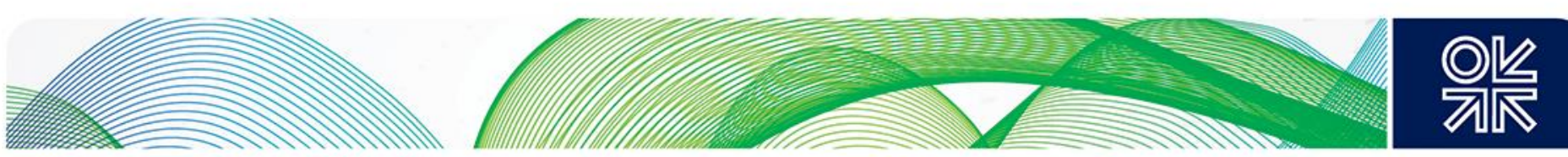

However, the largest loss that contributes to the liquidity crisis comes from the tariff shortfall. This loss is the difference between the current expected DisCo revenues and what would be the expected DisCo revenues if the retail tariffs were cost-reflective. The tariff shortfall is a result of the regulator not updating the tariff structure with the current industry-wide and macroeconomic conditions. The foreign exchange component of the tariff is based on the USD; however, the regulator and the government have not updated the retail tariff to reflect the existing foreign exchange rate. The value of the US dollar moved from NGN197 in 2015 to NGN362 in 2016. The tariff shortfall accounted for 88 per cent of the total market deficit between January 2015 and December 2016. The tariff shortfall was NGN420 billion (USD1.36 billion) from January 2015 to December 2016 and is expected to be NGN1,150 billion (USD3.75 billion) from January 2017 to December 2021, implying that there is a projected increase in the annual shortfall.

A total funding of NGN1.934 trillion (USD6.339 billion) will be required to cover the tariff shortfalls from 2017 to 2021 (see Table 4.1). The PSRP proposes that the FGN and the World Bank will cover the tariff shortfall between 2017 and 2021 (see Table 4.2) through loans to the NESI.

Table 4.1: Funding requirements for the tariff shortfall from 2017 to 2021

\begin{tabular}{|l|l|l|l|}
\hline & NGN billion & USD million & Percentage \\
\hline Sector Revenue shortfall (2017-21) & 1,150 & 3,770 & $59.5 \%$ \\
\hline Sector Historical Deficit (2015-16) & 420 & 1,378 & $21.7 \%$ \\
\hline CBN Payment Assurance Facility Debt Service & 363 & 1,191 & $18.8 \%$ \\
\hline Interest & 132 & 434 & \\
\hline Principal repayments/ amortization & 231 & 757 & \\
\hline Total Funding Requirements & 1,934 & 6,339 & \\
\hline
\end{tabular}

Source: (FGN, 2018).

Table 4.2: Funding sources for tariff shortfalls from 2017-21

\begin{tabular}{|l|l|l|l|}
\hline & NGN billion & USD million & Percentage \\
\hline $\begin{array}{l}\text { Central Bank of Nigeria Payment Assurance facility } \\
\text { (domestic debt) }\end{array}$ & 702 & 2,301 & $36.3 \%$ \\
\hline $\begin{array}{l}\text { Additional Budgetary Contribution (domestic and } \\
\text { external debt) }\end{array}$ & 927 & 3,039 & $47.9 \%$ \\
\hline World Bank performance-based loan (external debt) & 305 & 1,000 & $15.8 \%$ \\
\hline Total Government financing & 1,934 & 6,339 & $100.0 \%$ \\
\hline
\end{tabular}

Source: (FGN, 2018). 

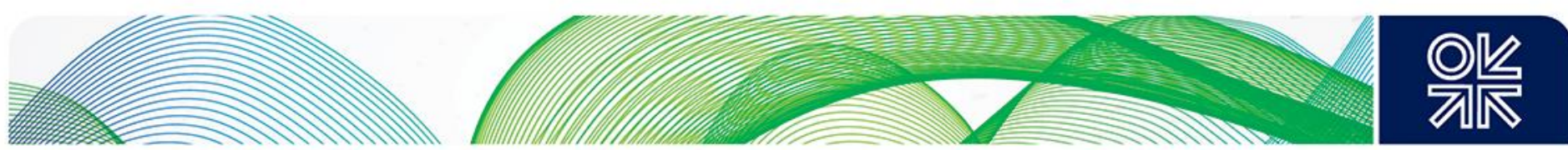

\section{Regulatory/government dimension}

The regulatory/government dimension is the second dimension of analysis. The need for FGN regulation is evident from the underperformance of the NESI. The role of the FGN in correcting NESI inefficiencies has its own effects on performance in the commercial dimension. This section presents the structure, conduct, performance, and regulation of government and its agents. It shows the exogenous impact that the regulatory/governmental actors have on the performance of the commercial dimension.

As shown in Figure 5.1, the NESI is independently monitored and regulated by the Nigerian Electricity Regulatory Commission (NERC) as stipulated in the EPSR (2005) Act. NERC regulates the price of electricity through its periodically published MYTO and sets the mode of operation on the grid through its grid codes. Whilst NERC monitors and regulates the NESI, the Federal Ministry of Power, Works, and Housing (FMPWH) sets government policy within the NESI, which NERC is legally obligated to consider in establishing its regulations. Other peripheral regulators in the NESI are the Federal Ministry of Environment (FMEnv) - which is responsible for regulating the environmental and social impacts of NESI actors - and the Department of Petroleum Resources (DPR) - which regulates the GasCos. The DPR is responsible for setting the quantity of gas that each GasCo is required to supply to the domestic market. Despite the DPR being the regulator for GasCos, it is the Ministry of Petroleum Resources (MPR) that sets the price for domestically supplied gas in Nigeria. The Federal Ministry of Finance (FMoF) also creates policy to boost the liquidity of the NESI while the Central Bank of Nigeria (CBN), which regulates the financial sector, implements the FMoF's liquidity boost policy in the NESI.

Leaning on the EPSR (2005) Act, this paper categorizes NERC's regulation of the NESI into two types: protective regulation and competition regulation. Sections 32 and 80 of the EPSR (2005) Act spell out the function of NERC to protect consumers, while Section 82 spells out NERC's responsibility to continually explore the potential to increase competition within the NESI. Amongst other functions of NERC, these two types of regulation have had the greatest effect on the structure, conduct, and performance of the NESI. 

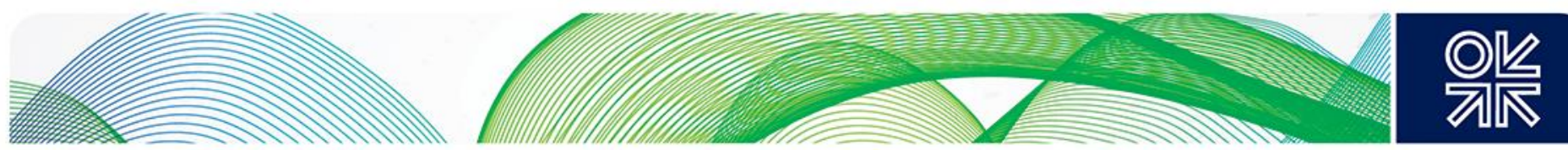

Figure 5.1: Regulation and policy making in the NESI

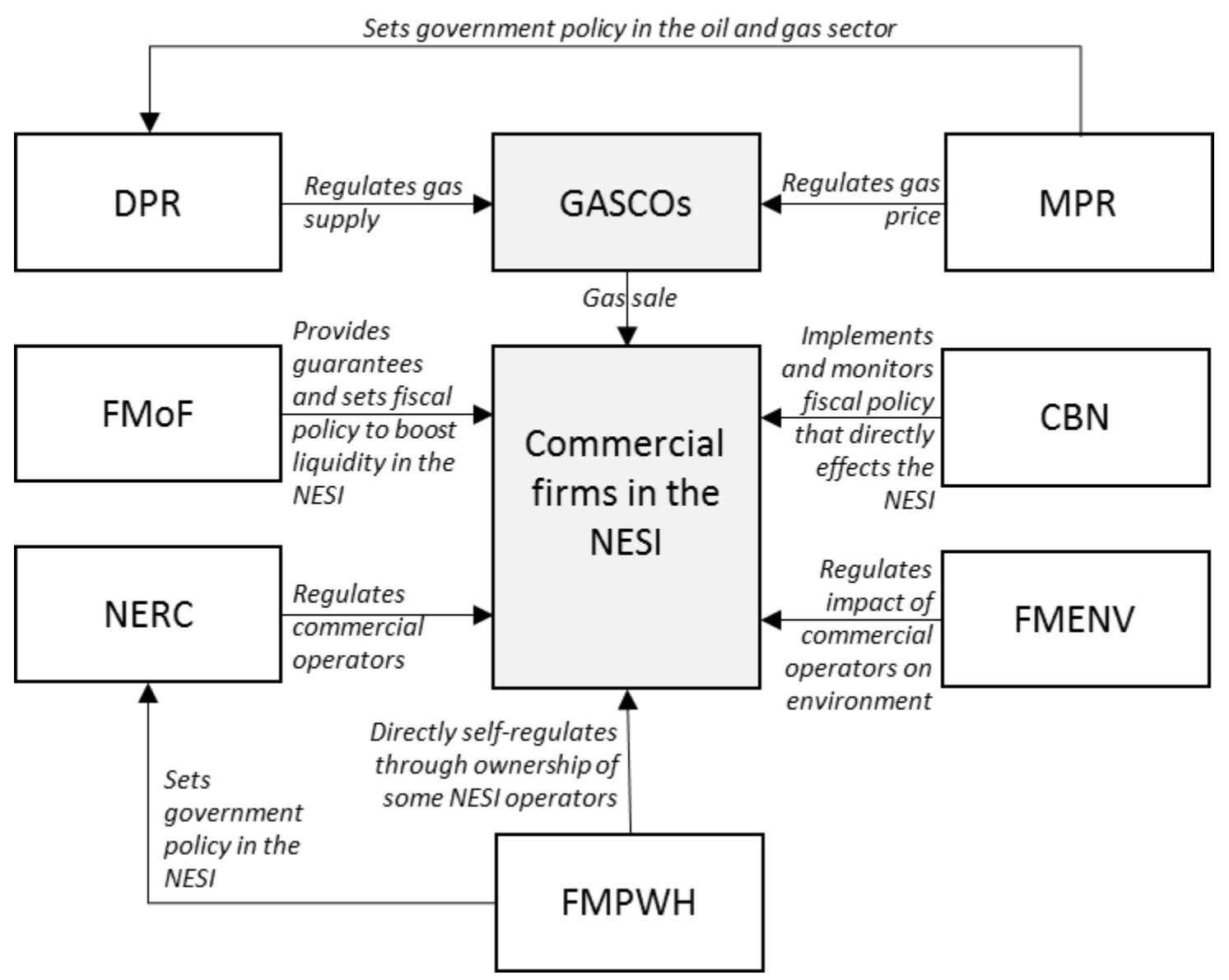

Source: Author.

\subsection{Protective regulation}

Protective regulatory policies are intended to protect consumers by preventing or eliminating the existence of activities and conditions that are regarded as unfair to consumers (Nagel, 1994). Protective regulation by NERC involves ensuring that consumers within the NESI get a quality supply of electricity at a fair price. NERC's responsibility also includes ensuring that consumers are not unfairly treated by NESI operators during disputes over electricity supply. In practice, the aim of regulation in NESI is to keep the retail price of electricity as low as possible for consumers without inhibiting the operators' ability to recover their investments and allowed return on investment. There are two main modes of protective regulation in the NESI. The first occurs at the retail end of electricity sales and the second at the wholesale end of gas sales.

\subsubsection{Retail electricity sales}

There are three major modes of protective regulation/policy at the retail end of the NESI. The first, which is arguably the most contested among industry actors, is the non-implementation of the MYTO retail tariff review. The retail tariff review process is a joint effort by NERC, DisCos, and the public ${ }^{16}$ to agree on a fair price for retail electricity. This review process is supposed to happen periodically:

\footnotetext{
${ }^{16}$ Through public consultations.
} 

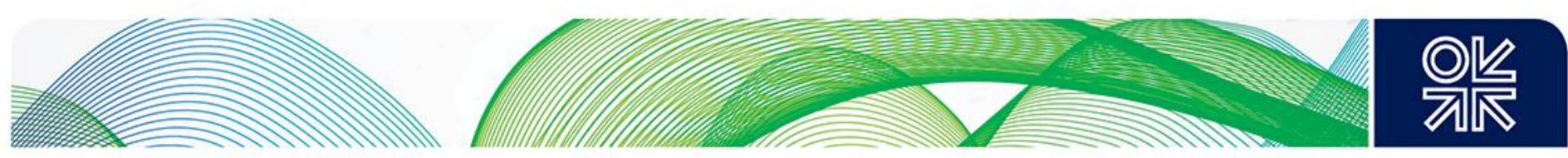

- every six months for minor reviews on inflation rate, foreign exchange rate, gas pricing, and electricity supply capacity,

- $\quad$ every five years for a major review to agree on revenue requirements and to make corresponding tariff adjustments.

NERC, as of December 2018, had missed six minor reviews of the retail tariff. All four indices employed by the MYTO to calculate the retail tariff in 2015, which should have been reviewed, no longer reflect the DisCos' cost of delivering power to consumers. It is widely acknowledged in industry that NERC has not implemented the reviews because of FGN pressure to prevent electricity prices from rising for consumers. Consumers do not mind paying more for reliable electricity, as they currently do through expensive self-generation alternatives; however, they do not want to pay higher prices without seeing an immediate and significant change in the reliability of electricity on the grid. Some consumers do not even want to pay higher tariffs without prior improvements having been made to the electricity supply service. There is an inadequacy of trust between consumers and DisCos, which is not helped by DisCos, who carry out what is commonly referred to as 'estimated billing'.

Estimated billing is a method of billing by the DisCos which passes on their unhallowed commercial losses to paying consumers. Instead of paying for what an individual customer consumes, which should be recorded on a consumption meter, the DisCos add up electricity sales and commercial losses in an area and divide the total among customers. Customers usually end up with a higher bill than they ought to pay because, under a system of estimated billing, they are paying for more than the allowed commercial losses that are already built into the electricity price. DisCos are obligated to charge consumers according to their metered consumption; however, many consumers do not have meters. DisCos are also required to provide meters to consumers, but they argue that their current revenue cannot support rapid mass-scale deployment of meters. They argue that the non-cost reflectiveness of the end-user tariff makes them unable to provide consumer metering at the required scale and speed.

The government's response to the problem of estimated billing was the Meter Asset Provider (MAP) regulation of 2018. This MAP regulation, which allows third-party firms known as meter asset providers (MAPs) to procure, supply, and maintain meter assets to consumers who are willing to pay for their meters, is the Government's second protective regulation at the retail end of the NESI. Consumers will be able to pay for their meters through an extra line charge on the bill from DisCos over a 10-year period. The DisCos are responsible for reimbursing the MAPs for their services, and are also responsible for meeting revenue collection targets in their distribution coverage area. The DisCos claim that this regulation does not adequately share operational risk, because the risk of poor maintenance of meters is borne by the DisCo, which is still tasked with collecting revenues from consumers based on measurements from meters supplied and maintained by another firm. This regulation, however, stands and is in the early stages of its implementation.

NERC's third protective regulation/policy is the customer enumeration directive, which requires DisCos to enumerate their entire consumer base. In 2018, NERC issued a directive that ordered all DisCos to enumerate their entire customer base by 31 March 2019. There are two main reasons for this: the first is to help reduce commercial and collection losses and the second is to reduce the fixed cost components of the distribution charge, which will go down when previously uncounted customers are included in the MYTO model calculation. Leaving some customers uncounted would keep the tariff higher than it should be. There is contention between the DisCos and other NESI actors about the possibility of the retail tariff being kept high by keeping the customer count low.

\subsubsection{Wholesale gas sales}

At the point of sale between GasCos and gas GenCos, the MPR also implements protective regulation on the price of gas, which directly feeds into the price of electricity. The Domestic Gas Supply Obligation (DGSO) is a regulation set by DPR that places a legal obligation on GasCos to supply an annuallydetermined quantity of gas to the domestic market. While DPR sets the quantity of DGSO for each 

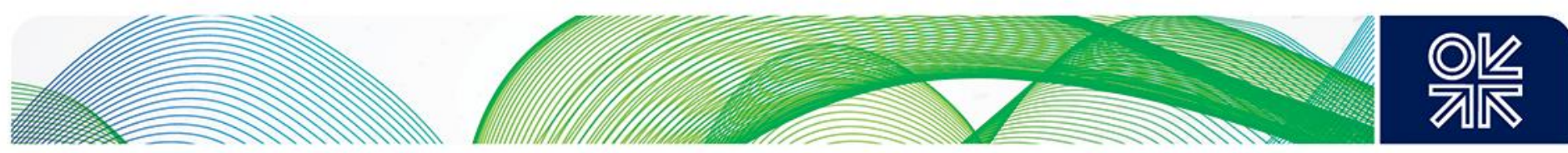

GasCo, it is the MPR that sets the price, which is kept artificially low to control domestic energy costs. This is a critical area for price control because if left unregulated, the gas supplied to the domestic market would leave NESI consumers exposed to two risks: the globally determined price of gas and the foreign exchange rate for the USD. The price of gas is set by the MPR in US dollars. The price of retail electricity is, however, set in Naira. A floating gas price and an absence of minor reviews at the retail end of the NESI would inflate the NESI deficits even further. The DGSO pricing regime, which was set in 2008, is however set to change. The 2017 National Gas Policy proposes the adoption of a more attractive pricing mechanism for GasCos. The new pricing mechanism will allow the price of domestically supplied gas to float with the export liquefied natural gas (LNG) price. The price of domestic gas feeding the NESI will be the export LNG price less regasification costs. The proposed gas pricing regime is a direct response to the performance of the domestic gas sector in the country. This action by the FGN is a price incentive for GasCos to invest in domestic gas supply. While the proposed pricing regime is sure to increase sector deficits, the FGN has committed to facilitate an NGN1,150 billion (USD3.75 billion) loan support to fund the sector's deficit from 2017 to 2021. It is expected that this will eventually be paid back by consumers.

In order to protect consumers from higher electricity tariffs and the potential operational crisis that could ensue from a protracted liquidity crisis, the FGN intervened in 2014 with an NGN213 billion (USD694 million) loan to help improve liquidity in the sector, through the CBN. This loan later became a component of the 2015 tariff update to be paid back by consumers.

\subsection{Competition regulation}

NERC introduced the eligible customer regulation in 2017, after the Minister of the FMPWH had declared the eligible customer policy. This regulation allows consumers who consume $2 \mathrm{MWh} / \mathrm{h}$ to buy electricity from third parties instead of the DisCos. The EPSR (2005) Act allowed this regime to exist, after its declaration had been made by the Minister. The purpose of this regulation is to create competition in the retail end of the NESI. Eligible customers may buy electricity directly from existing GenCos or new IPPs. An eligible customer transaction can be executed with or without the inclusion of a DisCo. DisCos may act as transporters of electricity within an eligible customer power purchase agreement. An IPP may also build a power plant close enough to an eligible customer for there to be no need for DisCos to be included in the arrangement.

While the FGN expects to see higher operational efficiencies from DisCos by introducing competition at the retail end of the NESI, the opposite is likely to happen. This is because the eligible customers are the most important customers to DisCos, providing the DisCos with high collection rates and higher retail tariffs. There is a cross subsidy regime in the NESI that allows high-demand consumers to subsidize low-demand consumers. The FGN will have to raise the retail cost of electricity to consumers if high-demand consumers, who subsidize the rest of the market, are taken away from the DisCos. Considering that the government and its agents have, so far, been very reluctant to allow DisCos to charge a higher cost-reflective retail price, this will further increase the sector deficit. The sector deficit will be further exacerbated because the DisCos have a relatively high collection efficiency with eligible customers. Taking eligible customers away from DisCos will reduce the collection efficiency and exacerbate the sector deficit.

\section{The first 14 solar IPPs}

The Nigerian on-grid RE target, which is known in the industry as Vision 30:30:30, was approved by the Federal Executive Council (FEC) of Ministers in 2005. The target is spelled out in the Nigerian RE and Energy Efficiency Policy (NREEEP). The Vision 30:30:30 target is to achieve 32,000 MW of available generation capacity on the grid by 2030 with 30 per cent RE penetration. The target expects Nigeria to have $9,100 \mathrm{MW}$ of RE on the grid, including solar PV (5,000 MW), solar thermal (1,000 MW), wind (800 $\mathrm{MW})$, biomass $(1,100 \mathrm{MW})$, and small and medium-scale hydroelectric $(1,200 \mathrm{MW})$ power generation 

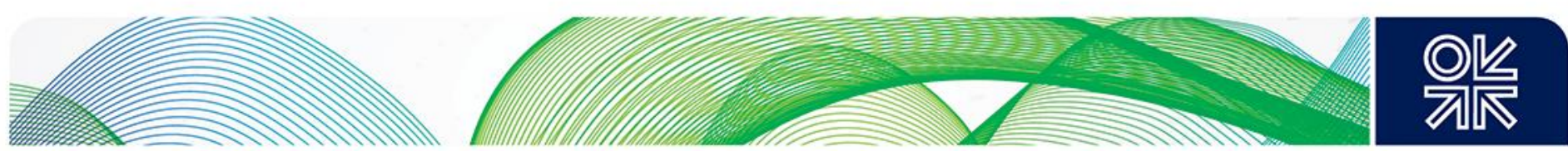

technologies. The remaining generation capacity for on-grid electricity generation is expected to come from gas-fired power generation technologies.

In July 2016, 14 solar IPPs signed PPAs with NBET at USD0.115/KWh. At least two of these projects started in 2010, when the FGN had published its roadmap to liberalize the sector and encourage private sector participation. In 2012, when NERC released MYTO 2012, it established attractive FITs - for solar projects, the FIT was NGN67/KWh ${ }^{17}$ (USD0.43/KWh). Figure 6.1 compares the Nigerian FIT with the South African (SA) RE FIT (REFIT) and the South African RE independent power procurement programme (REIPPP). The latter was a competitive process, which involved tariff bidding by IPPs. Several successful IPPs in the REIPPP were IPPs that had unsuccessfully tried to develop their project with the SA REFIT programme.

Figure 6.1: Feed-in-tariffs in South Africa and Nigeria between 2009 and 2012 in USD ${ }^{18}$

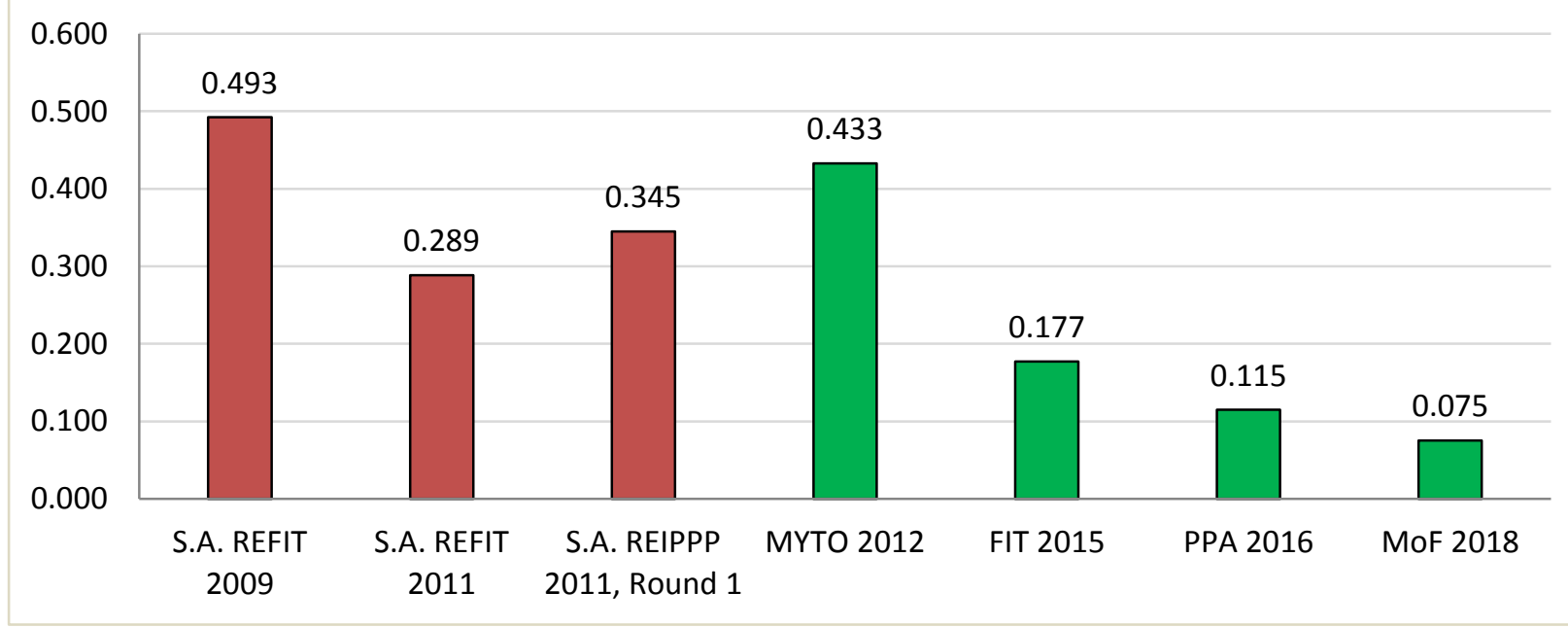

Source: Author.

The tariff in Nigeria's MYTO attracted several project developers who wanted to get into the industry on the eve of privatization, which would occur in 2013 . The developers were particularly convinced by the solar PV projects because of the inadequate gas supply infrastructure in the country. In 2015, NERC published the 'Regulations on Feed-in Tariff for RE-sourced electricity in Nigeria'. The 2015 FIT for solar PV projects was reviewed down to USD0.177/KWh due to falling solar panel costs with inflation, and forex escalations that resulted in a projected 8 per cent annual increase in the tariff. The 2015 regulation also mentioned that the DisCos would be obliged to source 50 per cent of their power from renewable sources if available. This was the last FIT regulation published by NERC before the FGN signed PPAs with developers at USD0.115/KWh (due to the buying power of the FGN as the only bankable bulk buyers of electricity). However, after signing their PPAs in July 2016, the project developers met a roadblock when they moved to obtain guarantees from the FGN. One of the guarantees they are still currently seeking is the Put-Call Option Agreement (PCOA). This agreement allows solar IPPs to 'put' the solar plant up for sale, requiring the FGN to buy the plant at an agreed price if the project is failing due to factors outside the IPP's control, but within the FGN's control. The PCOA also allows the FGN to 'call' for the asset to be sold to the government if the solar IPP is not meeting its operational agreements. The PCOA is in effect a sovereign guarantee covering the solar IPP.

The Minister of Finance had initially proposed to provide the PCOA in Naira - a proposal that the solar IPPs rejected. The IPPs rejected the proposal because most of their debt obligations would be

\footnotetext{
${ }^{17}$ MYTO 2 (2012).

${ }^{18}$ Data sourced from 'South Africa's Renewable Energy IPP Procurement Program: Success Factors and Lessons' by the World Bank and MYTO 2.
} 

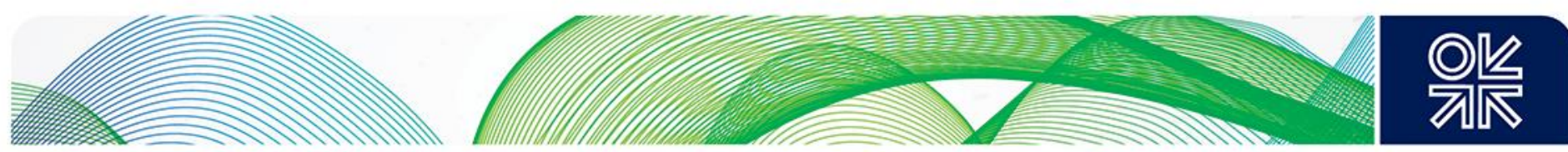

dominated in US dollars. In March 2018, the minister agreed to provide the PCOA, but with one condition - an additional reduction in tariff - which further highlighted the buying power of NBET. The minister, who is also the chair of the board of NBET, advised that the FGN could not afford to take on the PCOA liability with a tariff of USD0.115/KWh. The condition given to the solar IPPs by the minister was to drop their legally agreed PPA tariff to USD0.075KWh - the average wholesale tariff in 2017. Only two of the 14 developers agreed to this. There is still no solar IPP that has reached financial close..$^{19}$

In addition to the PCOA, the solar IPPs require a partial risk guarantee (PRG) for their projects to reach financial close. The PRG is an agreement between a development finance institution (DFI) and the offtaker, NBET. The PRG supports liquidity in the upstream sector by guaranteeing a fraction of NBET's payment to the GenCo. None of the 14 solar IPPs will reach financial close if NBET is not supported with a PRG facility for their individual projects. The FGN nominates projects that will get the PRG facility, and it does so because it takes the final risk. The PRG is effectively a loan to NBET to help its liquidity status - a loan that the FGN must pay back to the DFI. Despite agreeing to provide PRGs to nominated projects, some DFIs have now rescinded that offer pending satisfactory levels of PSRP implementation, whilst other DFls see the need to offer the PRGs despite the current pace of PSRP implementation.

\section{Discussion}

This paper explains how the structure of the NESI, the conduct of actors within it, and the resulting performance create barriers to energy transition on the electricity grid in Nigeria. This section argues that the underperformance of the NESI, which is caused by the short-term conduct of NESI actors, has created constraints for long-term on-grid RE investments on the grid in Nigeria. While the SCPR framework provides in-depth insights into the barriers to on-grid RE in Nigeria, this section also presents some of its limitations, and recommends the use of a political-economic framework to supplement the strengths of the SCPR framework.

\subsection{SCPR dynamic}

The findings in Sections 4 and 6 have shown how the SCPR dynamic determines the performance of the NESI. This section presents the argument that the structure of the NESI inhibits RE deployment on the grid in Nigeria via the conduct of NESI actors, underperformance of the NESI, and the resulting intervention of the FGN in the NESI. There are three inhibitive loops identified in the NESI that constrain on-grid RE investments.

The first inhibitive loop is caused by the monopsony position of NBET. As mentioned in Section 6, 14 solar IPPs have already signed PPAs with NBET; however, they are as yet unable to deploy RE on the grid as a result of their inability to reach financial close on their individual projects. The solar IPPs are not able to reach financial close because they are not yet able to secure two critical guarantees that would make their projects bankable. The first guarantee is the PRG, which is provided by DFIs at the FGN's expense, to boost NBET's liquidity. Some DFIs have put this facility on hold until the FGN has achieved a satisfactory level of implementation of the PSRP. The second guarantee is the USDdenominated PCOA, which the FGN has refused to provide to solar IPPs at the agreed wholesale tariff. All but two of the solar IPPs have refused to lower their tariff from USD0.115/KWh to USD0.075/KWh in order to get a PCOA, as required by the Minister of Finance. The underperformance of the NESI has resulted in the FGN's policy to withhold the PCOA, which constrains additional generation investment (C1). This is one of the three inhibitive loops in the NESI that create barriers to on-grid RE investment (see Figure 7.1).

\footnotetext{
${ }^{19}$ As of January 2019.
} 

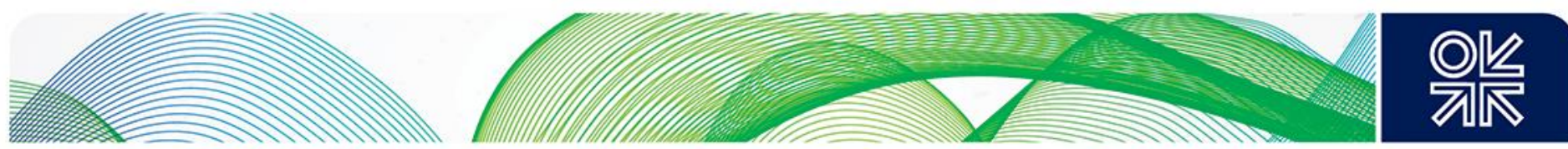

Figure 7.1: Inhibitive loop caused by NBET's monopsony

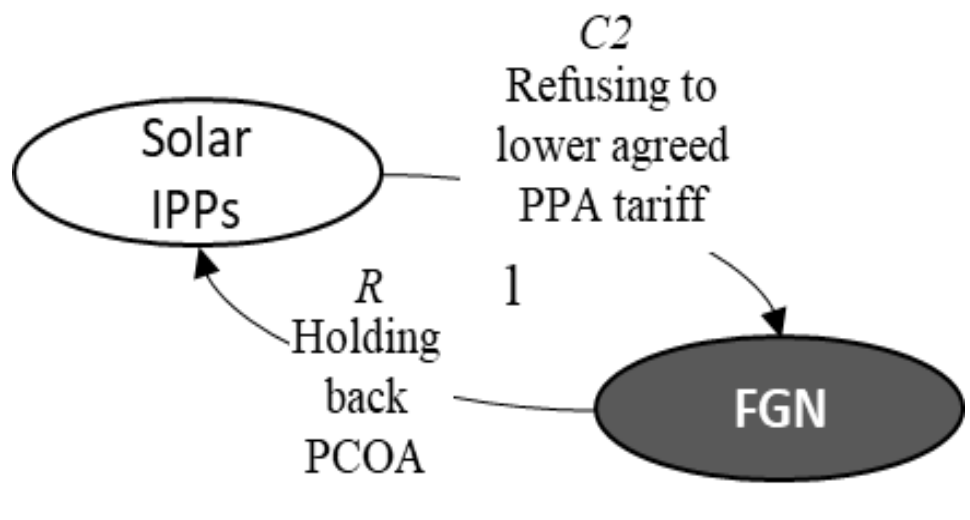

Source: author.

This loop is held up by the buyer power of NBET, which has a monopsony as the only bankable bulk buyer of electricity in the wholesale market. This monopsony can be broken up by introducing competition in the wholesale electricity market, where large productive, creditworthy consumers can be allowed to buy directly from GenCos. If solar IPPs sell directly to large, creditworthy consumers, it may remove the need for FGN-backed guarantees and therefore remove the constraint defined in the first loop.

As noted above, only two of the solar IPPs have reduced their PPA tariff to USD0.075/KWh. ${ }^{20}$ These two firms have signed PCOAs but are unable to reach financial close $(C 1)$. The FGN has refused to provide PCOAs at USD0.115/KWh, to prevent itself from being overburdened by sovereign liabilities resulting from the liquidity and debt crisis in the NESI. The liquidity and debt crises in the sector are caused by a large tariff shortfall and ATC\&C losses at the retail end of the NESI. These losses caused the DisCos to pay only 27 per cent of their bill from NBET in 2017. This is largely due to the tariff deficit resulting from non-cost-reflective tariffs. Between February 2015 and December 2016, the DisCos were unable to pay NGN476 billion to NBET. Of that amount, NGN420 billion was due to the tariff shortfall at the retail end of the sector. This tariff shortfall thus represents about 88 per cent of the market deficit in the NESI. The tariff shortfall is caused by the non-cost reflectiveness of the tariffs that the NERC allows the DisCos to charge consumers.

The second inhibitive loop is caused by the unproductive consumer protection policy of the FGN. NERC is unable to set cost-reflective retail tariffs because the FGN does not want the price of electricity to go up for consumers. The FGN's refusal to allow NERC to raise prices stems from consumer pressure on FGN to prevent higher electricity bills from DisCos, who have carried out estimated billing and who have not met the service expectations of the consumers. The DisCos defend their conduct by pointing to their inadequate revenues which stem from non-cost-reflective tariffs - creating a second full loop that inhibits RE investment performance in the sector. This loop (see Figure 7.2) is caused by the FGN's ineffectual consumer protection policy for the NESI and could be avoided if the FGN allows NERC to establish cost-reflective tariffs. If the cost-reflective tariffs cost too much for the government politically, the FGN can introduce competition in the wholesale market, where creditworthy consumers will be allowed to buy reliable electricity at a cost-reflective price. If the government is able to introduce costreflective tariffs for all consumers, it should also identify and support vulnerable consumers. If the government is unable to introduce general cost-reflective tariffs for all consumers due to political resistance, then creditworthy consumers should be moved to a parallel electricity market where they can be charged cost-reflective tariffs at high levels of reliability. There would be an incentive for

\footnotetext{
${ }^{20}$ As of February 2018.
} 

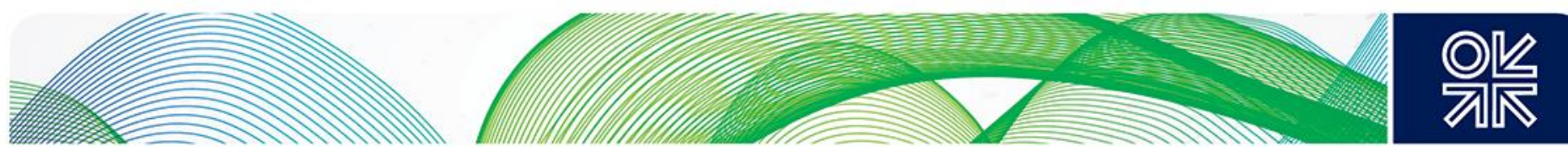

creditworthy consumers to join that parallel electricity market if the cost-reflective tariffs in the parallel market are lower than the current composite tariff, which includes the subsidized NESI tariff and expensive diesel-fuelled self-generation costs.

Figure 7.2: Inhibitive loop caused by the FGN's subsidy regime

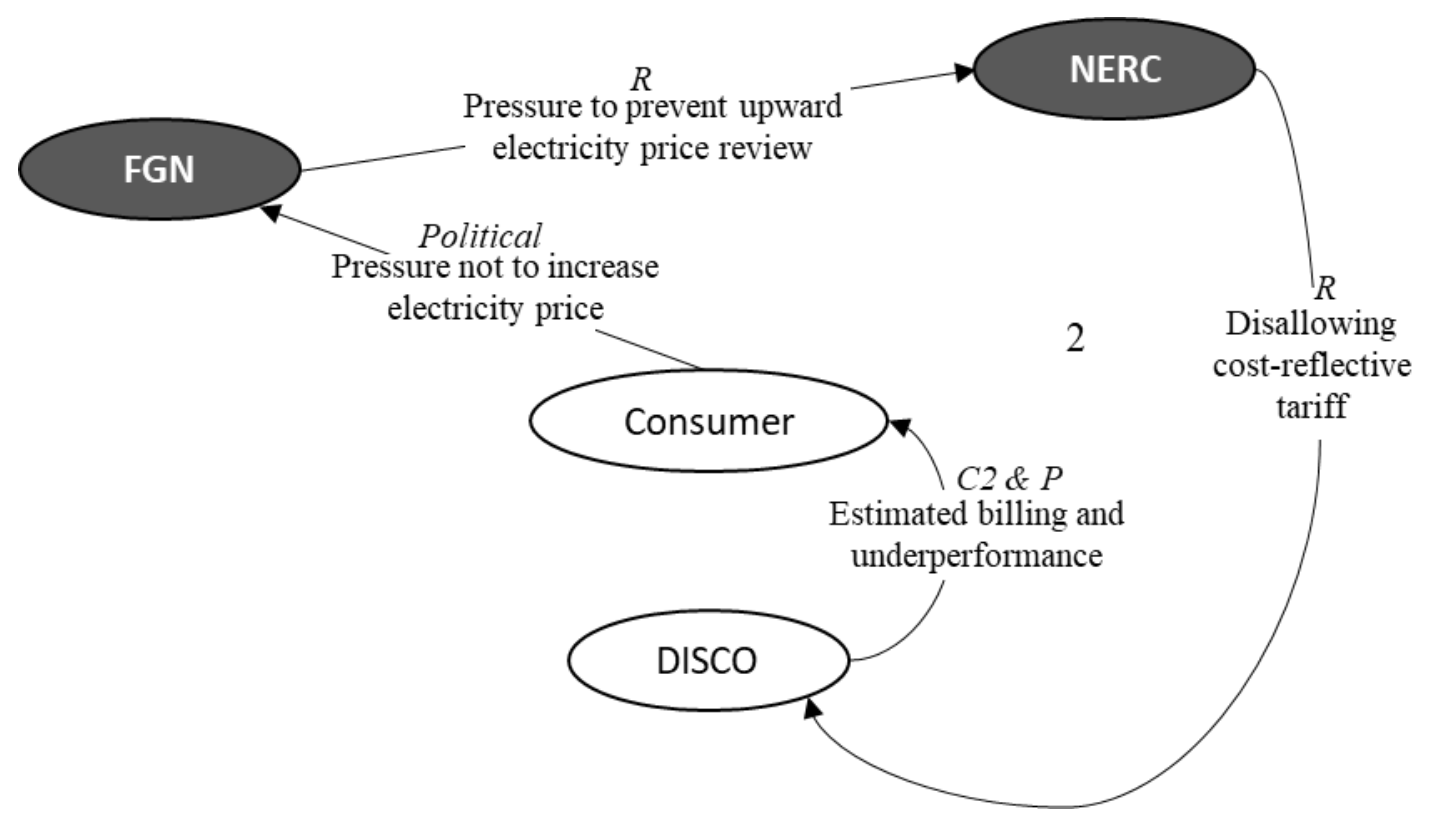

Source: Author.

There is also a third loop - a loop of distrust between the DisCos and consumers (see Figure 7.3). The DisCos continue to use the estimated billing system (C2) and still do not meet consumers' expectations of electricity supply. This causes energy theft, consumer apathy, and consumer distrust leading to low collection rates and commercial losses. This loop of distrust is not helped by the FGN's antagonistic approach towards the DisCos - an approach some NESI actors say led to the eligible customer policy (see Section 5.2), an inherently useful policy in principle, but one that will inadvertently create unproductive competition for the DisCos. This loop can be removed through the introduction of costreflective tariffs. And in the event that cost-reflective tariffs are politically improbable, the government may introduce a parallel electricity market, which will allow cost-reflective retail tariffs to be charged to creditworthy consumers, who do not need electricity subsidies. The income generated from the parallel electricity market will ease the liquidity crisis, and can be used to improve critical parts of the grid infrastructure that will help solve some of the problems in the NESI incrementally. As liquidity improves, investment, performance, and consumer trust should also increase. Consumer trust may also increase if evidence of reliable supply to consumers in a parallel market can be seen.

Figure 7.3: Inhibitive loop of distrust between DisCos and consumers

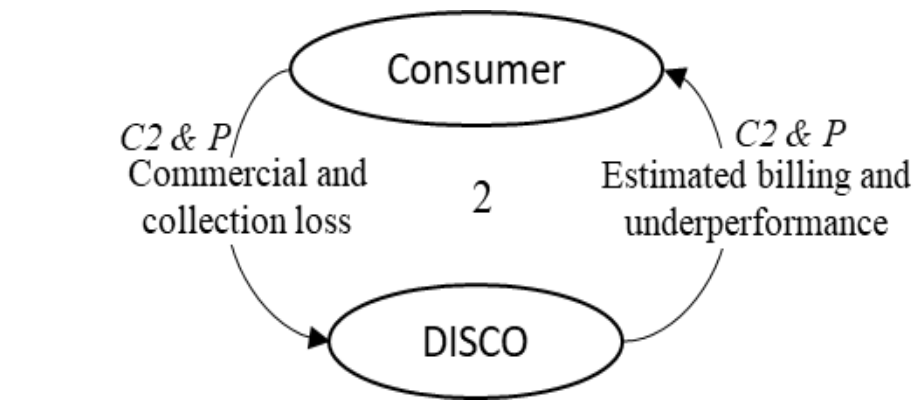

Source: Author. 

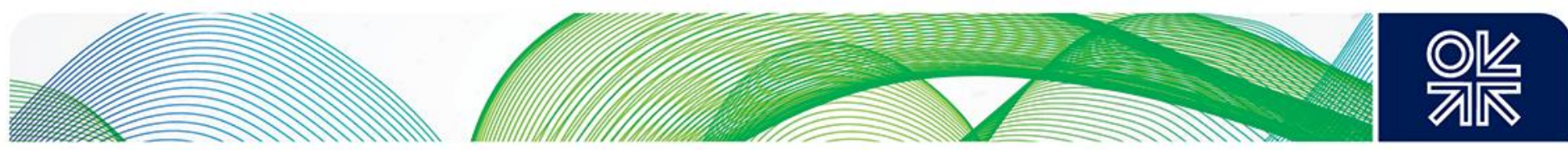

The three inhibitive loops within the NESI create a system of underperformance, which constrains all electricity generation investments on the grid, including on-grid RE investments. The causal dynamics that inhibit RE deployment on the grid in Nigeria are shown in Figure 7.4. The three loops within these dynamics need to be broken before RE can be deployed on the grid in Nigeria. The PSRP developed by the FGN in 2017 seeks to address many issues within the power sector, including the three inhibitive loops identified in this section. However, the 'NBET monopsony' loop (see Figure 7.1) is addressed in the PSRP in a way that is unfavourable to both on-grid RE deployment and any other on-grid electricity generation technology deployment. The PSRP recommends that the government holds off on encouraging more generation capacity until the NESI performance is significantly improved, to avoid blowing up the NESI market deficit. The introduction of a parallel electricity market for creditworthy consumers will help to break all three inhibitive loops, which are constraints to on-grid RE investments. 


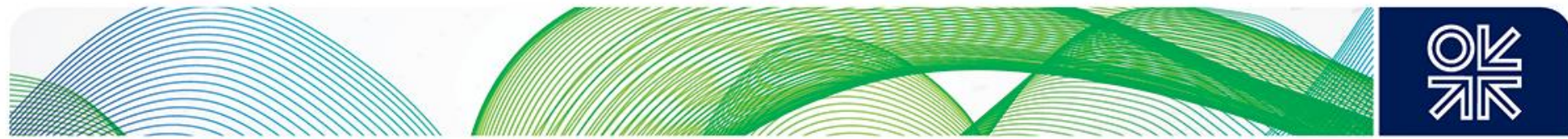

Figure 7.4: Inhibition to on-grid RE investment in Nigeria

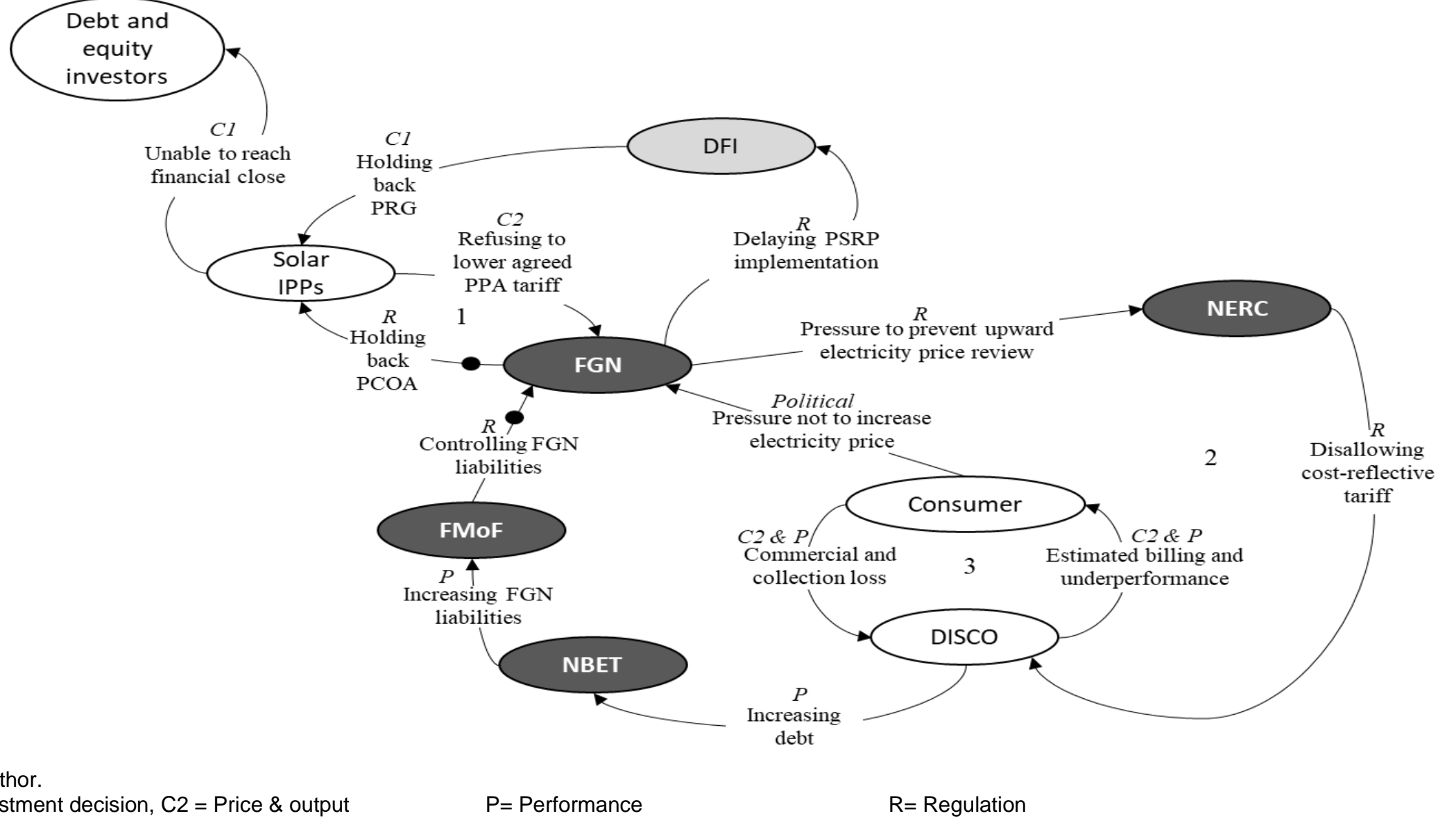

Source: Author.

C1 = Investment decision, C2 = Price \& output

$\mathrm{P}=$ Performance

R= Regulation 

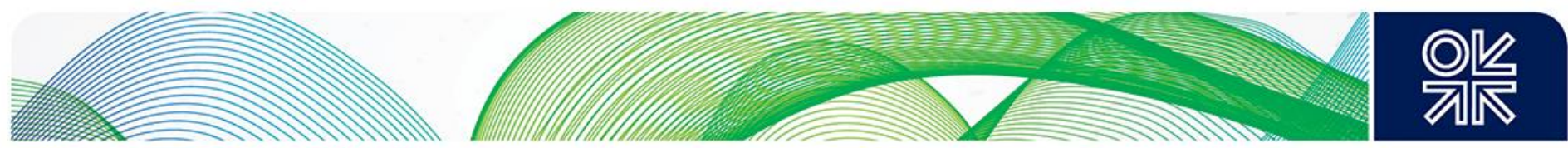

\subsection{Limitations: analysis in the political dimension}

The SCPR framework developed by Peng and Poudineh (2016) provides deep insights into the causal dynamics that inhibit RE deployment on the grid in Nigeria. It shows how the structure of the NESI and the conduct of its actors affect performance and necessitate regulation. It also shows how structure, conduct, regulation, and performance within the NESI inhibit the deployment of RE on the grid.

In addition, further examination is required to answer deeper questions about the causal dynamics presented in Figure 7.4. The legal and regulatory structure of the NESI, which the SCPR depends on, does not fully cover the informal relationships in the NESI. Although the modified SCPR framework presented by Peng and Poudineh (2017) accounts for the effects of agents in the political dimension, it doesn't explain why the conducts of agents sometimes succeed and other times fail. It explains that firms are able to negotiate their interest in the political dimension through agents, and establish change in the structure, conduct and regulation of the market. However, it does not answer the question of why some agents are successful and others are not in changing regulatory regimes. It is critical to understand why certain agents are successful and others are not, because that would provide additional insights and causal links within the NESI.

To illustrate this point, the FGN has not allowed NERC to establish cost-reflective tariffs; yet it has liberalized the telecoms sector, where tariffs are cost-reflective. Why is the FGN able to remove subsidies in the telecoms sector and unable to do so in the NESI? In the NESI, why were PPAs signed for 14 solar IPPs in 2016 and then been delayed indefinitely since 2017, despite NESI performance remaining relatively stagnant during this period? These are critical questions because they ask why solutions such as those included in the PSRP cannot be successfully implemented. Further examination needs to be done on why some agents or groups of agents are successful in changing regulatory regimes and policies, whilst others are not. Further examination will provide a richer set of causal dynamics that explain the constraints to on-grid RE deployment in Nigeria.

\section{Conclusion}

This paper set out to show the causal dynamics present within the NESI that inhibit on-grid RE deployment in Nigeria. It answers the research question: how does the structure of the Nigerian energy market and the behaviour of its participants create barriers to energy transition on the electricity grid in Nigeria? This question was answered using the SCPR framework. An analysis of the NESI, using the SCPR framework, produced three key findings. The common thread among the three findings is that the constraints to on-grid RE investments are a result of the underperformance of the NESI and the non-transparency of the solar IPP procurement process. The underperformance of the NESI is a result of three interrelated loops of conduct and regulation.

This first loop, the NBET monopsony loop, shows the adverse impact of NBET's buyer power. It prevents other willing buyers to procure new generation capacity on the grid. It also creates an unsustainable fiscal burden on NBET. The second loop is the 'distrust loop' that exists between DisCos and consumers. This distrust is fuelled on one hand by losses through electricity theft and low electricity bill payment by consumers. On the other hand, it is fuelled by estimated billing and underperformance by DisCos. The FGN is not helping to undo this distrust with its antagonistic posture towards the DisCos. The third finding is the 'subsidy loop' that prevents NERC from implementing cost-reflective retail tariffs as part of its regulatory regime. NERC is unable to review the electricity price upward because the FGN has prevented them from doing so; the FGN prevents electricity price increases due to political pressure from consumers; consumers do not want an increase in electricity price because the DisCos do not meet their electricity supply expectations; and to complete the loop, DisCos cannot meet consumer expectations because they cannot charge consumers cost-reflective tariffs. The implementation of NESI-wide cost-reflective tariffs will help to break the three loops by improving liquidity in the sector. However, if general cost-reflective tariffs are politically impossible to implement, introduction of a parallel electricity market for creditworthy consumers will help to gradually break all three inhibitive loops. 

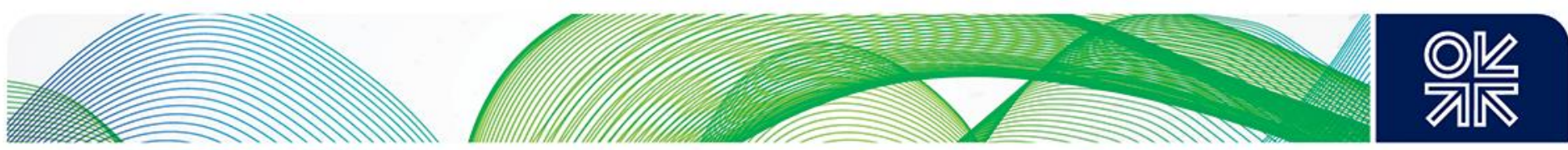

In addition to the three findings mentioned, this paper recommends further analysis on the political inhibitions to on-grid RE deployment. The SCPR is unable to explain why the conduct of agents is sometimes successful and at other times not successful. 

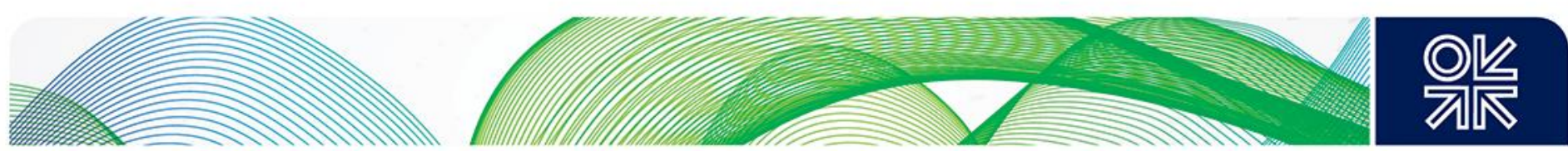

\section{References}

Akpodiogaga-a, P. and Odjugo, O., 2010. 'General overview of climate change impacts in Nigeria'. Journal of Human Ecology, 29(1), pp.47-55.

Bain, J.S., 1968. Industrial organization. John Wiley \& Sons.

Depoorter, B.W., 1999. 'Regulation of natural monopoly'. (Part V-Regulation of contracts), Encyclopedia of Law and Economics, Edward Elgar.

Eggoh, J.C., Bangaké, C. and Rault, C., 2011. 'Energy consumption and economic growth revisited in African countries'. Energy Policy, 39(11), pp.7408-21.

Friedrichs, J. and Inderwildi, O.R., 2013. 'The carbon curse: Are fuel rich countries doomed to high CO2 intensities?'. Energy Policy, 62, pp.1356-65.

Federal government of Nigeria (FGN), 2018, Power Sector Recovery Programme: 2017-2021. [WWW Document]. NESI STATS. Available at: https://mypower.ng/wp-content/uploads/2018/02/PSRP Master-Document-January-2018.pdf [accessed 29 July 2019].

Geels, F.W., 2011. 'The multi-level perspective on sustainability transitions: Responses to seven criticisms'. Environmental innovation and societal transitions, 1(1), pp.24-40.

Inderst, R. and Mazzarotto, N., 2008. 'Buyer power in distribution'. In ABA Antitrust Section Handbook, Issues in Competition Law and Policy (Vol. 3, pp. 1953-78). ABA.

Jamasb, T., Newbery, D., and Pollitt, M., 2006. 'Core indicators for determinants and performance of electricity sector reform in developing countries'. International Journal of Regulation and Governance, 6(1), pp.43-78.

Joseph, I.O., 2014. 'Issues and challenges in the Privatized Power Sector in Nigeria'. Journal of Sustainable Development Studies, 6(1).

Kahsai, M.S., Nondo, C., Schaeffer, P.V., and Gebremedhin, T.G., 2012. 'Income level and the energy consumption-GDP nexus: Evidence from Sub-Saharan Africa'. Energy Economics, 34(3), pp.739-46.

KPMG, 2016. A Guide to the Nigerian Power Sector. Lagos.

Nagel, S., 1994. Encyclopedia of Policy Studies, Second Edition, CRC Press.

Pablo-Romero, M.D.P. and Sánchez-Braza, A., 2015. 'Productive energy use and economic growth: Energy, physical and human capital relationships'. Energy Economics, 49, pp.420-9.

Peng, D. and Poudineh, R., 2016. 'A holistic framework for the study of interdependence between electricity and gas sectors'. Energy Strategy Reviews, 13, pp.32-52.

Peng, D. and Poudineh, R., 2017. 'Gas-to-power supply chains in Developing Countries: Comparative case studies of Nigeria and Bangladesh'. OIES Paper EL 24, Oxford Institute for Energy Studies.

Transmission Company of Nigeria (TCN), 2015. [WWW Document]. The Nigerian Electricity System Operator (NESO). Available at: https://nsong.org/App_Themes/Blue/images/NationalGrid.png [accessed 29 July 2019].

World Bank, 2019a. Poverty headcount ratio at \$1.90 a day (2011 PPP) (\% of population) / Data [WWW Document]. World Bank Databank. Available at: https://data.worldbank.org/indicator/SI.POV.DDAY [accessed 29 July 2019].

World Bank, 2019b. Access to electricity (\% of population) / Data [WWW Document]. World Bank Databank. Available at: https://data.worldbank.org/indicator/EG.ELC.ACCS.ZS [accessed 29 July 2019].

World Bank, 2019c. Population growth (annual \%) Nigeria / Data [WWW Document]. World Bank Databank. Available at: https://data.worldbank.org/indicator/SP.POP.GROW?locations=NG [accessed 28 August 2019]. 